\title{
Comprehensive isoprene and terpene gas-phase chemistry improves simulated surface ozone in the southeastern US
}

\author{
Rebecca H. Schwantes ${ }^{1}$, Louisa K. Emmons ${ }^{1}$, John J. Orlando ${ }^{1}$, Mary C. Barth ${ }^{1}$, Geoffrey S. Tyndall ${ }^{1}$, \\ Samuel R. Hall ${ }^{1}$, Kirk Ullmann ${ }^{1}$, Jason M. St. Clair ${ }^{2,3}$, Donald R. Blake ${ }^{4}$, Armin Wisthaler ${ }^{5,6}$, and Thao Paul V. Bui ${ }^{7}$ \\ ${ }^{1}$ Atmospheric Chemistry Observations and Modeling Laboratory, National Center for Atmospheric Research, \\ Boulder, CO 80301, USA \\ ${ }^{2}$ Atmospheric Chemistry and Dynamics Laboratory, NASA Goddard Space Flight Center, Greenbelt, MD 20771, USA \\ ${ }^{3}$ Joint Center for Earth Systems Technology, University of Maryland, Baltimore County, Baltimore, MD 21228, USA \\ ${ }^{4}$ Department of Chemistry, University of California, Irvine, 570 Rowland Hall, Irvine, CA 92697-2025, USA \\ ${ }^{5}$ Institute for Ion Physics and Applied Physics, University of Innsbruck, Technikerstrasse 25, 6020 Innsbruck, Austria \\ ${ }^{6}$ Department of Chemistry, University of Oslo, P.O. Box 1033 Blindern, 0315 Oslo, Norway \\ ${ }^{7}$ Earth Science Division, NASA Ames Research Center, Moffett Field, CA 94035-1000, USA
}

Correspondence: Rebecca H. Schwantes (rschwant@ucar.edu)

Received: 6 October 2019 - Discussion started: 11 October 2019

Revised: 24 January 2020 - Accepted: 5 February 2020 - Published: 30 March 2020

\begin{abstract}
Ozone is a greenhouse gas and air pollutant that is harmful to human health and plants. During the summer in the southeastern US, many regional and global models are biased high for surface ozone compared to observations. Past studies have suggested different solutions including the need for updates to model representation of clouds, chemistry, ozone deposition, and emissions of nitrogen oxides $\left(\mathrm{NO}_{x}\right)$ or biogenic hydrocarbons. Here, due to the high biogenic emissions in the southeastern US, more comprehensive and updated isoprene and terpene chemistry is added into CESM/CAM-chem (Community Earth System Model/Community Atmosphere Model with full chemistry) to evaluate the impact of chemistry on simulated ozone. Comparisons of the model results with data collected during the Studies of Emissions Atmospheric Composition, Clouds and Climate Coupling by Regional Surveys (SEAC ${ }^{4} \mathrm{RS}$ ) field campaign and from the US EPA (Environmental Protection Agency) CASTNET (Clean Air Status and Trends Network) monitoring stations confirm the updated chemistry improves simulated surface ozone, ozone precursors, and $\mathrm{NO}_{x}$ reservoir compounds. The isoprene and terpene chemistry updates reduce the bias in the daily maximum $8 \mathrm{~h}$ average (MDA8) surface ozone by up to $7 \mathrm{ppb}$. In the past, terpene oxidation in particular has been ignored or heavily reduced in chemical schemes used in many regional and global models, and this
\end{abstract}

study demonstrates that comprehensive isoprene and terpene chemistry is needed to reduce surface ozone model biases. Sensitivity tests were performed in order to evaluate the impact of lingering uncertainties in isoprene and terpene oxidation on ozone. Results suggest that even though isoprene emissions are higher than terpene emissions in the southeastern US, remaining uncertainties in isoprene and terpene oxidation have similar impacts on ozone due to lower uncertainties in isoprene oxidation. Additionally, this study identifies the need for further constraints on the aerosol uptake of organic nitrates derived from isoprene and terpenes in order to reduce uncertainty in simulated ozone. Although the updates to isoprene and terpene chemistry greatly reduce the ozone bias in CAM-chem, a large bias remains. Evaluation against $\mathrm{SEAC}^{4} \mathrm{RS}$ field campaign results suggests future improvements to horizontal resolution and cloud parameterizations in CAM-chem may be particularly important for further reducing this bias. 


\section{Introduction}

Many regions of the world have poor air quality due to high levels of tropospheric ozone $\left(\mathrm{O}_{3}\right)$. Tropospheric ozone is also a greenhouse gas and is an important source of $\mathrm{OH}$ radicals, which impacts the lifetime of other greenhouse gases such as methane (Monks et al., 2015; IPCC, 2013). Recent health studies have suggested ozone negatively impacts human health more than previously thought by increasing the risk of both respiratory and circulatory mortality (Turner et al., 2016). Additionally, to protect human health and vegetation in 2015, the US EPA (Environmental Protection Agency) strengthened the ozone standard to not exceed a maximum daily $8 \mathrm{~h}$ average (MDA8) of $70 \mathrm{ppb}$ for more than $3 \mathrm{~d} \mathrm{yr}^{-1}$ (U.S. EPA, 2015). Models must accurately simulate ozone for the right reasons to be most effective for predicting future air quality trends (e.g., Val Martin et al., 2015) or to attribute sources of ozone correctly (e.g., Cooper et al., 2015). Because ozone is not directly emitted into the atmosphere and is controlled by large nonlinear sources and losses, ozone is intrinsically difficult to simulate in climate and chemistry models.

Generally, global models capture ozone spatial patterns throughout the troposphere reasonably well, but simulated ozone is typically biased high in the Northern Hemisphere and low in the Southern Hemisphere, and there are regional and seasonal biases that are not fully understood (Young et al., 2018). During the summer in the southeastern US, there is a persistent high bias for surface ozone in many models compared to observations (Fiore et al., 2009; Reidmiller et al., 2009; Brown-Steiner et al., 2015; Tilmes et al., 2015; Canty et al., 2015; Im et al., 2015). Model bias in surface ozone is a good indicator that the budgets and processing of nitrogen oxides $\left(\mathrm{NO}_{x}\right)$ or volatile organic compounds (VOCs) are poorly constrained. Past studies have suggested different solutions including the need for updates to model representation of clouds (Ryu et al., 2018), emissions of NO (Travis et al., 2016; McDonald et al., 2018b) or biogenic hydrocarbons (Kaiser et al., 2018), chemistry (Squire et al., 2015), chemical solver (Sun et al., 2017), and deposition (Val Martin et al., 2014; Clifton et al., 2019).

Tropospheric ozone is produced in the atmosphere when ozone precursors, anthropogenic or biogenic VOCs and $\mathrm{NO}_{x}$, interact in the presence of sunlight (Monks et al., 2015). The hydroxyl radical $(\mathrm{OH})$ reacts with a VOC to form a peroxy radical $\left(\mathrm{RO}_{2}\right)$, which reacts with $\mathrm{NO}$ to form an organic nitrate or an alkoxy radical and $\mathrm{NO}_{2} . \mathrm{NO}_{2}$ will photolyze to form $\mathrm{NO}$ and ozone. Organic nitrates are an example of a $\mathrm{NO}_{x}$ reservoir species, a species that has the potential to recycle $\mathrm{NO}_{x}$ back into the system, transport $\mathrm{NO}_{x}$ to a different location, or to permanently remove $\mathrm{NO}_{x}$ from the atmosphere. Correctly representing the production and loss pathways of $\mathrm{NO}_{x}$ reservoir species is critical for accurately representing ozone for the right reasons.
In the southeastern US, there are particularly large emissions of biogenic hydrocarbons like isoprene and terpenes, which motivates updating the formation and fate of isopreneand terpene-derived organic nitrates in order to assess if more complex and current chemistry reduces model biases in surface ozone. The recent significant improvements in our understanding of isoprene oxidation chemistry (Wennberg et al., 2018, and references therein) have motivated many models to update their isoprene chemistry including GEOSChem (Fisher et al., 2016; Bates and Jacob, 2019), GFDL AM3 (the atmopsheric component of the Geophysical Fluid Dynamics Laboratory Coupled Model; Li et al., 2018), MAGRITTEv1.1 (Model of Atmospheric composition at Global and Regional scales using Inversion Techniques for Trace gas Emissions; Müller et al., 2019), WRF-Chem (Weather Research and Forecasting model coupled with Chemistry; Zare et al., 2018), CESM2 (Community Earth System Model; Emmons et al., 2020), and CMAQ (Community Multiscale Air Quality; Pye et al., 2013).

Most studies so far have focused on updating isoprene oxidation with significantly less attention to terpenes. In general terpene oxidation has been ignored or heavily reduced in chemical schemes in many regional and global models used in the past despite recent field campaigns suggesting the importance of terpene chemistry (Xu et al., 2015; Zhang et al., 2018). Many mechanisms represent monoterpenes as a single tracer (e.g., Emmons et al., 2020; Li et al., 2018; Müller et al., 2019). Monoterpenes were expanded to include two surrogate compounds first in WRF-Chem (Browne et al., 2014; Zare et al., 2018) and then in GEOS-Chem (Fisher et al., 2016). These models with expanded terpene chemistry demonstrate the importance of terpene-derived organic nitrates for the $\mathrm{NO}_{x}$ budget in both the southeastern US (Fisher et al., 2016) and over the boreal forests of Canada (Browne et al., 2014). These past studies motivate adding increased complexity for terpenes. Two surrogate compounds are not sufficient to accurately represent all terpene chemistry given the large variety of chemical structures and reactivities (Guenther et al., 2012). Our understanding of terpene chemistry is more limited than isoprene chemistry, but experimental and theoretical data are still available to generate a chemical scheme (Atkinson and Arey, 2003; Johnson and Marston, 2008; $\mathrm{Ng}$ et al., 2017, and references therein).

Here, isoprene and terpene chemistry in MOZART-TS1 (Model of OZone And Related chemical Tracers), the default chemical mechanism used in CESM2/CAM-chem (the Community Earth System Model/Community Atmosphere Model with full chemistry), will be updated to determine the extent to which improvements to the gas-phase chemical mechanism for biogenic VOCs can explain the simulated surface ozone bias over the southeastern US. A bias in simulated surface ozone over North America in summer compared to observations was present in past releases of CESM/CAM-chem (Tilmes et al., 2015; Brown-Steiner et al., 2015) and continues to exist in the current release (CESM2.1.0) used in this 
work (see Sect. 4.3). For isoprene, the chemical mechanism updates are of similar complexity to Müller et al. (2019) and Bates and Jacob (2019) and more complex than Travis et al. (2016) and Li et al. (2018). For terpenes, the chemistry updates are significantly more complex than any other reduced scheme currently available (Browne et al., 2014; Fisher et al., 2016; Zare et al., 2018).

The updated isoprene and terpene chemistry will be evaluated against more explicit chemical mechanisms using a box model and against observations using CESM2/CAMchem. In particular, the formation and fate of the organic nitrates between the new and old schemes will be described and evaluated. There are a number of lingering uncertainties for both isoprene and terpene chemistry related to the formation and fate of organic nitrates (e.g., differences in measured organic-nitrate yields between studies or disagreement among researchers on how to estimate organic-nitrate yields for unstudied compounds). These uncertainties will be assessed to determine which uncertainties have the largest impact on simulated surface ozone.

\section{Development of MOZART-TS2}

In this study a new version (T2) of the MOZART tropospheric chemical mechanism has been developed for use in CESM/CAM-chem and other models. In CAM-chem the T2 mechanism is combined with the current stratospheric mechanism in CESM2 (Emmons et al., 2020), with the result called MOZART-TS2 or TS2 hereafter. The TS2 mechanism includes a more complex representation of isoprene and terpene oxidation based on recent experimental data than in MOZART-TS1 (Emmons et al., 2020; Knote et al., 2014) or TS1 hereafter. The updates for isoprene chemistry include an additional 21 transported species, 18 nontransported species, and 139 reactions, which increases the simulation time by $\sim 18 \%$. The updates for terpene chemistry include an additional 25 transported species, 22 nontransported species, and 219 reactions, which increases the simulation time by $\sim 26 \%$. Thus, together these isoprene and terpene updates increase the simulation time by $\sim 50 \%$. As described in Sect. 4.1 and 4.2, this additional cost is necessary in order to correctly simulate $\mathrm{HO}_{x}$ and $\mathrm{NO}_{x}$ recycling and $\mathrm{O}_{3}$ production.

A list of all TS2 species, photolysis reactions, and kinetic reactions is provided in the Supplement (Tables S2, S5, and S6). A simplified version of TS2 for isoprene and terpene $\mathrm{OH}$-initiated oxidation is shown in Figs. 1 and 2, for $\mathrm{NO}_{3}$ initiated oxidation in Figs. S1 and S2 (in the Supplement), and for $\mathrm{O}_{3}$-initiated oxidation in Fig. S3. These figures do not contain all of the detail in TS2, but they illustrate the complexity to facilitate comparisons with other reduced schemes and define many of the surrogate species used throughout the text. Explicit chemical mechanisms including MCM v3.3.1 (Master Chemical Mechanism; Jenkin et al., 2015) and the
Caltech isoprene mechanism (Wennberg et al., 2018) and several review papers (Atkinson and Arey, 2003; Johnson and Marston, 2008; Ng et al., 2017) strongly guided the creation of the reduced TS2 mechanism. Surrogate compounds are shared from $\mathrm{NO}_{3-}, \mathrm{O}_{3^{-}}$, and $\mathrm{OH}$-initiated oxidation to ensure accurate representation of the chemistry while reducing the number of surrogate compounds and the computational cost.

When available, all reaction rate constants were updated to those recommended in either JPL (Jet Propulsion Laboratory; Burkholder et al., 2015) or IUPAC (International Union of Pure and Applied Chemistry; Atkinson et al., 2004, 2006). For those reaction rates not in IUPAC or JPL, typically the Caltech isoprene mechanism (Wennberg et al., 2018) or MCM v3.3.1 (Jenkin et al., 1997; Saunders et al., 2003; Jenkin et al., 2012, 2015) was used. For isoprene and terpene reactions, the peroxy $\left(\mathrm{RO}_{2}\right)$ and peroxyacyl $\left(\mathrm{RCO}_{3}\right)$ reaction rates were consistently assigned throughout the mechanism using the assumptions specified in Table S1.

\subsection{Updates to Henry's law constants}

Currently, in TS1, only certain species undergo wet and dry deposition (Emmons et al., 2020). For TS2, all compounds undergo wet and dry deposition except for radicals and compounds constrained with lower-boundary conditions. As listed in Table S4, Henry's law constants were updated to the most recent literature recommendations (Burkholder et al., 2015; Sander, 2015; Schwartz and White, 1981; Leu and Zhang, 1999; Goldstein and Czapski, 1997; Fried et al., 1994; Chameides, 1984; Reichl, 1995; Kames and Schurath, 1995; Leng et al., 2013; Chan et al., 2010; Staudinger and Roberts, 2001; Dohnal and Fenclova, 1995; Hiatt, 2013; Guo and Brimblecombe, 2007; McNeill et al., 2012; Allou et al., 2011; Sieg et al., 2009; Iraci et al., 1999; Smith and Martell, 1976; Copolovici and Niinemets, 2005; van Roon et al., 2005). The effective Henry's law equations used in CAM-chem are described in the notes at the end of Table S4. Henry's law constants for halogens, important mainly for stratospheric chemistry, were not changed from previous versions (Emmons et al., 2020). For all oxygenated organic gases that condense to form secondary organic aerosol (SOA), Henry's law coefficients were based on values from GECKO-A (Generator for Explicit Chemistry and Kinetics of Organics in the Atmosphere) as in Hodzic et al. (2014, 2016) with no changes from previous versions (Emmons et al., 2020). When Henry's law constants were unavailable in the literature, the value was approximated based on a close surrogate or by GROMHE (GROup contribution Method for Henry's law Estimate; Raventos-Duran et al., 2010). GROMHE is the theoretical structure activity relationship method used to estimate Henry's law constants by GECKO-A (Aumont et al., 2005). If the Henry's law temperature dependence $(\Delta H / R)$ was unavailable in the literature, $6014 \mathrm{~K}$ was assumed to be consistent with GECKO-A. 


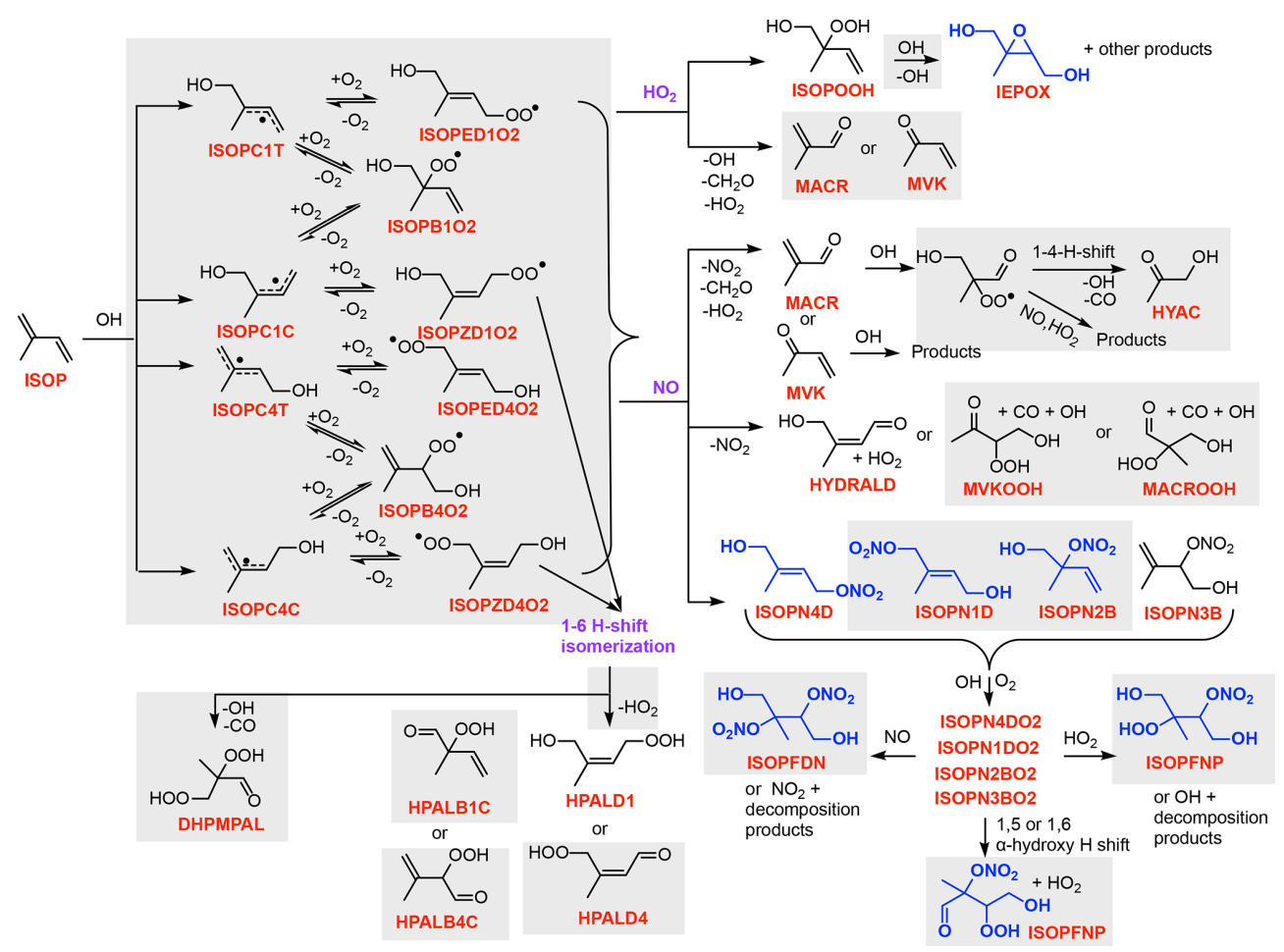

Figure 1. Simplified schematic of the TS2 mechanism for isoprene OH-initiated oxidation. Gray boxes indicate new chemistry added or updated in TS2. Blue compounds undergo aerosol uptake. As shown, only certain isomers of organic nitrates undergo aerosol uptake as explained in Sect. 2.4. All species names used in TS2 are described in Table S2. Similar schematics for $\mathrm{NO}_{3}$ - and $\mathrm{O}_{3}$-initiated oxidation of isoprene are provided in Figs. S1 and S3 in the Supplement.

The reactivity factor $\left(F_{0}\right)$ used for dry deposition and ranging from 0 to 1 , with 1 being as reactive as ozone, is also listed in Table S4. The $F_{0}$ for oxygenated volatile organic compounds is assumed to be 1 , consistent with recent observational studies (Karl et al., 2010; Nguyen et al., 2015).

\subsection{Updates to isoprene chemistry}

Isoprene oxidation by $\mathrm{OH}$ (Sect. 2.2.1), $\mathrm{O}_{3}$ (Sect. 2.2.2), and $\mathrm{NO}_{3}$ (Sect. 2.2.3) were all updated in TS2 from TS1. All new photolysis reactions were mapped with an optional scaling factor to photolysis rate constants already incorporated into CESM2. Scaling to known photolysis rates is common in reduced chemical mechanisms and even explicit mechanisms like MCM as photolysis rates for many surrogate compounds have not been measured. In general, products and photolysis rate constants were guided by explicit schemes: MCM v3.3.1 (Jenkin et al., 2015) and the Caltech isoprene mechanism (Wennberg et al., 2018). $\delta$-hydroperoxy aldehydes (HPALD1 and HPALD2) were assumed to photolyze with the cross sections of methacrolein (Wennberg et al., 2018) and the quantum yield estimated by Liu et al. (2017). Carbonyl nitrates were assumed to photolyze with the fast photolysis rate constants reported in Müller et al. (2014). Like MCM v3.3.1 (Jenkin et al., 2015), the various carbonyl nitrate photolysis rates are scaled to that of propanone nitrate (NOA). The photolysis rate constant for isoprene carbonyl nitrate from isoprene $\mathrm{NO}_{3}$-initiated oxidation $(\mathrm{NC} 4 \mathrm{CHO})$ is based on the measurement from Xiong et al. (2016).

\subsubsection{OH-initiated oxidation}

Isoprene reacts with $\mathrm{OH}$ and then $\mathrm{O}_{2}$ to form six distinct isoprene hydroxy peroxy radicals (Fig. 1), which are represented explicitly in TS2 based on reaction rate constants reported by Teng et al. (2017). The Caltech isoprene mechanism recommends a possible reduction to represent this first-generation peroxy radical chemistry, but this reduction scheme does not perform as well in urban regions with high $\mathrm{NO}$ and short $\mathrm{RO}_{2}$ lifetimes (Wennberg et al., 2018). Here this chemistry is represented explicitly (i.e., four isoprene hydroxy alkyl radical isomers and six isoprene hydroxy peroxy radical isomers) because radical species are not transported in CESM/CAM-chem and so do not considerably contribute to the computational cost. This more explicit chemistry allows TS2 to be used at finer horizontal resolutions that better resolve urban regions with high NO levels, which is a goal for future studies. The $\delta$-Z-isoprene hydroxy peroxy radicals will isomerize in TS2 to form four isomers $(2-\beta$ and $2-\delta$ ) of hydroperoxy aldehydes (HPALDs) among other products based on recommendations from Wennberg et al. (2018) but more reduced. There are still large uncertainties in the rates, 


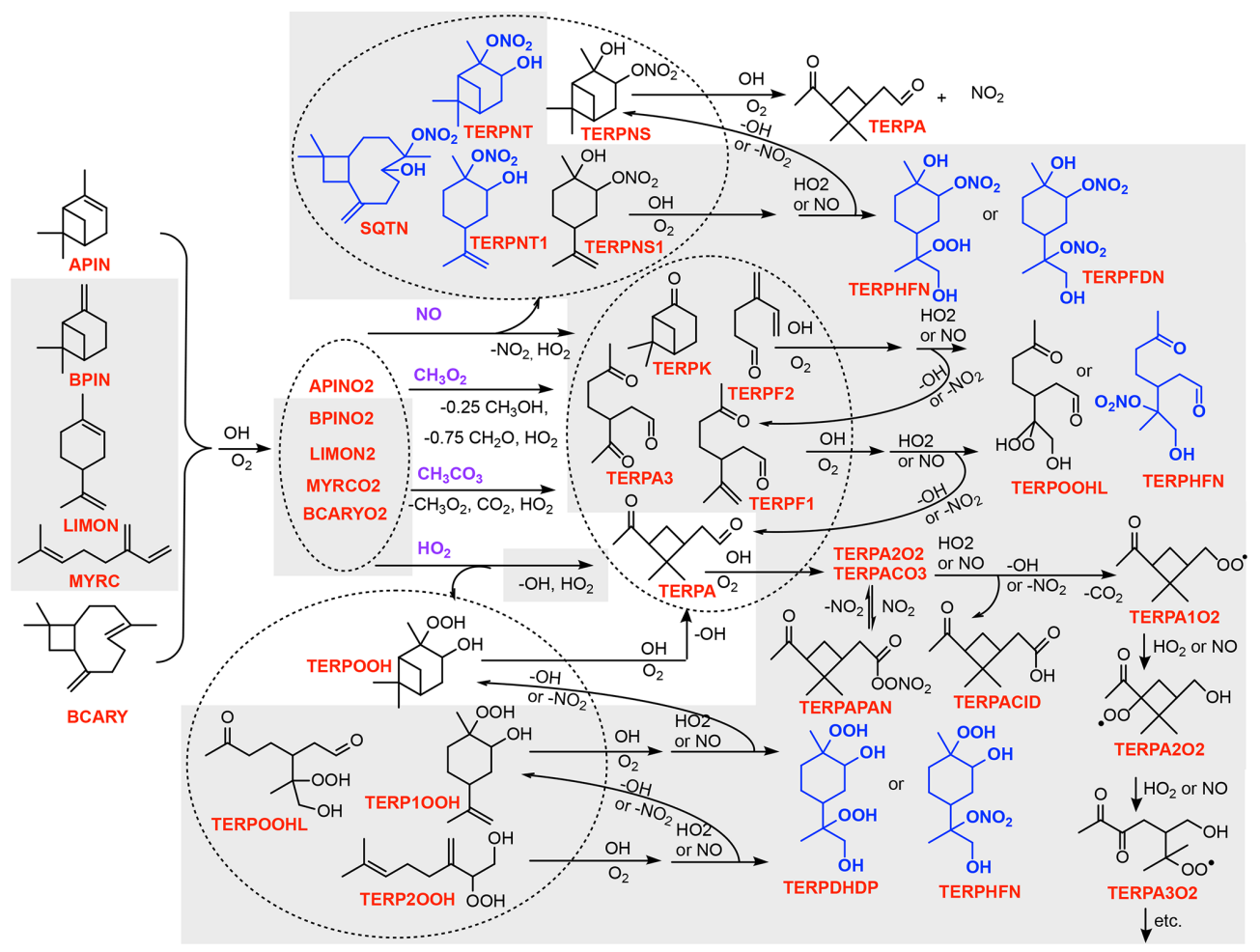

Figure 2. Simplified schematic of the TS2 chemical mechanism for terpene $\mathrm{OH}$-initiated oxidation. Gray boxes indicate new chemistry added or updated in TS2. Blue compounds undergo aerosol uptake. All species names used in TS2 are described in Table S2. Similar schematics for $\mathrm{NO}_{3}$ - and $\mathrm{O}_{3}$-initiated oxidation of terpenes are provided in Figs. $\mathrm{S} 2$ and $\mathrm{S} 3$ in the Supplement.

product yields, and $\mathrm{HO}_{x}$ recycling from photolysis and $\mathrm{OH}$ oxidation of HPALDs. Once more is known, greater detail may be added to TS2.

While TS1 assumes a unity yield of isoprene hydroxy hydroperoxide (ISOPOOH) from the isoprene $\mathrm{RO}_{2}+\mathrm{HO}_{2}$ reaction, TS2 adds a small yield of methyl vinyl ketone and methacrolein from this pathway (Liu et al., 2013; Wennberg et al., 2018). The ISOPOOH $+\mathrm{OH}$ reaction rate and products have been updated to be consistent with St. Clair et al. (2016). OH addition to ISOPOOH forms a 0.85 yield of isoprene epoxydiol (IEPOX) and $\mathrm{OH}$; a 0.07 yield of glycolaldehyde, hydroxyacetone, and $\mathrm{OH}$; and a 0.08 yield of ISOPHFP, which is a surrogate compound for all isoprene highly functionalized hydroperoxides (Krechmer et al., 2015; Riva et al., 2016; St. Clair et al., 2016; Liu et al., 2016; Piletic et al., 2019). ISOPHFP undergoes aerosol uptake in TS2 to more accurately represent loss processes of $\mathrm{HO}_{x}$, but like organic nitrates it does not explicitly form SOA. SOA is formed by a volatility basis set (VBS) scheme in CAMchem, which was not updated in this work. Directly forming SOA from low-volatility products like ISOPHFP in CAMchem is a goal for future work. Chemistry for IEPOX, the dominant product from the $\mathrm{ISOPOOH}+\mathrm{OH}$ reaction, has also been updated in TS2 (Bates et al., 2014, 2016; Jacobs et al., 2013; Wennberg et al., 2018). TS2 only has one isomer of ISOPOOH and IEPOX, which is more reduced than the
Caltech mechanism (Wennberg et al., 2018), but this simplification has minimal impact on the total ISOPOOH or IEPOX concentration (Sect. 4.1). To save computational cost, multiple isomers were only incorporated into TS2 if grouping them together would bias the $\mathrm{HO}_{x}$ or $\mathrm{NO}_{x}$ budgets. For example, the two dominant isomers of ISOPOOH react with $\mathrm{OH}$ to produce similar yields of $\mathrm{OH}$ and a similar distribution of IEPOX isomers (Wennberg et al., 2018), so grouping isomers of ISOPOOH and IEPOX together to reduce computational cost is warranted. In contrast, TS2 includes multiple isomers of HPALDs and hydroxy nitrates because different isomers react with $\mathrm{OH}$ to produce varying levels of $\mathrm{OH}$ and $\mathrm{NO}_{2}$, so combining these isomers together would inaccurately influence the $\mathrm{HO}_{x}$ and $\mathrm{NO}_{x}$ budgets.

In TS2, additional organic nitrates are added to better represent $\mathrm{NO}_{x}$ recycling in the mechanism. Four (ISOPN4D, ISOPN1D, ISOPN2B, and ISOPN3B) instead of two firstgeneration hydroxy nitrate isomers are included using the temperature and pressure dependent yields recommended by Wennberg et al. (2018) and Teng et al. (2017) $(\sim 0.13$ at $297 \mathrm{~K}$ ). Often different isomers of the same compound will have very different fates in the atmosphere. For example, $\beta$ - and $\delta$-hydroxy nitrates have different reaction rates with $\mathrm{OH}$ and $\mathrm{O}_{3}$ and form different products (Lee et al., 2014). Additionally, tertiary organic nitrates will be more likely to undergo aerosol uptake due to their rapid hydrolysis in the 
particle phase compared to secondary or primary organic nitrates (Sect. 2.4). The organic nitrates in TS2 were carefully selected not only to account for these varying fates but also when possible to combine isomers with similar reaction rates, oxidation products, and overall atmospheric fate together to reduce computational cost. The differences in organic-nitrate formation and fate between TS1 and TS2 are described in more detail in Sect. 5.1.

In TS1, OH oxidation of the first-generation hydroxy nitrates immediately forms stable products from the $\mathrm{RO}_{2}+\mathrm{NO}$ channel rather than going through a peroxy radical intermediate. Conversely, in TS2, when an isoprene hydroxy nitrate is oxidized by $\mathrm{OH}$, a peroxy radical forms, which can either isomerize or react with $\mathrm{NO}$ or $\mathrm{HO}_{2}$ (Jacobs et al., 2014; Lee et al., 2014; Wennberg et al., 2018). Because $\mathrm{NO}_{x}$ emissions are generally decreasing or expected to decrease in the United States (Kharol et al., 2015; U.S. EPA, 2018; Jiang et al., 2018) and mixed regimes are becoming more prevalent, chemical mechanisms that do not fix the fate of the peroxy radical to the first-generation fate will become increasingly important. For example, in TS2, peroxy radicals from $\mathrm{OH}$ oxidation of unsaturated organic nitrates produced from the $\mathrm{RO}_{2}+\mathrm{NO}$ channel and IEPOX produced from the $\mathrm{RO}_{2}+\mathrm{HO}_{2}$ channel can react either with $\mathrm{NO}$ or $\mathrm{HO}_{2}$ in the later-generation step. A wide variety of later-generation organic nitrates are added to TS2 including those from decomposition $\left(\mathrm{C}_{2}-\mathrm{C}_{4}\right)$ and functionalization (ISOPFNP and ISOPFDN in Fig. 1). Including additional surrogate compounds for highly functionalized nitrates, whose fates are likely to remove $\mathrm{NO}_{x}$ through aerosol uptake/hydrolysis or wet/dry deposition, is important for accurately representing the $\mathrm{NO}_{x}$ budget.

Methacrolein and methyl vinyl ketone, which are firstgeneration products from isoprene, react with $\mathrm{OH}$ to form separate peroxy radicals in TS2 (Fig. 1), so that the methacrolein hydroxy peroxy radical can undergo an isomerization reaction (Crounse et al., 2012). In TS2, methacrolein and methyl vinyl ketone peroxy radicals react with $\mathrm{HO}_{2}$ to form not only hydroxy hydroperoxides (MACROOH and $\mathrm{MVKOOH}$ ) like in TS1 but also $\mathrm{OH}$ and decomposition products (Praske et al., 2015; Wennberg et al., 2018). The organic-nitrate yields from the methacrolein and methyl vinyl ketone $\mathrm{RO}_{2}+\mathrm{NO}$ reactions have been updated and form distinct organic nitrates (MACRN and MVKN) (Crounse et al., 2012; Praske et al., 2015). Products from the reaction of $\mathrm{HO}_{2}$ with all acyl peroxy radicals including the one derived from methacrolein were updated to IUPAC recommendations (Atkinson et al., 2006) based on the following studies (Hasson et al., 2004; Jenkin et al., 2007; Dillon and Crowley, 2008; Niki et al., 1985; Horie and Moortgat, 1992) and averaging in results from a more recent study (Grob et al., 2014).

\subsection{2 $\mathrm{O}_{3}$-initiated oxidation}

$\mathrm{O}_{3}$-initiated oxidation of isoprene is simply described in Fig. S3 and largely based on Grosjean et al. (1993a), Aschmann and Atkinson (1994), Nguyen et al. (2016), and IUPAC (Atkinson et al., 2006). Given isoprene is typically emitted in regions with high relative humidity $(\mathrm{RH})$, the stabilized Criegee intermediates are not represented explicitly in the mechanism and instead are assumed to react immediately with $\mathrm{H}_{2} \mathrm{O}$ and $\left(\mathrm{H}_{2} \mathrm{O}\right)_{2}$ in equal amounts, which is approximately the case for $\mathrm{RH}>60 \%$, to form hydroxymethyl hydroperoxide (HMHP), formaldehyde and $\mathrm{H}_{2} \mathrm{O}_{2}$, or formic acid (Nguyen et al., 2016). HMHP, a new product in TS2, photolyzes and reacts with $\mathrm{OH}$ based on Roehl et al. (2007), Allen et al. (2018), and Wennberg et al. (2018). The reaction of $\mathrm{HOCH}_{2} \mathrm{OO}+\mathrm{HO}_{2}$, which includes HMHP as a product, was updated to IUPAC recommendations (Atkinson et al., 2006).

\subsection{3 $\mathrm{NO}_{3}$-initiated oxidation}

Isoprene $\mathrm{NO}_{3}$-initiated oxidation in TS2 is described in a simplified schematic in Fig. S1 and is largely based on the following studies: Schwantes et al. (2015) and Wennberg et al. (2018) for first-generation and Schwantes et al. (2015), Lee et al. (2014), Xiong et al. (2016), and Jacobs et al. (2014) for second-generation products. Both TS1 and TS2 only have one surrogate compound for the nitrooxy peroxy radical formed when isoprene reacts with $\mathrm{NO}_{3}$. Based on the products formed, TS1 assumes all the nitrooxy peroxy radicals are $\delta$ isomers, while TS2 uses the yields in Schwantes et al. (2015), which estimated approximately equal amounts of $\beta$ - and $\delta$-nitrooxy peroxy radicals. Additionally, TS2 assumes a non-unity yield of nitrooxy hydroperoxide from the $\mathrm{RO}_{2}+\mathrm{HO}_{2}$ channel, consistent with recent work (Schwantes et al., 2015; Wennberg et al., 2018; Rollins et al., 2009; Kwan et al., 2012). Where structurally similar, organic nitrates from $\mathrm{OH}$ and $\mathrm{NO}_{3}$ oxidation are shared to reduce computational cost (Figs. 1 and S1). Two isomers $(\beta$ and $\delta$ ) of isoprene nitrooxy hydroxy epoxide formed from $\mathrm{OH}$ oxidation of nitrooxy hydroperoxide are added to TS2 (Schwantes et al., 2015; Wennberg et al., 2018). Similar to OH-initiated oxidation, the organic nitrates derived from $\mathrm{NO}_{3}$-initiated oxidation react with $\mathrm{OH}$ to form a peroxy radical that can isomerize or react with $\mathrm{NO}$ or $\mathrm{HO}_{2}$ (Lee et al., 2014; Jacobs et al., 2014; Schwantes et al., 2015; Wennberg et al., 2018; Xiong et al., 2016).

\subsection{Updates to terpene chemistry}

In TS1, all monoterpenes are grouped into one surrogate (MTERP), and all sesquiterpenes are grouped into one surrogate (BCARY). The $\mathrm{OH}, \mathrm{O}_{3}$, and $\mathrm{NO}_{3}$ reaction rate constants are different between MTERP and BCARY, but the oxidation chemistry is identical. An expanded version of 
the TS1 terpene chemistry used primarily in WRF-Chem, called T1 (Emmons et al., 2020; Knote et al., 2015a), replaced MTERP with four monoterpene surrogates: $\alpha$-pinene (APIN), $\beta$-pinene (BPIN), limonene (LIMON) and myrcene (MYRC). In $\mathrm{T} 1$, the five terpene surrogates have different reaction rates with $\mathrm{OH}, \mathrm{O}_{3}$, and $\mathrm{NO}_{3}$, but their oxidation chemistry is identical. Here in TS2, we start from the T1 mechanism and group all rather than a subset of the terpenes in MEGAN v2.1 (Model of Emissions of Gases and Aerosols from Nature; online in CESM) according to their chemical structure and reactivity into the five terpene surrogate compounds: APIN, BPIN, LIMON, MYRC, and BCARY (Table S3). Unlike T1, in TS2 each terpene surrogate has unique chemistry. Even though the chemistry is different for each terpene surrogate in TS2, the first- and latergeneration products are often shared to save computational cost. For example, the terpene hydroxy nitrate surrogate compounds are split according to their chemical structure (saturated versus unsaturated and primary/secondary versus tertiary) instead of based on their VOC precursor (i.e., there are not unique APIN hydroxy nitrates and BPIN hydroxy nitrates). Terpene oxidation chemistry by $\mathrm{OH}$ (Sect. 2.3.1), $\mathrm{O}_{3}$ (Sect. 2.3.2), and $\mathrm{NO}_{3}$ (Sect. 2.3.3) were all updated in TS2 from TS1. Like isoprene, rates for all photolysis reactions were mapped to photolysis rate constants already incorporated into CESM2 (Table S5). In general, photolysis reactions and rate constants were guided by MCM v3.3.1 (Jenkin et al., 2015).

\subsubsection{OH-initiated oxidation}

The terpene surrogate compounds react with $\mathrm{OH}$ to form hydroxy peroxy radicals that react with $\mathrm{NO}, \mathrm{NO}_{3}, \mathrm{RO}_{2}$, or $\mathrm{HO}_{2}$. For APIN, BPIN, LIMON, MYRC, and BCARY, the products from the $\mathrm{RO}_{2}+\mathrm{NO}$ reaction, which have been reasonably well studied, were used to extrapolate the products from the $\mathrm{RO}_{2}+\mathrm{NO}_{3}$ and $\mathrm{RO}_{2}+\mathrm{RO}_{2}$ reactions. The hydroxy hydroperoxide yield from the $\mathrm{RO}_{2}+\mathrm{HO}_{2}$ channel has only been measured for $\alpha$-pinene (Noziere et al., 1999; Eddingsaas et al., 2012). For the rest, the hydroxy hydroperoxide yield is estimated based on the parameterization recommended by Wennberg et al. (2018) assuming the same $\mathrm{RO}_{2}$ distribution used in the $\mathrm{RO}_{2}+\mathrm{NO}$ reaction. Below we explain briefly the experimental and theoretical studies used to determine the product distribution from the $\mathrm{RO}_{2}+\mathrm{NO}$ reaction for each terpene surrogate compound. Organic-nitrate yields from the $\mathrm{RO}_{2}+\mathrm{NO}$ pathway for many later-generation terpene oxidation products (e.g., pinonaldehyde, nopinone, and limonaldehyde) have not been measured; in this case, the organic-nitrate yield is approximated from the parameterization by Wennberg et al. (2018) up to a maximum of 0.3 . Experimental work on the alkane system suggests that the organic-nitrate yield plateaus at 0.3 (Arey et al., 2001; Yeh and Ziemann, 2014). No past literature studies have evaluated whether this plateau is different for oxygenated VOCs, which could have important consequences on ozone. Future experimental studies constraining organic-nitrate yields from oxygenated VOCs are highly recommended for further improvement of the TS2 mechanism. Due to the large uncertainties in the organic-nitrate yields from terpene oxidation, no temperature or pressure dependency was included.

The APIN $\mathrm{RO}_{2}$ will react with $\mathrm{NO}$ to form hydroxy nitrates (yield $=0.23$ ) (Noziere et al., 1999; Ruppert et al., 1999; Rindelaub et al., 2015), acetone (Aschmann et al., 1998; Noziere et al., 1999; Orlando et al., 2000; Wisthaler et al., 2001), formaldehyde (Noziere et al., 1999; Orlando et al., 2000), pinonaldehyde (TERPA) (Arey et al., 1990; Hakola et al., 1994; Wisthaler et al., 2001; Aschmann et al., 2002a), and the remaining products are based on theoretical work (Vereecken et al., 2007). The hydroxy nitrate isomer distribution is based on one experimental study (Berndt et al., 2016) and theoretical work (Vereecken et al., 2007). The products from the $\mathrm{RO}_{2}+\mathrm{HO}_{2}$ channel (TERPOOH, TERP1OOH, and TERPA) are based on experimental (Noziere et al., 1999; Eddingsaas et al., 2012) and theoretical (Vereecken et al., 2007) studies. Fewer studies have been conducted on $\beta$-pinene than $\alpha$-pinene, but still enough information is available to develop a scheme. The BPIN $\mathrm{RO}_{2}$ will react with NO to form nopinone (TERPK) (Arey et al., 1990; Hakola et al., 1994; Wisthaler et al., 2001; Lee et al., 2006b; Jaoui and Kamens, 2003), formaldehyde (Hatakeyama et al., 1991; Orlando et al., 2000; Lee et al., 2006b), acetone (Aschmann et al., 1998; Orlando et al., 2000; Wisthaler et al., 2001; Lee et al., 2006b), hydroxy nitrates (yield = 0.25) (Ruppert et al., 1999), and the remaining products are based on theory (Vereecken and Peeters, 2012). The $\mathrm{RO}_{2}$ isomer distribution is based on the measured product yields defined above for hydroxy nitrates and nopinone and theoretical work from Vereecken and Peeters (2012).

The LIMON $\mathrm{RO}_{2}$ isomer distribution is approximated using the structure-activity relationship (SAR) developed by Peeters et al. (2007). These $\mathrm{RO}_{2}$ will react with $\mathrm{NO}$ to form hydroxy nitrates (yield = 0.23) (Ruppert et al., 1999), formaldehyde (Lee et al., 2006b), and a terpene oxidation product containing one double bond (TERPF1), which represents both limonaldehyde and limaketone. $\mathrm{MYRC} \mathrm{RO}_{2}$ isomer distribution is also approximated by the SAR developed by Peeters et al. (2007) and reacts with NO to form hydroxy nitrates (yield $=0.29$ ) (Ruppert et al., 1999), acetone (Reissell et al., 1999; Orlando et al., 2000; Lee et al., 2006b), formaldehyde (Orlando et al., 2000), and what is assumed to be the main product, TERPF2, which is a functionalized terpene oxidation product with two double bonds. OHinitiated oxidation is quite uncertain for $\beta$-caryophyllene, the surrogate for all sesquiterpenes. From the $\mathrm{BCARY} \mathrm{RO}_{2}$ reaction with NO, we form a sesquiterpene nitrate called SQTN (yield $=0.3$ ) and TERPF2. The sesquiterpenes have two to four double bonds (Guenther et al., 2012), so we assume TERPF2 forms as the primary first-generation product. Because SQTN has at least one double bond and is low in 
volatility, it or its oxidation products, which will retain the nitrate group, will likely deposit or undergo aerosol uptake. Thus, we do not include further reaction of SQTN with $\mathrm{OH}$ or photolysis.

In order to save computational cost and still represent the chemistry as accurately as possible, the first- and latergeneration products for all the terpene surrogate compounds are shared. There are a number of aldehyde surrogate compounds including: TERPA, which represents pinonaldehydetype products; TERPA2, which represents norpinaldehydetype products; and TERPA3, which represents aldehydes largely produced from limonaldehyde and limaketone oxidation. These aldehyde products react with $\mathrm{OH}, \mathrm{O}_{3}$, and $\mathrm{NO}_{3}$ based on pinonaldehyde from MCM v3.3.1 (Saunders et al., 2003). Each of these will form corresponding carboxylic/peroxy acids (TERPACID, TERPACID2, and TERPACID3) and peroxy acyl nitrates (TERPAPAN, TERPA2PAN, and TERPA3PAN). One ketone is included: TERPK, which represents nopinone-type products and reacts with OH using the rate from Calogirou et al. (1999). There are two unsaturated compounds (TERPF1 and TERPF2), which represent functionalized terpene oxidation products with one or two double bonds. TERPF1 reacts with $\mathrm{OH}$, $\mathrm{O}_{3}$, and $\mathrm{NO}_{3}$ like limonaldehyde (Calogirou et al., 1999), and TERPF2 reacts with $\mathrm{OH}$ and $\mathrm{NO}_{3}$ like isoprene (Atkinson et al., 2006) and $\mathrm{O}_{3}$ like first-generation products from $\beta$-caryophyllene (Winterhalter et al., 2009). There are three hydroperoxides: TERPOOH, which represents saturated hydroxy hydroperoxides with a ring (e.g., from $\alpha$-pinene); TERPOOHL, which represents saturated hydroxy hydroperoxides without a ring (e.g., from limonene); TERP1OOH, which represent hydroxy hydroperoxides with one double bond; and TERP2AOOH, which represents hydroxy hydroperoxides with two double bonds. In order to represent terpenes with multiple double bonds accurately, the later-generation products must continue to contain a double bond that undergoes $\mathrm{OH}$ addition. There are four firstgeneration hydroxy nitrates: TERPNS (primary and secondary saturated), TERPNS1 (primary and secondary unsaturated), TERPNT (tertiary saturated), and TERPNT1 (tertiary unsaturated). Saturated and unsaturated hydroxy nitrates are separated because they have different reaction rates and products from oxidation by $\mathrm{OH}$. Tertiary hydroxy nitrates are separated from primary/secondary hydroxy nitrates because tertiary nitrates will undergo aerosol uptake due to their rapid hydrolysis (Sect. 2.4). There are also a number of low-volatility highly functionalized compounds such as TERPFDN, which represents highly functionalized terpene dinitrates; TERPHFN, which represents highly functionalized terpene nitrates; and TERPDHDP, which represents terpene dihydroxy dihydroperoxides.

The terpene products described above were selected so that compounds that are chemically similar (i.e., contain the same functional groups and react with $\mathrm{OH}, \mathrm{O}_{3}$, and $\mathrm{NO}_{3}$ at similar rates) are grouped together. The complexity of the chemistry is largely determined by the current knowledge of the system. There may be advantages to adding more complexity into TS2 in the future as more knowledge about terpene oxidation especially later-generation chemistry becomes available. Given that the later-generation chemistry of terpenes is not well understood and that chemistry of many terpene products is largely estimated based on similar more well-studied compounds, adding separate products for each of the terpene surrogate compounds would increase cost without adding a lot of additional information into the system.

\subsection{2 $\quad \mathrm{O}_{3}$-initiated oxidation}

$\mathrm{O}_{3}$-initiated oxidation of the terpene surrogate compounds in TS2 is described in a simplified schematic in Fig. S3. $\mathrm{O}_{3}$-initiated oxidation of APIN is based on MCM (Saunders et al., 2003), IUPAC (Atkinson et al., 2006), theoretical calculations (Zhang and Zhang, 2005; Kurten et al., 2015), and experimental results (Ma et al., 2008). The $\mathrm{OH}$ yield (0.77) is quite high (Chew and Atkinson, 1996; Paulson et al., 1998; Rickard et al., 1999; Siese et al., 2001; Berndt et al., 2003; Forester and Wells, 2011). The stabilized Criegee intermediates are not represented explicitly in the mechanism and instead are assumed to react immediately with $\mathrm{H}_{2} \mathrm{O}$ to form either $\mathrm{H}_{2} \mathrm{O}_{2}$ and pinonaldehyde or pinonic acid (TERPACID). $\mathrm{O}_{3}$-initiated oxidation of BPIN is based on MCM (Saunders et al., 2003), IUPAC (Atkinson et al., 2006), experimental results (Hakola et al., 1994; Grosjean et al., 1993b; Yu et al., 1999; Ma and Marston, 2008; Winterhalter et al., 2000; Hasson et al., 2001), and theory (Nguyen et al., 2009). The $\mathrm{OH}$ yield ( 0.3$)$ from $\beta$-pinene ozonolysis is much lower than that from $\alpha$-pinene due to differences in their molecular structures (Atkinson et al., 1992; Rickard et al., 1999). Again the stabilized Criegee intermediates are not explicitly represented and instead assumed to react directly with $\mathrm{H}_{2} \mathrm{O}$ to form $\mathrm{H}_{2} \mathrm{O}_{2}$ and nopinone.

Only a few products with low yields have been detected from limonene ozonolysis (Atkinson and Arey, 2003). The chemical mechanism for $\mathrm{O}_{3}$-initiated LIMON oxidation is based on MCM (Saunders et al., 2003) and IUPAC (Atkinson et al., 2006). The $\mathrm{OH}$ yield is 0.66 (Aschmann et al., 2002a; Forester and Wells, 2011; Herrmann et al., 2010). The majority of products are grouped into one surrogate species, TERPF1, which is a terpene functionalized oxidation product with one double bond. Again stabilized Criegee intermediates were not included explicitly and instead assumed to react with $\mathrm{H}_{2} \mathrm{O}$ to form $\mathrm{H}_{2} \mathrm{O}_{2}$ and TERPF1 or TERPACID in similar yields to that in the $\alpha$-pinene system. $\mathrm{O}_{3}$-initiated oxidation of MYRC is based on Ruppert et al. (1999), Boge et al. (2013), and Lee et al. (2006a) with an OH yield of 0.63 from Aschmann et al. (2002a). The dominant products are hydroxy acetone (HYAC), acetone, and 4-vinyl-4-pentenal (TERPF2). $\mathrm{O}_{3}$-initiated oxidation of BCARY is based on Winterhalter et al. (2009) and Jaoui et al. (2003) with an $\mathrm{OH}$ 
yield of 0.08 (Shu and Atkinson, 1994; Winterhalter et al., 2009) to form TERPACID and TERPF2.

\subsection{3 $\quad \mathrm{NO}_{3}$-initiated oxidation}

For $\mathrm{NO}_{3}$-initiated oxidation, $\alpha$-pinene has been studied the most completely. Based on the few studies investigating the other monoterpenes, $\alpha$-pinene oxidation by $\mathrm{NO}_{3}$ is unique (Hallquist et al., 1999; Fry et al., 2014; Kurten et al., 2017), so $\alpha$-pinene is handled separately in TS2 as APIN. In TS2, monoterpenes react with $\mathrm{NO}_{3}$ to form a nitrooxy peroxy radical, which then reacts with $\mathrm{HO}_{2}, \mathrm{NO}, \mathrm{NO}_{3}, \mathrm{CH}_{3} \mathrm{CO}_{3}$, $\mathrm{CH}_{3} \mathrm{O}_{2}$, and itself to form different yields of organic nitrates as summarized in a simplified schematic in Fig. S2. There are few experimental studies that explicitly state the $\mathrm{RO}_{2}$ fate, when reporting a nitrate yield. In all future experiments, reporting the $\mathrm{RO}_{2}$ fate is recommended so that laboratory results can be directly used in the development of condensed and explicit chemical mechanisms.

In TS1, when the nitrooxy peroxy radical reacts with $\mathrm{HO}_{2}$, one nitrooxy hydroperoxide isomer forms with a unity yield. In contrast, TS2 forms four nitrooxy hydroperoxide isomers: TERPNPT (saturated tertiary), TERPNPS (saturated secondary/primary), TERPNPT1 (unsaturated tertiary), and TERPNPS1 (unsaturated primary/secondary) (Fig. S2). Recent work suggests that the $\alpha$-pinene nitrooxy peroxy radical reacts with $\mathrm{HO}_{2}$ to form nitrooxy hydroperoxide $(0.3)$ and pinonaldehyde (0.7) (Kurten et al., 2017). The yield of nitrooxy hydroperoxides for all other surrogate terpene compounds is estimated from the parameterization in Wennberg et al. (2018). Berndt and Boge (1997) measured a 0.14 nitrate or 0.07 dinitrate yield from the $\alpha$-pinene nitrooxy peroxy + NO reaction. Because the $\alpha$-pinene nitrooxy alkoxy radical is unlikely to decompose to form organic nitrates (Fry et al., 2014; Kurten et al., 2017), this signal is assumed to be from dinitrates. Thus, in TS2, all terpene surrogate nitrooxy peroxy radicals react with $\mathrm{NO}$ to form a yield of 0.07 dinitrates. Most $\mathrm{NO}_{3}$-initiated oxidation laboratory experiments have focused on $\mathrm{RO}_{2}+\mathrm{RO}_{2}$ chemistry. The fate of the alkoxy radical can be inferred from these product distributions and used to estimate the oxidation products from the other pathways (i.e., $\mathrm{RO}_{2}+\mathrm{HO}_{2}, \mathrm{RO}_{2}+\mathrm{NO}_{3}$, and $\mathrm{RO}_{2}+\mathrm{NO}$ ).

APIN nitrooxy peroxy radical $+\mathrm{RO}_{2}$ reactions form organic nitrates and pinonaldehyde (Wangberg et al., 1997; Hallquist et al., 1999; Spittler et al., 2006). The nitrooxy peroxy radical isomer distribution is based on MCM v3.3.1 (Saunders et al., 2003). The APIN nitrooxy alkoxy radical is assumed not to form any organic nitrates. For BPIN, the tertiary peroxy radical (yield of 0.9) is dominant (Boyd et al., 2015), so the $\mathrm{RO}_{2}+\mathrm{RO}_{2}$ reactions are presumed to mostly form alkoxy radicals rather than carbonyl or hydroxy nitrates. Nopinone is produced in a low yield (0.02) (Hallquist et al., 1999). The alkoxy radical from $\delta$-3-carene, which is grouped with $\beta$-pinene, breaks preferentially at the $\mathrm{C}-\mathrm{C}\left(\mathrm{H}_{2}\right)$ bond to retain the nitrate group rather than the $\mathrm{C}-\mathrm{C}\left(\mathrm{ONO}_{2}\right)$ bond to release $\mathrm{NO}_{2}$ (Kurten et al., 2017). Recent experimental work suggests the alkoxy radical from $\beta$-pinene also breaks preferentially to retain the nitrate group (Claflin and Ziemann, 2018). For $\mathrm{RO}_{2}+\mathrm{RO}_{2}$ reactions from BPIN, the organic-nitrate yield is based on Hallquist et al. (1999) and Fry et al. (2009), which is reasonably consistent with recent work quantifying organic nitrates in $\beta$-pinene SOA (Claflin and Ziemann, 2018). The BPIN alkoxy radical is assumed to decompose to form organic nitrates based on the average between $\beta$-pinene and $\delta$-3-carene, which are grouped into one surrogate compound (Fry et al., 2014).

LIMON NO 3 -initiated oxidation is more complicated because of the two double bonds. Spittler et al. (2006) determined that $\mathrm{NO}_{3}$ addition is more selective than $\mathrm{OH}$, and so $\mathrm{NO}_{3}$ dominantly reacts with the endocylic double bond of limonene. LIMON $\mathrm{NO}_{3}$-initiated oxidation was assumed to form a similar initial nitrooxy peroxy radical distribution as $\alpha$-pinene. The organic-nitrate yield for $\mathrm{RO}_{2}+\mathrm{RO}_{2}$ reactions is based on Hallquist et al. (1999), Spittler et al. (2006), and Fry et al. (2014). MYRC $\mathrm{NO}_{3}$-initiated oxidation has not been constrained by any studies. MYRC nitrooxy peroxy radical distribution was calculated based on SARs (Pfrang et al., 2006) and the following assumptions. For conjugated double bonds, $\mathrm{NO}_{3}$ adds to the less substituted position and equal amounts of $\delta$ - and $\beta$-peroxy radicals form consistent with isoprene oxidation (Teng et al., 2017; Schwantes et al., 2015). For the non-conjugated double bond, $\mathrm{NO}_{3}$ adds in the same ratio as that for $\alpha$-pinene. For organic-nitrate yields, all secondary/tertiary alkoxy radicals were assumed to release $\mathrm{NO}_{2}$, and all primary alkoxy radicals were assumed to produce carbonyl nitrates. The $\mathrm{RO}_{2}+\mathrm{RO}_{2}$ reaction was assumed to form the same organic-nitrate yield as $\alpha$-pinene. All of these assumptions are quite speculative. Better understanding of less studied monoterpenes like myrcene is necessary.

There are also few constraints on $\mathrm{NO}_{3}$-initiated oxidation of $\beta$-caryophyllene. All sesquiterpene-derived organic nitrates are grouped together as SQTN, consistent with OHinitiated oxidation. Fry et al. (2014) detected all of the organic nitrates from $\beta$-caryophyllene in the particle phase. Thus, the main loss of SQTN in the atmosphere and in TS2 is aerosol uptake and wet/dry deposition to permanently remove $\mathrm{NO}_{x}$ in the atmosphere. The BCARY peroxy radical distribution and organic-nitrate yields were assumed to be similar to that of $\alpha$-pinene. Sesquiterpene $\mathrm{NO}_{3}$-initiated oxidation is quite uncertain and difficult to constrain given current literature data. However, sesquiterpene-derived nitrates, which quickly partition to the particle phase or deposit on surfaces, may be important missing removal pathways for $\mathrm{NO}_{x}$ and so deserve further study.

The four nitrooxy hydroperoxides derived from $\mathrm{NO}_{3}-$ initiated oxidation react with $\mathrm{OH}$ and photolyze largely based on MCM v3.3.1 (Saunders et al., 2003). However, in MCM v3.3.1, terpene-unsaturated nitrooxy hydroperoxides react with $\mathrm{OH}$ via hydrogen abstraction rather than addition to the double bond. This oversimplification in MCM v3.3.1 leads to 
inaccurate $\mathrm{NO}_{x}$ recycling (Sect. 4.2). Instead of using MCM v3.3.1 recommendations, $\mathrm{OH}$ is assumed to react with the unsaturated nitrooxy hydroperoxides at the same rate as limonaldehyde (Calogirou et al., 1999) and to largely form the corresponding saturated nitrooxy hydroperoxide (Fig. S2).

\subsection{Aerosol uptake of isoprene and terpene organic nitrates}

In CESM/CAM-chem, uptake of gas-phase organic nitrates to aerosols is represented simply by converting an organic nitrate to nitric acid, thereby neglecting the entire particlephase hydrolysis reaction. TS1 uses aerosol uptake parameters based on Fisher et al. (2016) for organic nitrates derived from isoprene $(\gamma=0.005)$ and terpenes $(\gamma=0.01)$. Fisher et al. (2016) recommends a bulk aerosol uptake coefficient for all isoprene hydroxy nitrate isomers, even though only tertiary and $\delta$-allylic-hydroxy nitrates will undergo hydrolysis fast enough for aerosol uptake to be relevant in the atmosphere (Jacobs et al., 2014). In TS2, only tertiary isoprene and terpene organic nitrates and isoprene $\delta$-allylic-hydroxy nitrates undergo aerosol uptake (Jacobs et al., 2014) but with a larger aerosol uptake coefficient $(\gamma=0.02)$ recommended by Wolfe et al. (2015). Recently, Takeuchi and Ng (2019) directly measured the fraction of particulate organic nitrates undergoing hydrolysis, which is consistent with the expected tertiary nitrate fraction for $\beta$-pinene $+\mathrm{NO}_{3}$ but lower than that expected for $\alpha$-pinene $+\mathrm{NO}_{3}$ and $\alpha$ - and $\beta$ pinene $+\mathrm{OH}$. A better understanding of the fraction of tertiary organic nitrates and how this relates to the measured fraction of particulate nitrates undergoing hydrolysis are needed for further improvements to TS2. The newly added multi-functional isoprene and terpene low-volatility organic nitrates in TS2 undergo rapid aerosol uptake $(\gamma=0.1)$ based on Marais et al. (2016). In TS2, aerosol uptake of organic nitrates is only a gas-phase sink for organic nitrates and does not form SOA directly. SOA in TS2 only forms from a VBS scheme (Tilmes et al., 2019), which was not updated in this work. Better connecting gas-phase chemistry and SOA formation is a goal for future work, as uptake of organic nitrates to form SOA is important for accurately representing gas-phase ozone as well as the overall magnitude of SOA. Aerosol uptake of organic nitrates is quite uncertain (Sect. 5.2), and further studies investigating the processes of organic-nitrate uptake and hydrolysis as well as more complex implementation of these processes in models is warranted and a goal for future work.

\section{Methods}

The newly developed TS2 mechanism was evaluated against explicit mechanisms using a box model (Sect. 3.1) and against field observations using CESM/CAM-chem (Sect. 3.2).

\subsection{Box modeling}

MOZART-TS2 was compared with MOZART-TS1, MCM v3.3.1 (Jenkin et al., 2015), and the Caltech isoprene mechanism (Wennberg et al., 2018) using BOXMOX v1.7 (Knote et al., 2015b), a box model wrapper for the Kinetic PreProcessor (KPP) (Sandu and Sander, 2006). MCM v3.3.1 was downloaded via the website $\mathrm{http} / / \mathrm{mcm}$.leeds.ac.uk/MCM (last access: 7 September 2018, Jenkin et al., 1997; Saunders et al., 2003; Jenkin et al., 2012, 2015). The Reduced Caltech Isoprene Mechanism (RCIM), isoprene reduced plus v4.1, was downloaded from https://doi.org/10.22002/D1.247 (last access: 23 March 2018, Bates and Wennberg, 2017). The inorganic reactions from MCM v3.3.1 were used for all mechanisms in order to focus on differences caused by isoprene and terpene chemistry. To capture differences in $\mathrm{OH}, \mathrm{O}_{3}$, and $\mathrm{NO}_{3}$ oxidation, an ideal diurnal cycle was simulated in the box model with the planetary boundary layer (PBL) height; temperature; general photolysis rate constants; and emissions of $\mathrm{NO}, \mathrm{CO}$, isoprene, formaldehyde, formic acid, methanol, glycolaldehyde, sulfur dioxide, sesquiterpenes, and monoterpenes from the CESM/CAM-chem base TS1 simulation. Aerosol uptake of the inorganic compounds $\mathrm{HO}_{2}, \mathrm{~N}_{2} \mathrm{O}_{5}$, $\mathrm{NO}_{2}$, and $\mathrm{NO}_{3}$ were included based on the reaction rate constants output from the CESM/CAM-chem base simulation. Dry deposition of the inorganic compounds $\mathrm{O}_{3}, \mathrm{CO}, \mathrm{NO}$, $\mathrm{NO}_{2}, \mathrm{HNO}_{3}, \mathrm{~N}_{2} \mathrm{O}_{5}, \mathrm{HO}_{2} \mathrm{NO}_{2}, \mathrm{H}_{2} \mathrm{O}_{2}$, and $\mathrm{SO}_{2}$ were included using the dry deposition velocities from the CESM/CAMchem base simulation. The box is mixed based on the planetary boundary layer height with background air, which has fixed concentrations of isoprene, terpenes, $\mathrm{H}_{2} \mathrm{O}, \mathrm{CH}_{4}, \mathrm{H}_{2}$, $\mathrm{CO}, \mathrm{O}_{3}, \mathrm{NO}, \mathrm{NO}_{2}, \mathrm{SO}_{2}$, and $\mathrm{N}_{2} \mathrm{O}$ from the CESM/CAMchem TS1 base simulation.

Each mechanism (Caltech, MCM, and TS1/TS2) calculates photolysis rates differently. In CESM/CAM-chem, general photolysis rates are calculated using a lookup table (Lamarque et al., 2012), and all other photolysis rates are mapped to these general photolysis rates with an optional scaling factor. In the box model setup, general photolysis rates from CESM/CAM-chem are used for all mechanisms, and the scaling factors are mechanism specific. This approach ensures consistency in the general photolysis reactions across mechanisms, but it still evaluates mechanismspecific scaling factors for photolysis of isoprene and terpene oxidation products.

CESM/CAM-chem TS1 base case model output was used to initialize BOXMOX. In order to pick a location with high biogenic emissions, the grid box containing the Coffeeville US EPA CASTNET (Clean Air Status and Trends Network) monitoring site located in Mississippi $\left(34.002747^{\circ} \mathrm{N}\right.$, $89.799183^{\circ} \mathrm{W}$ ) was selected because it has a forest land use type as classified by the US EPA. 3 August 2013 was selected to represent this ideal day due to high biogenic emissions (i.e., highest noon isoprene and monoterpene emissions in August) and minimal cloud cover (i.e., within the 
top five highest noon $j_{\mathrm{NO}_{2}}-$ simulated $\mathrm{NO}_{2}$ photolysis values in August). To reduce complexity and increase traceability, each box model simulation was initialized with only one non-oxygenated VOC at a time (e.g., only isoprene or $\alpha$-pinene). To ensure reasonable oxidant concentrations, isoprene, monoterpene, and sesquiterpene emissions were scaled by $1.6,13$, and 88 , respectively, such that their molar total was equal to the molar total emissions of the major non-oxygenated VOCs (alkanes, alkenes, aromatics, isoprene, and terpenes). This method was selected instead of holding the oxidants (i.e., $\mathrm{OH}, \mathrm{O}_{3}$, and $\mathrm{NO}_{3}$ ) constant in order to evaluate differences in $\mathrm{O}_{3}, \mathrm{HO}_{x}$, and $\mathrm{NO}_{x}$ between the mechanisms. These idealized scenarios are designed to examine and clearly present the impact variations in the chemistry of a single VOC have on oxidants and oxidation products and not to accurately represent the chemistry of a specific location.

\subsection{Global modeling}

The Community Earth System Model/Community Atmosphere Model with chemistry v2.1.0 was used with a horizontal resolution of $0.9^{\circ} \times 1.25^{\circ}$ (Emmons et al., 2020; Tilmes et al., 2019). The meteorology (air and surface temperature, horizontal winds, surface pressure, sensible and latent heat flux, and wind stress) was nudged with a $50 \mathrm{~h}$ relaxation time as described in Lamarque et al. (2012) to the ModernEra Retrospective analysis for Research and Applications v2 (MERRA2) (Gelaro et al., 2017) meteorological fields interpolated to the native CAM model resolution of 32 levels. In Figs. S6 and S7, the impact of using different vertical resolutions and nudging relaxation times are shown for ozone, ozone precursors, and isoprene oxidation products. Using a stronger nudging relaxation time (i.e., $5 \mathrm{~h}$ rather than the $50 \mathrm{~h}$ used in this study) increases model bias in the vertical profile shape of ozone (Fig. S6). Using 32 vertical levels, the vertical resolution to which CAM physics, dynamics, and cloud parameterizations are tuned, slightly improves the model bias for ozone near the surface compared to using 56 vertical levels, the native resolution of the MERRA2 meteorological files (Fig. S6). This study uses 32 vertical levels and a weak relaxation time $(50 \mathrm{~h})$ for nudging in order to reduce variability while also limiting the impact of nudging on model parameterizations.

Biogenic emissions were calculated online in the Community Land Model (CLM) based on the Model of Emissions of Gases and Aerosols from Nature v2.1 (Guenther et al., 2012). Satellite-derived plant functional type (PFT) and leaf area index (LAI) from AVHRR (Advanced VeryHigh-Resolution Radiometer) and MODIS (Moderate Resolution Imaging Spectroradiometer) data are used in the CLM model (Lawrence and Chase, 2007). The default biogenic emissions used in CESM/CAM-chem v2.1.0 were expanded to include more volatile organic compounds as listed in Table S3 for all simulations. Global anthropogenic emissions are from the Community Emissions Data System (CEDS) (Hoesly et al., 2018), and global biomass burning emissions are from van Marle et al. (2017).

Four main model simulations were conducted. First, the TS1 case uses the default CESM2.1.0/CAM-chem code and the default TS1 chemical mechanism with the two changes described above: 32 vertical levels and an expansion of the biogenic volatile organic compounds emitted from the land model (Table S3). Second, the Henry's law case uses the Henry's law constant updates as described in Sect. 2.1 in the wet and dry deposition schemes. Third, the isoprene case uses the Henry's law updates and the isoprene oxidation chemistry described in Sect. 2.2. Fourth, the TS2 case includes all of the TS2 chemistry updates: Henry's law, isoprene, and terpene updates (described in Sect. 2.3). Each case is progressively more complicated. Because new surrogates incorporated into the chemical mechanism of CESM are initialized to 0 , these four cases were separately spun up for 2.5 years (i.e., 1 January 2011 to 31 July 2013) to ensure that all new species were equilibrated and all simulations were performed consistently. Sensitivity tests were also conducted to evaluate the impact of uncertainties remaining in the chemical mechanism on simulated surface ozone. All sensitivity tests were identical to the TS2 case with small variations in the chemistry as described in Sect. 5.2. These sensitivity tests were spun up from exact restarts from the TS2 case for 3 months, which is sufficient because no new species were added.

\section{Results}

Evaluation against more explicit schemes like the Caltech mechanism and MCM verifies that TS2 more accurately simulates isoprene (Sect. 4.1) and terpene (Sect. 4.2) chemistry compared to TS1. These comparisons verify that the current number of tracers and reactions in TS2 are sufficient to reasonably capture the isoprene and terpene chemistry represented by more explicit schemes. Comparisons with CASTNET monitoring observations (Sect. 4.3) and SEAC ${ }^{4} \mathrm{RS}$ field campaign data (Sect. 4.4) suggest that ozone, ozone precursors, and $\mathrm{NO}_{x}$ reservoir species are generally better represented in TS2 than TS1.

\subsection{Isoprene evaluation against explicit schemes}

As described in detail in Sect. 3.1, CESM/CAM-chem TS1 base case model output from the grid box containing the Coffeeville US EPA CASTNET monitoring site was used to initialize BOXMOX so that TS2 can be compared to explicit chemical mechanisms like RCIM (Reduced Caltech Isoprene Mechanism) and MCM in an idealized diurnal cycle. As shown in Fig. 3, in general TS1, TS2, MCM, and RCIM agree fairly well for major oxidants and isoprene oxidation products. TS1 already included a good general structure for 
isoprene oxidation (Sect. 2.2), which is likely why ozone changes from TS1 to TS2 are moderate (Fig. 3), at least under the single NO regime tested by the box model. There are large differences in some of the low- $\mathrm{NO}_{x}$ oxidation products (ISOPOOH and IEPOX) and the isomer distribution of the first-generation hydroxy nitrates (ISOPN). TS1 produces a fixed yield of $\delta$ - and $\beta$-hydroxy nitrates, while TS2 similar to MCM and RCIM allows for the $\delta$ - and $\beta$-hydroxy nitrate distribution to vary based on the isoprene $\mathrm{RO}_{2}$ lifetime (Sect. 2.2.1).

The overall isoprene $\mathrm{RO}_{2}$ distribution impacts the distribution of first- (ISOPN) and later-generation organic nitrates (e.g., NOA, $\mathrm{NO}_{3} \mathrm{CH}_{2} \mathrm{CHO}$, MACRN, and MVKN). As shown in Fig. 3, these organic nitrates are more similar to the explicit schemes in TS2 than TS1. Simulated organic nitrates from $\mathrm{NO}_{3}$-initiated oxidation are also improved. For example, in TS2 isoprene nitrooxy hydroperoxide (ISOP$\mathrm{NOOH}$ ), which forms from isoprene $+\mathrm{NO}_{3}$ oxidation, is consistent with the recently updated RCIM and not MCM or TS1 (Fig. 3) because ISOPNOOH is no longer formed in unity yield in TS2 and RCIM (Sect. 2.2.3). In general, MCM overestimates hydroperoxides because it consistently assumes unity yields when multi-functional peroxy radicals react with $\mathrm{HO}_{2}$ contrary to the most recent experimental evidence (Orlando and Tyndall, 2012; Wennberg et al., 2018).

As shown in Fig. 3, RCIM simulates less ozone than TS2. Several sensitivity tests were performed in order to understand this difference. The revised reactions for each of these sensitivity tests are listed explicitly in Table S7. In Test 1, TS2 was altered to use RCIM assumptions for PAN (peroxy acetyl nitrate) formation and loss and for photolysis of $\mathrm{C}_{4}$ dihydroperoxy carbonyls (DHPMPAL; Fig. 1). Unlike TS2, RCIM does not include PAN photolysis or the $\mathrm{CH}_{3} \mathrm{CO}_{3}+\mathrm{CH}_{3} \mathrm{CO}_{3}$ reaction, and RCIM uses different reaction rate constants than TS2 for PAN formation, thermal decomposition, and reaction with $\mathrm{OH}$ (Table S7). In TS2, DHPMPAL is added as a surrogate compound with fast, but not instantaneous, photolysis rates. In RCIM, DHPMPAL is assumed to photolyze so fast that only its photolysis products are included in the mechanism. The PAN assumptions from RCIM decrease $\mathrm{O}_{3}$, and the DHPMPAL assumptions from RCIM increase OH. TS2 was not updated based on Test 1 results. In TS2, reliable rate recommendations from JPL for PAN formation/thermal decomposition and $\mathrm{OH}$ oxidation are used (Burkholder et al., 2015). The photolysis of the $\mathrm{C}_{4}$ dihydroperoxy carbonyls is unknown and expected to be fast but possibly not instantaneous. Future studies measuring the photolysis rate of $\mathrm{C}_{4}$ dihydroperoxy carbonyls are warranted given the impact on $\mathrm{OH}$ using different assumptions.

Then for Test 2, TS2 was adjusted to include the assumptions in Test 1 and the photolysis rates for carbonyl nitrates used in RCIM. This further reduces $\mathrm{O}_{3}$ nearly to the level produced by RCIM itself (Fig. 3). TS2 was also not adjusted based on Test 2 results because the photolysis rates for the carbonyl nitrates in RCIM are lower than that sug- gested by recent experimental studies (Müller et al., 2014) and were recently updated to values similar to those used in TS2 when RCIM was incorporated into the GEOS-Chem chemical transport model (Bates and Jacob, 2019).

In general, the box-modeling results (Fig. 3) demonstrate that TS2 simulates first- and later-generation isoprene oxidation products better than TS1 compared to explicit schemes. Confidence that simulated ozone is right for the right reasons is enhanced in TS2 because the chemistry is more accurately represented. These results confirm that although TS1 may have too few tracers to fully capture isoprene chemistry, adding only 39 more species significantly increases the chemical accuracy without needing the immense cost that a nearly fully explicit chemical mechanism like MCM would require.

\subsection{Terpene evaluation against explicit schemes}

More significant changes were made to the terpene chemistry than the isoprene chemistry when developing TS2 (Sect. 2.3). TS2 is compared to TS1 and the more explicit MCM mechanism in Figs. 4-6 and S4-S5 for all five surrogate compounds: APIN, BPIN, LIMON, MYRC, and BCARY. TS2 separates hydroxy nitrates and hydroxy hydroperoxides based on their chemical structure (i.e., primary/secondary versus tertiary, saturated or unsaturated, and presence of multi-functional groups) instead of their generation. Thus, $\mathrm{MCM} \mathrm{C}_{4}$ and greater organic hydroperoxides, nitrates, and peroxy acyl nitrates are summed in Fig. 4 as a fairer comparison with the surrogate compounds in TS2. Nitrooxy hydroperoxides (NTERPOOH) are not included as total nitrates or total hydroperoxides because TS2 considers these separately.

TERPROD1 and TERPROD2 are terpene oxidation products from first- and second-generation chemistry, respectively, in TS1. In TS2, these have been separated based not on their generation but on their chemical structure: terpene aldehydes (TERPA, TERPA2, TERPA3), terpene ketones (TERPK), terpene unsaturated products (TERPF1, TERPF2), and terpene acids (TERPACID, TERPACID2, TERPACID3) (Sect. 2.3.1). MCM first- and secondgeneration species are combined into the same categories for comparison with the TS2 mechanism. In general, the types of compounds formed and their concentrations are reasonably consistent between MCM and TS2.

Although MCM is one of the most explicit chemical mechanisms available, after careful examination of the chemistry, there are a number of general assumptions in MCM that are outdated or overly simplified for terpene oxidation. Even though TS2 is more condensed compared to MCM, TS2 may be more accurate because it has been updated more recently, and simplifications used in TS2 were carefully selected to limit their impact on $\mathrm{NO}_{x}$ and $\mathrm{HO}_{x}$ recycling.

To justify this, several sensitivity tests were performed as summarized in Table S7. These sensitivity tests confirm that 

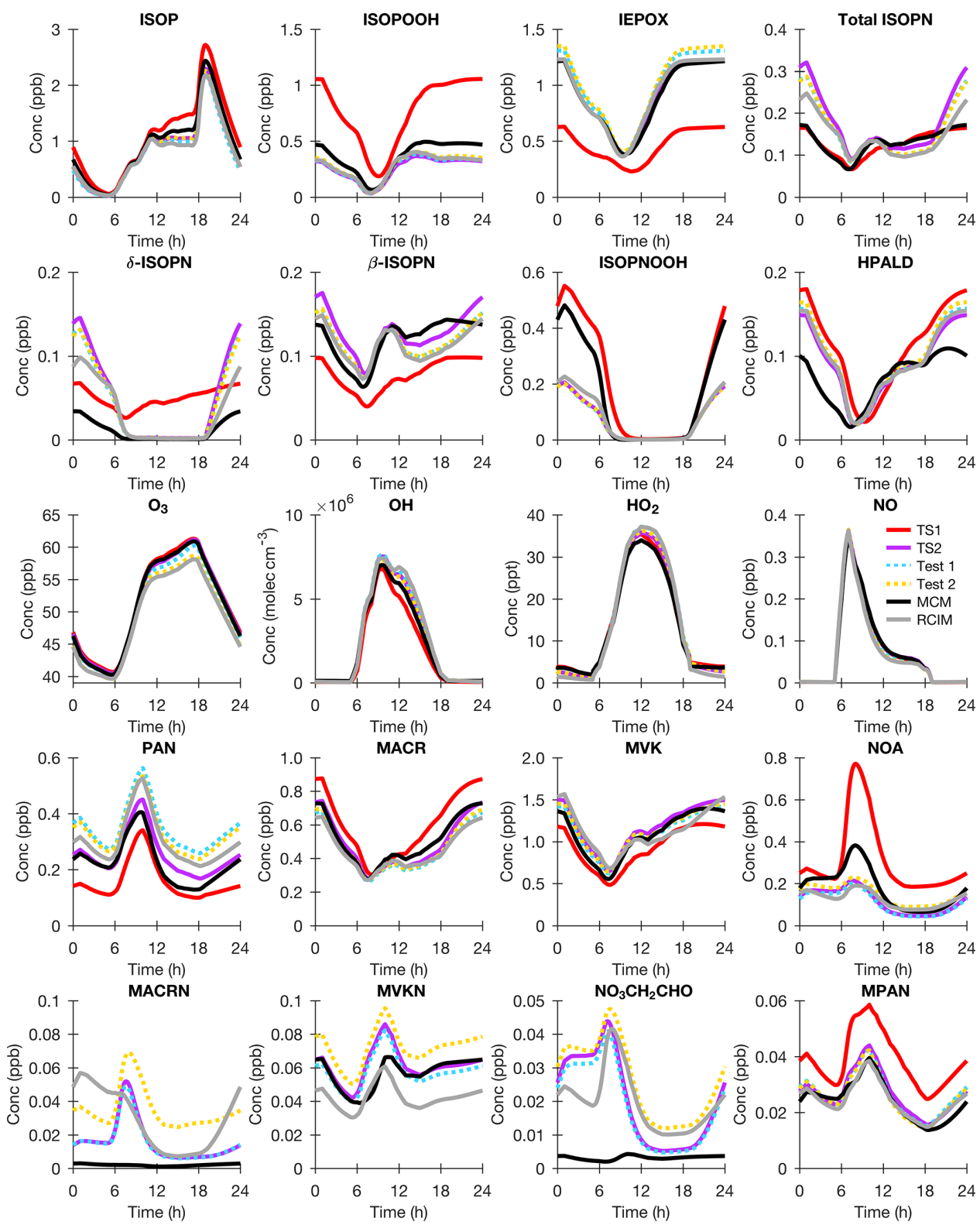

Figure 3. BOXMOX results for isoprene oxidation using TS1 (red), MCM (black), RCIM (gray), TS2 (purple), TS2 with RCIM assumptions for peroxy acetyl nitrate (PAN) and $\mathrm{C}_{4}$ dihydroperoxy carbonyls (blue; Test 1), and TS2 with RCIM assumptions for PAN, $\mathrm{C}_{4}$ dihydroperoxy carbonyls, and carbonyl nitrates (gold; Test 2). The model configuration is explained in Sect. 3.1. The following acronyms are used: ISOP (isoprene), ISOPOOH (isoprene hydroxy hydroperoxide), IEPOX (isoprene dihydroxy epoxide), ISOPN (isoprene hydroxy nitrate), ISOP$\mathrm{NOOH}$ (isoprene nitrooxy hydroperoxide), HPALD (isoprene hydroperoxy aldehyde), $\mathrm{O}_{3}$ (ozone), $\mathrm{OH}$ (hydroxyl radical), $\mathrm{HO}_{2}$ (hydroperoxy radical), NO (nitrogen monoxide), PAN (peroxy acetyl nitrate), MACR (methacrolein), MVK (methyl vinyl ketone), NOA (propanone nitrate), MACRN (methacrolein hydroxy nitrate), MVKN (methyl vinyl ketone hydroxy nitrate), $\mathrm{NO}_{3} \mathrm{CH}_{2} \mathrm{CHO}$ (ethanal nitrate), and MPAN (methacryloyl peroxynitrate).

much of the disagreement between MCM and TS2 is due to several differences in assumptions and not due to the simplification process. In Test 1 , the nitrate yields from pinonaldehyde oxidation were reduced to those recommended by MCM. TS2 uses the nitrate yield estimation procedure in Wennberg et al. (2018) with an upper limit of 0.3 , as more explicitly described in Sect. 2.3.1. Test 2 included adjustments from Test 1 and reduced the nitrate yields from limonaldehyde oxidation to those recommended by MCM. Test 3 included all the adjustments in Test 2 as well as adjustments in the MCM assumptions for the oxidation of unsaturated hydroxy nitrates. In MCM, unsaturated hydroxy nitrates derived from terpenes often will react with $\mathrm{OH}$ via $\mathrm{H}$ abstraction to produce only $\mathrm{NO}_{2}$ and an unsaturated aldehyde or 

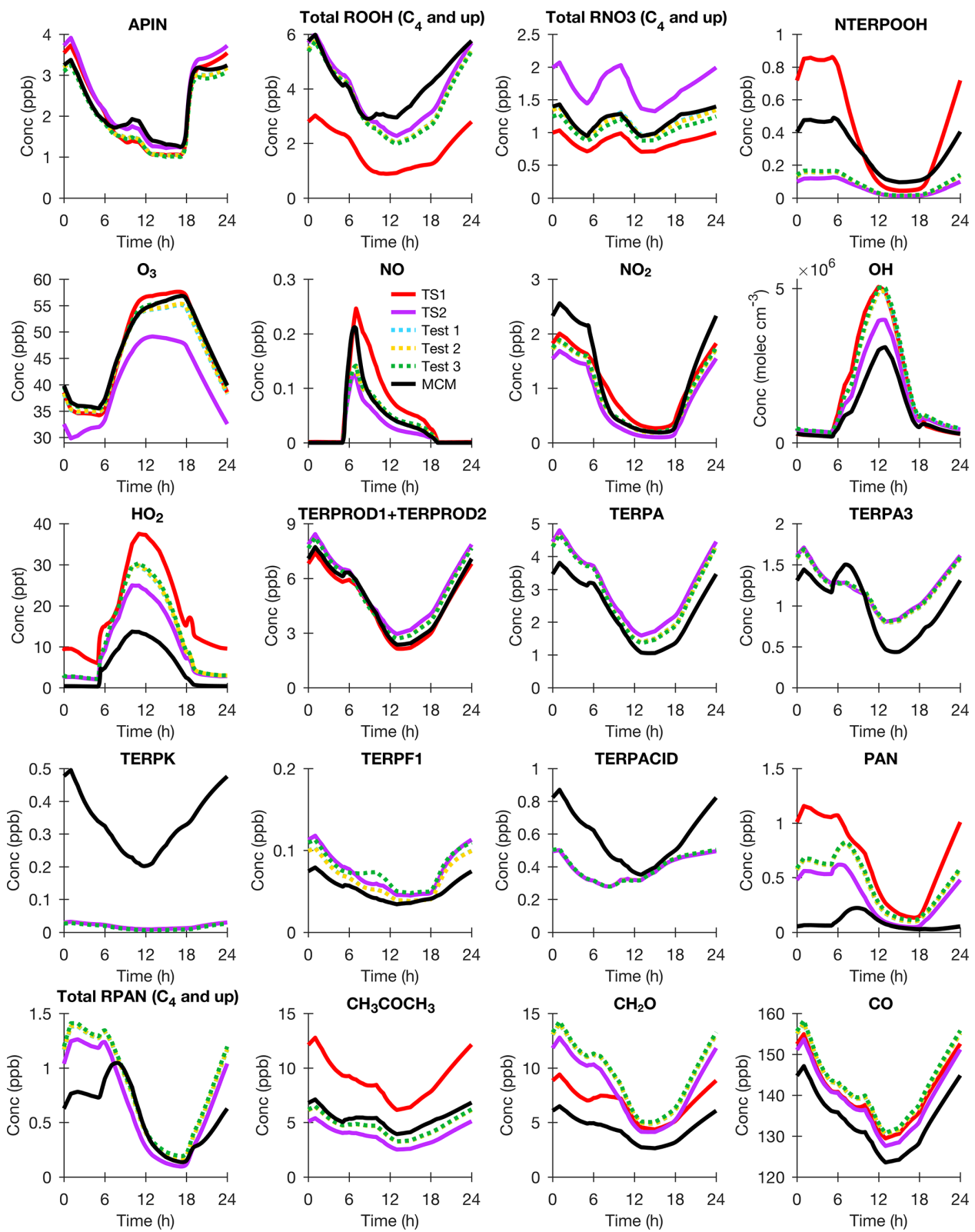

Figure 4. BOXMOX results for $\alpha$-pinene (APIN) oxidation using TS1 (red), MCM (black), TS2 (purple), TS2 with MCM pinonaldehyde nitrate yield (blue; Test 1), TS2 with MCM pinonaldehyde and limonaldehyde nitrate yield (gold; Test 2), and TS2 with MCM pinonaldehyde and limonaldehyde nitrate yield and assumptions for oxidation of unsaturated hydroxy nitrates (green; Test 3). The model configuration is explained in Sect. 3.1. APIN ( $\alpha$-pinene surrogate), TERPOOH (terpene hydroxy hydroperoxide), total $\mathrm{ROOH}$ (all terpene hydroperoxides $\mathrm{C}_{4}$ and up), TERPNIT (terpene hydroxy nitrate), total $\mathrm{RNO}_{3}$ (all terpene nitrates $\mathrm{C}_{4}$ and up), NTERPOOH (terpene nitrooxy hydroperoxide), $\mathrm{CH}_{3} \mathrm{COCH}_{3}$ (acetone), TERPROD1 + TERPROD2 (all terpene first- and second-generation products except hydroperoxides, nitrates, and PANs), TERPA (terpene aldehyde like pinonaldehyde), TERPA3 (terpene aldehyde like limonaldehyde), TERPK (terpene ketone), TERPF1 (terpene product - one double bond), TERPACID (terpene acid), PAN (peroxy acetyl nitrate), and total RPAN (all terpene PANs $\mathrm{C}_{4}$ and up).

ketone rather than via addition to the double bond to produce a multi-functional organic nitrate. Because $\mathrm{OH}$ addition to a double bond consistently occurs at a faster rate than $\mathrm{H}$ abstraction, this simplification inaccurately increases $\mathrm{NO}_{2}$ recycling and ozone formation.
Similarly, in MCM unsaturated hydroxy hydroperoxides will react with $\mathrm{OH}$ via $\mathrm{H}$ abstraction to produce $\mathrm{OH}$ and an unsaturated aldehyde or ketone or via $\mathrm{H}$ abstraction of the hydrogen on the hydroperoxide group to form a hydroxy peroxy radical. In particular, when $\mathrm{OH}$ reacts with an unsaturated hydroperoxide with a fast rate, given the presence 
of a double bond, to $\mathrm{H}$-abstract the hydrogen on the hydroperoxide moiety, an unrealistically fast cycle is created (i.e., $\mathrm{RO}_{2} \underset{\mathrm{OH}}{\stackrel{\mathrm{HO}_{2}}{\rightleftharpoons}} \mathrm{ROOH}$; each cycle removes two $\mathrm{HO}_{x}$ radicals). These unrealistically fast cycles lead to an overestimation of the removal of $\mathrm{HO}_{x}$ depending on the number of cycles that occur, an overestimation of the first-generation hydroperoxides, and an underestimation of later-generation low-volatility hydroperoxides, which will impact predicted SOA if SOA formation is coupled directly to the gas-phase chemistry.

Unlike MCM, TS2 does not contain these unrealistically fast cycles and is designed to accurately account for lowvolatility compounds so that in the future terpene SOA formation can be accurately coupled directly to gas-phase chemistry like recent studies have done for isoprene (Marais et al., 2016; Bates and Jacob, 2019; Stadtler et al., 2018) and monoterpenes (Zare et al., 2019). In MCM, unsaturated aldehydes and ketones typically react with $\mathrm{OH}$ via addition to the double bond as well as $\mathrm{H}$ abstraction, so this simplification only impacts unsaturated hydroxy nitrate and hydroxy hydroperoxide oxidation. Future studies that use MCM for prediction of ozone or SOA in terpene-rich regimes should update these simplifications so that ozone, SOA, and the $\mathrm{HO}_{x}$ and $\mathrm{NO}_{x}$ budgets are accurately simulated.

In Fig. 4 , oxidation of the $\alpha$-pinene (APIN) surrogate compound is compared with TS1 and MCM. Terpene oxidation is largely based on $\alpha$-pinene in TS1, so as expected APIN in TS2 compares reasonably well with MTERP in TS1 (Fig. 4). When accounting for total hydroperoxides, MCM and TS2 agree well. Total organic nitrates are higher and ozone is lower in TS2 than MCM mostly due to the use of different nitrate yields from pinonaldehyde oxidation (Test 1). Unfortunately, there are few studies measuring the organic-nitrate yields from later-generation products, making it difficult to determine whether the organic-nitrate yield parameterizations from MCM are better than those from Wennberg et al. (2018) used in TS2. These sensitivity tests demonstrate that more measurements of organicnitrate yields from multi-functional later-generation products are needed. NTERPOOH is larger in MCM than TS1 because MCM in general assumes a unity yield of hydroperoxides from all multi-functional peroxy radicals reaction with $\mathrm{HO}_{2}$ contrary to recent studies (e.g., Kurten et al., 2017).

Because the $\beta$-pinene (BPIN) surrogate compound is less reactive with $\mathrm{O}_{3}$ and $\mathrm{NO}_{3}$ than $\alpha$-pinene, TS1 greatly underestimates the $\beta$-pinene concentration at night and does not simulate $\beta$-pinene oxidation products well either (Fig. 5). In TS1, organic nitrates are underpredicted, and ozone is overpredicted compared to MCM. There are some differences in MCM compared to TS2. The organic nitrates are larger in TS2, but most of this bias is caused by inaccurate oxidation of the unsaturated hydroxy nitrates derived from terpenes in MCM (Test 3). The nopinone (TERPK) yield for $\mathrm{OH}-$ and $\mathrm{NO}_{3}$-initiated oxidation of $\beta$-pinene in TS2, which is based on recent experimental and theoretical studies (Sect. 2.3.1 and 2.3.3), is much lower than the yield assumed by MCM. The TS2 mechanism assumes the formation of aldehyde-type products based largely on theoretical studies (Vereecken and Peeters, 2012; Kurten et al., 2017) and consistent with a recent experimental study as well (Xu et al., 2019). Most reduced chemical schemes do not separate $\alpha$-pinene and $\beta$ pinene, but the results from these box model comparisons demonstrate the need for such separation (Figs. 4 and 5). TS1, which largely assumes all monoterpenes react like $\alpha$ pinene, simulates very different oxidant and terpene oxidation product concentrations than TS2.

All limonene (LIMON) surrogate compounds contain two double bonds and so are more reactive than $\alpha$-pinene. Because TS1 does not account for this extra double bond, limonene oxidation is not well represented compared to MCM (Fig. 6). As explained above, contrary to experimental knowledge, MCM assumes that $\mathrm{OH}$ reacts with an unsaturated hydroxy nitrate to hydrogen abstract rather than react with a double bond (Test 3), which causes a large underprediction of organic nitrates and an overprediction of ozone. This especially impacts limonene oxidation, which due to the presence of two double bonds, produces unsaturated firstgeneration products. Consistent with MCM, limonene oxidation in TS2 produces mostly terpene unsaturated products like limonaldehyde and limaketone (TERPF1). In MCM, the nitrate yields from these terpene unsaturated products are lower than that assumed in TS2, which has a moderate impact on the total organic nitrates and ozone (Test 2). TS2 simplifies limonene chemistry by not explicitly tracking aldehydes on hydroperoxides, nitrates, or unsaturated terpene products and by not adding separate tracers for unsaturated and saturated terpene acids and terpene PANs. These simplifications cause some disagreement between TS2 TERPF1, TERPA3, TERPACID, and total terpene PANs compared to MCM. Even with these simplifications, TS2 terpene PANs, which will impact the $\mathrm{NO}_{x}$ budget, are consistent with MCM. At this time, later-generation chemistry from limonene oxidation is not understood well enough to motivate increasing the computational cost by adding in many additional tracers to directly track the presence of aldehydes along with the other functional groups (e.g., nitrates, hydroperoxides, and unsaturated products).

The box model comparisons for myrcene (MYRC) and $\beta$ caryophyllene (BCARY) surrogate compounds are shown in Figs. S4 and S5. Because these surrogate compounds contain more than one double bond, the differences between TS2, TS1, and MCM are similar to those shown for limonene in Fig. 6. Comparisons against MCM for myrcene are not available because no equivalent tracer exists in MCM. The TS2 surrogate compound for $\beta$-caryophyllene is assumed to have three double bonds since sesquiterpenes have between two and four double bonds (Guenther et al., 2012), so differences are expected when comparing directly with MCM's $\beta$-caryophyllene, which only has two double bonds. 

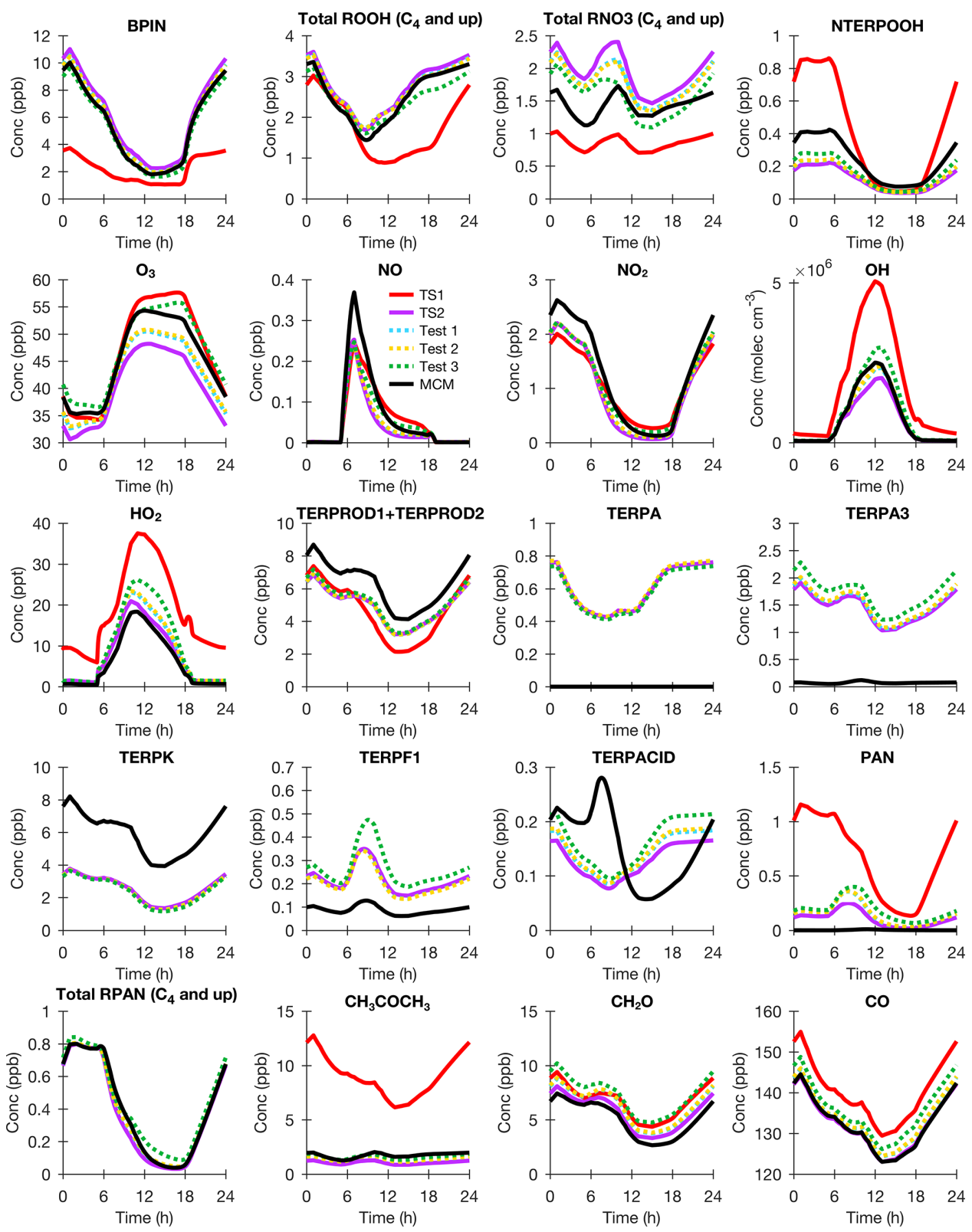

Figure 5. BOXMOX results for $\beta$-pinene (BPIN) oxidation using TS1 (red), MCM (black), TS2 (purple), TS2 with MCM pinonaldehyde nitrate yield (blue; Test 1), TS2 with MCM pinonaldehyde and limonaldehyde nitrate yield (gold; Test 2), and TS2 with MCM pinonaldehyde and limonaldehyde nitrate yield and assumptions for oxidation of unsaturated hydroxy nitrates (green; Test 3). The model configuration is explained in Sect. 3.1. All species names are identical to Fig. 4.

From all of the box model comparisons (Figs. 4-6 and S4-S5), some general trends for terpene oxidation can be deduced. As explained above, MCM v3.3.1 has some limitations that influence $\mathrm{O}_{3}$ formation. Especially for reactive terpenes with more than one double bond, MCM does not accurately represent $\mathrm{NO}_{x}$ recycling because of inaccurate simplifications for unsaturated hydroxy nitrate oxidation. Because this is an erroneous representation of the chemistry, this sensitivity test is not evaluated in the global model in Sect. 5.2. The pinonaldehyde and limonaldehyde nitrate yields assumed in MCM are lower than those used in the TS2 mechanism (Test 1 and 2). The nitrate yields from these latergeneration products have not been experimentally measured and are highly uncertain. The impact of assuming lower nitrate yields from these first-generation terpene oxidation products are tested in the global model in Sect. 5.2. Using a more complex terpene oxidation scheme like TS2 seems to be important for accurately simulating later-generation products in addition to oxidants and first-generation products. For example, TS1 consistently overestimates the formation 
of acetone for all of the terpene surrogate compounds compared to MCM and TS2.

\subsection{Surface ozone impact in CESM/CAM-chem}

Comparing models with surface ozone measurements from the US EPA CASTNET monitoring network is particularly useful compared to air quality monitoring data because typically stations in the CASTNET network are in rural locations and carefully selected to be representative of a specific region (U.S. EPA, 2017). As discussed in the Introduction, CESM/CAM-chem using TS1 chemistry substantially overestimates surface ozone during the summer in the eastern US compared to data from the CASTNET monitoring network (Fig. 7a). Consistent with the box model results shown in Sect. 4.1 and 4.2, the ozone bias is greatly improved with the updated TS2 mechanism, but a large bias remains (Fig. 7b). In all cases, the surface ozone is the value in the lowest model layer with a midpoint of $\sim 66 \mathrm{~m}$ above the ground. Brown-Steiner et al. (2015) determined correcting CESM/CAM-chem data to $10 \mathrm{~m}$, where CASTNET data are measured, reduced MDA8 surface ozone values by $\sim 2 \%$. For now no correction was applied, but future work with more comprehensive comparisons to CASTNET monitoring data will evaluate this correction.

The chemistry updates were added in sequential order so that the effect of each update on ozone could be diagnosed. As shown in Fig. 8a, updates to the Henry's law constants had only moderate effects on MD8A surface ozone but in certain locations reduced MDA8 ozone by a couple parts per billion. Updates to Henry's law constants and isoprene reduced MDA 8 ozone more consistently throughout the US by a couple parts per billion and up to $6 \mathrm{ppb}$ (Fig. 8b). All TS2 updates (Henry's law, isoprene, and terpene updates) reduced MDA8 ozone generally in the eastern US by around 3-4 ppb and up to $7 \mathrm{ppb}$ (Fig. 8c). In particular, the terpene updates reduced the MDA8 ozone bias most substantially in the southeastern US where the model ozone bias is largest (Fig. 7). Terpene chemistry greatly impacts simulated surface ozone even though it has received much less attention in model and experimental studies in the past.

\subsection{Evaluation against field campaign data}

The CASTNET monitoring data are useful for evaluating surface ozone itself. However, to verify that the model is accurately simulating ozone for the right reasons, evaluation against ozone precursors (e.g., $\mathrm{NO}_{x}$ and VOCs) and $\mathrm{NO}_{x}$ reservoir species (e.g., PANs and organic nitrates) is necessary. Field campaigns like Studies of Emissions and Atmospheric Composition, Clouds and Climate Coupling by Regional Surveys (SEAC ${ }^{4} \mathrm{RS}$ ), whose goals included investigating oxidation chemistry of biogenic VOCs and measuring ozone, ozone precursors, and $\mathrm{NO}_{x}$ reservoir species, are critical for evaluating whether models are accurately repre- senting ozone. The SEAC ${ }^{4} \mathrm{RS}$ field campaign was conducted during August through September of 2013 (Toon et al., 2016) with many of the flights centered over the southeastern US. In SEAC ${ }^{4} \mathrm{RS}$ and in many other past field campaigns, terpene oxidation products were not quantitatively measured. More measurements in the future of terpene oxidation products will be beneficial for the further evaluation of TS2.

Median vertical profiles are displayed in Fig. 9 where data are grouped into $0.5 \mathrm{~km}$ bins, and urban plumes $\left(\mathrm{NO}_{2}>\right.$ $4 \mathrm{ppb}$ ), fire plumes (acetonitrile $>0.2 \mathrm{ppb}$ ), and stratospheric air $\left(\mathrm{O}_{3} / \mathrm{CO}>1.25\right)$ are excluded consistent with previous work (Travis et al., 2016). Only data collected in the southeastern US from 09:00 to 17:00 local sun time were selected. Version 7 of the SEAC ${ }^{4} \mathrm{RS} 60$ s merge was used. Data flagged as missing or as an upper limit of detection were not used, and data flagged as a lower limit of detection were set to 0 . For each compound, data unavailable in the observational dataset were also removed from the model dataset. This ensures that the observational and modeling data for each compound are directly comparable, but in some cases this also prohibits direct comparison between different species, since the sampling data may be different. For example, the model vertical profiles for $\mathrm{NO}_{2}$ are different for the chemilumenescence instrument from NOAA Earth System Research Laboratory (ESRL) and the thermal dissociation laser-induced fluorescence (TD-LIF) instrument because each instrument has different unavailable data (Fig. 9). As shown in Fig. 9, even though CESM/CAM-chem was only nudged to meteorological data with a $50 \mathrm{~h}$ relaxation time, temperature $(T)$, winds (zonal $-U$ and meridional $-V$ ), and clouds (as evaluated by $\mathrm{NO}_{2}$ photolysis) were all consistent between the simulations ensuring that this light nudging sufficiently reduced model variability.

Consistent with the surface ozone analysis in Sect. 4.3, CESM/CAM-chem overpredicts ozone throughout the planetary boundary layer. The Henry's law and isoprene updates do not change ozone much above the surface, while the terpene updates do reduce ozone in the PBL. The vertical profile shape for ozone is quite different between the model and observations. There are also clear differences between the model and observations for $\mathrm{NO}_{2}$ photolysis and ozone precursors like $\mathrm{NO}_{x}$ and VOCs. Possible explanations for the remaining biases are further described below and will be explored more completely in future work.

Although the simulated $\mathrm{NO}_{2}$ photolysis ( $\mathrm{N}_{\mathrm{NO}_{2}}$ in Fig. 9 ) is within the uncertainty of the observations, biases within the $\mathrm{NO}_{2}$ photolysis vertical profile shape suggest biases in simulated clouds. Sampling biases could also impact agreement between the model and observations for $\mathrm{NO}_{2}$ photolysis because field campaigns typically avoid sampling clouds on a scale not resolved by the model (Hall et al., 2018). In Ryu et al. (2018), WRF-Chem similar to CAM-chem underpredicts $\mathrm{NO}_{2}$ photolysis above $2 \mathrm{~km}$; when clouds derived from satellites are incorporated into WRF-Chem, the $\mathrm{NO}_{2}$ photolysis bias is removed and MDA8 surface ozone decreases by 

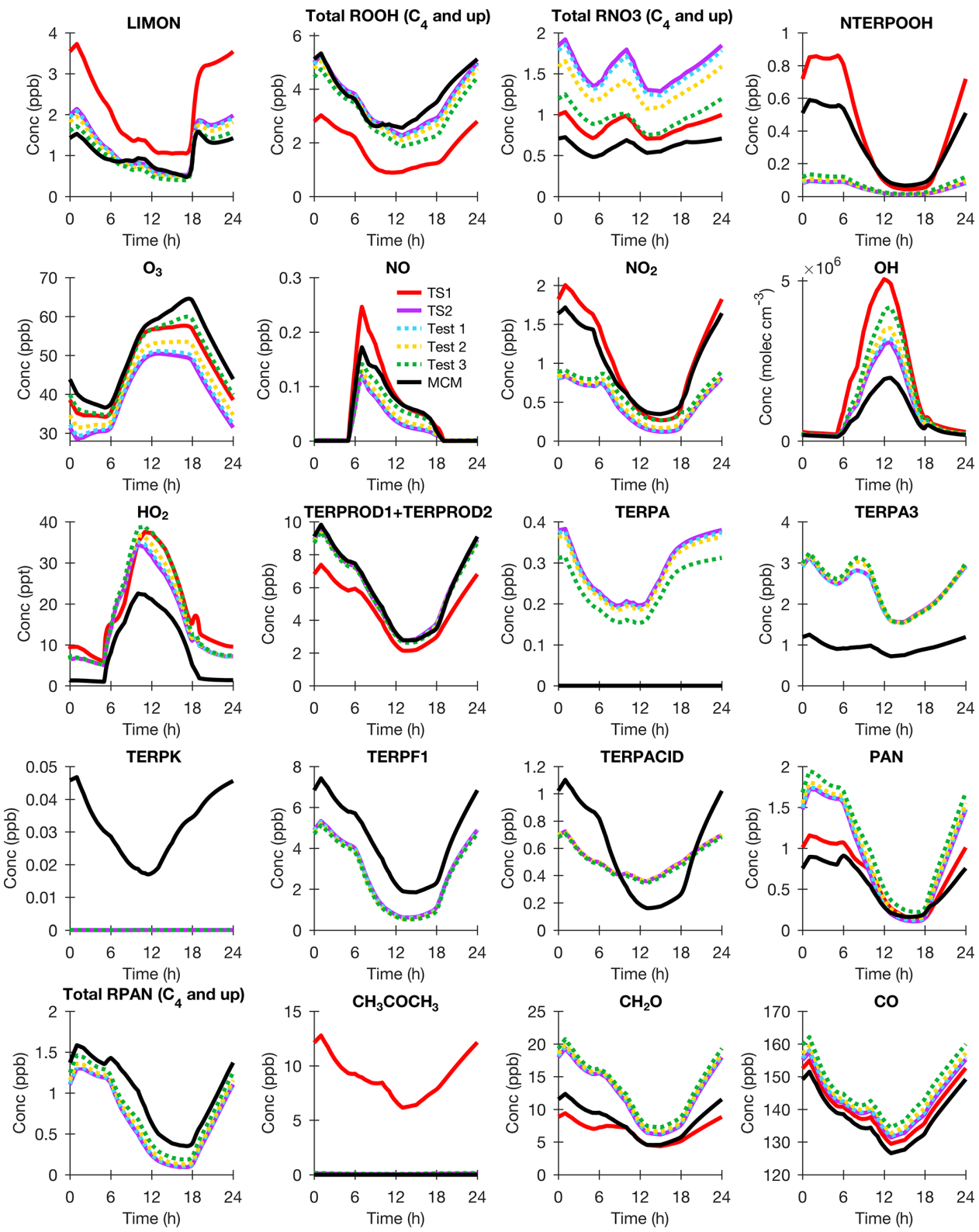

Figure 6. BOXMOX results for limonene (LIMON) oxidation using TS1 (red), MCM (black), TS2 (purple), TS2 with MCM pinonaldehyde nitrate yield (blue; Test 1), TS2 with MCM pinonaldehyde and limonaldehyde nitrate yield (gold; Test 2), and TS2 with MCM pinonaldehyde and limonaldehyde nitrate yield and assumptions for oxidation of unsaturated hydroxy nitrates (green; Test 3). The model configuration is explained in Sect. 3.1. All species names are identical to Fig. 4.

1 to $5 \mathrm{ppb}$. Additionally, studies using large-eddy simulations have determined that shallow cumulus clouds enhance vertical transport of passive (i.e., no aqueous-phase processing) chemical compounds as compared to clear-sky conditions (Vila-Guerau de Arellano et al., 2005; Li et al., 2017). The vertical biases in $\mathrm{NO}_{2}$ photolysis combined with the biogenic VOCs (isoprene and monoterpenes) not adequately lofting above the surface in the model compared to the observations (Fig. 9) possibly suggest that CAM-chem is not accurately simulating the dynamics and/or location of shallow cumulus clouds. A cloud-induced reduction in $j_{\mathrm{NO}_{2}}$ below $1 \mathrm{~km}$ and an increase between 2 and $4 \mathrm{~km}$ would improve the ozone and $j_{\mathrm{NO}_{2}}$ profile shapes. Cloud biases in CAM-chem will be further evaluated in future work due to their potential to improve simulated $\mathrm{NO}_{2}$ photolysis, biogenic VOCs, and ozone in and above the PBL.

$\mathrm{NO}$ and $\mathrm{NO}_{2}$, as measured by ESRL using chemilumenescence, are overpredicted near the surface in CESM/CAMchem for all model simulations. However, $\mathrm{NO}_{2}$ is reduced with the updates to the terpene chemistry. This demonstrates 
(a)

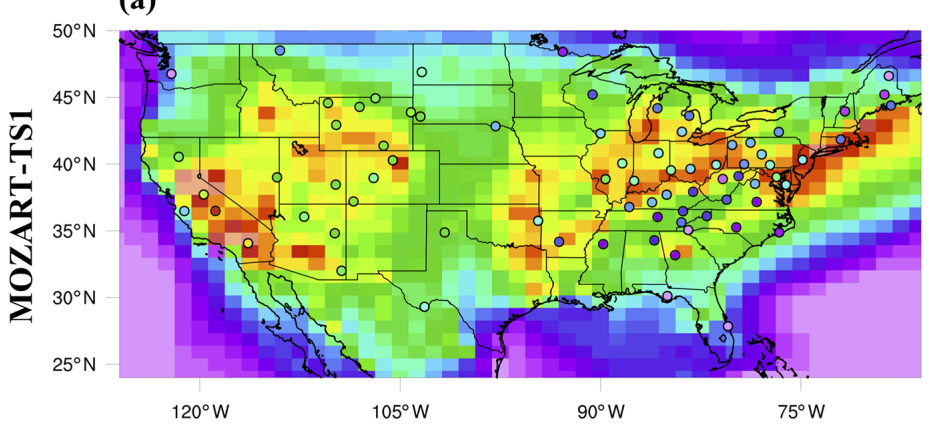

(b)

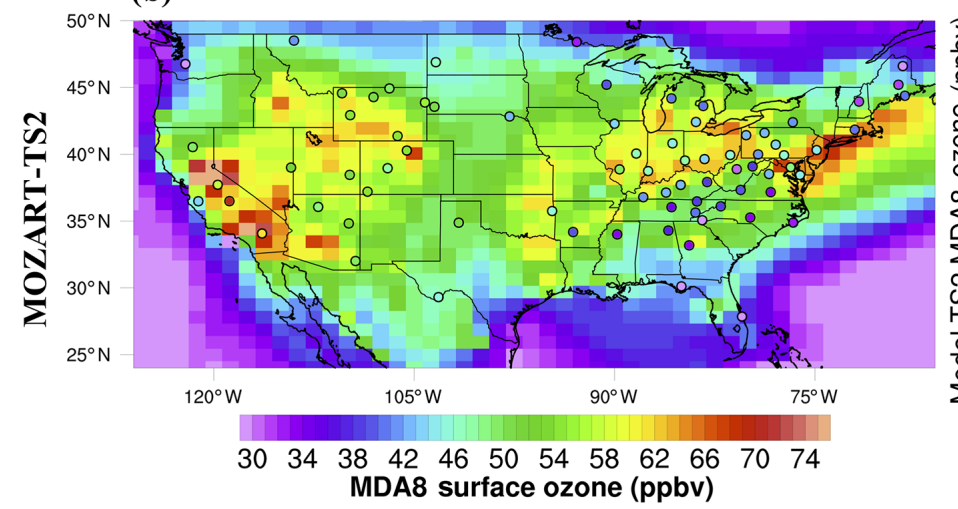

(c)

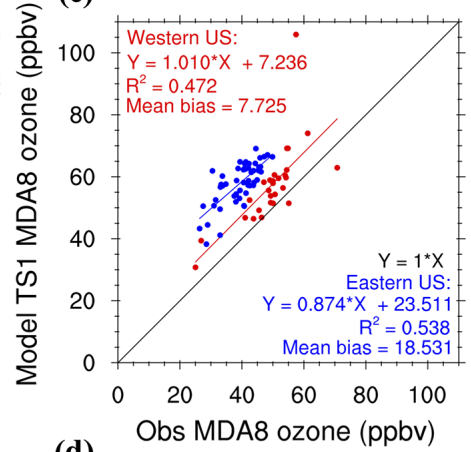

(d)

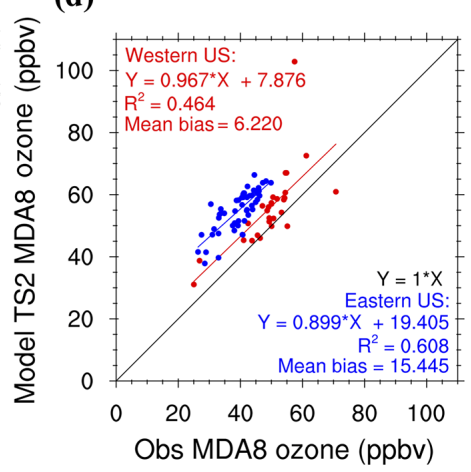

Figure 7. Surface ozone daily max $8 \mathrm{~h}$ average (MDA8) CESM/CAM-chem results over the contiguous US (CONUS) using the default TS1 mechanism (a) and the updated TS2 mechanism (b) compared to US EPA CASTNET data (filled circles) averaged over August 2013. The same data are presented in a scatter plot for TS1 (c) and TS2 (d) with the eastern US (longitude $>-96^{\circ}$ ) in blue and the western US (longitude $<-96^{\circ}$ ) in red.

that disagreement between simulated and observed $\mathrm{NO}_{2}$ is not necessarily due to emissions but can also be caused by an inaccurate representation of the losses of $\mathrm{NO}_{x}$ or $\mathrm{NO}_{x}$ reservoir compounds. Interestingly, the model bias compared to measurements for $\mathrm{NO}_{2}$ from the TD-LIF instrument is lower than that from ESRL, which will be explored more in future simulations at a finer horizontal resolution where $\mathrm{NO}_{x}$ emissions are better resolved.

In general, biogenic VOCs (isoprene and monoterpenes) are underpredicted by CESM/CAM-chem compared to the SEAC ${ }^{4}$ RS observations (Fig. 9). Even though the total monoterpenes measured using a proton transfer reaction mass spectrometer (PTR-MS) are underpredicted, interestingly $\alpha$-pinene and $\beta$-pinene measured by the whole-air sampler are overpredicted by CESM/CAM-chem near the surface when compared to the APIN and BPIN surrogate compounds, respectively. The APIN surrogate compound largely only includes $\alpha$-pinene, while the BPIN surrogate compound includes $\beta$-pinene and many other monoterpenes with a single double bond (Table S3). At least for $\beta$-pinene, possibly the unmeasured other monoterpenes included in the BPIN surrogate compound contribute to this bias. Further analysis at higher horizontal resolution where biogenic VOC emissions are better resolved will be done in the future to explore the differences between CESM/CAM-chem and the observations and also the differences between the two monoterpene measurement techniques.

The slight underprediction in the biogenic VOCs by CESM/CAM-chem could be caused by a number of possibilities. The $0.9^{\circ} \times 1.25^{\circ}$ resolution with a $30 \mathrm{~min}$ time step may not be sufficient to capture the varied landscape in the southeastern US, which has a number of large urban regions surrounded by forests. Additionally, Kim et al. (2016) used large-eddy simulations to demonstrate that isoprene chemical reactivity is impacted by turbulent mixing in the boundary layer because these two processes occur at similar rates. Considering the model bias in isoprene and monoterpenes is particularly high in the middle of the PBL, this effect may explain part of the low bias for isoprene and monoterpenes with similar reactivities to isoprene (e.g., limonene). However, the isoprene first-generation oxidation products, which are less reactive than isoprene and so less impacted by turbulent mixing, are also low compared to the SEAC ${ }^{4} \mathrm{RS}$ observations. This then suggests that emissions may be simply biased low for isoprene and monoterpenes. Interestingly, GEOSChem, using the same MEGAN v2.1 algorithm as used in CESM/CAM-chem, recently concluded that isoprene emissions are too high by $40 \%$ in the southeastern US (Kaiser 
(a) TS2 Henry's law updates - TS1

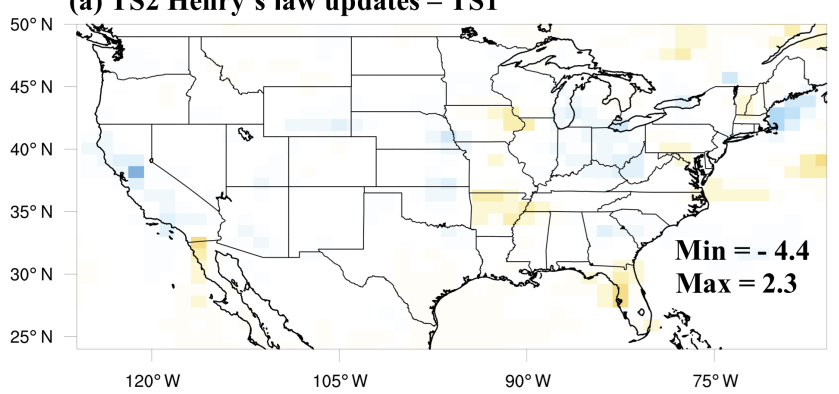

(b) TS2 Henry's law and isoprene updates - TS1

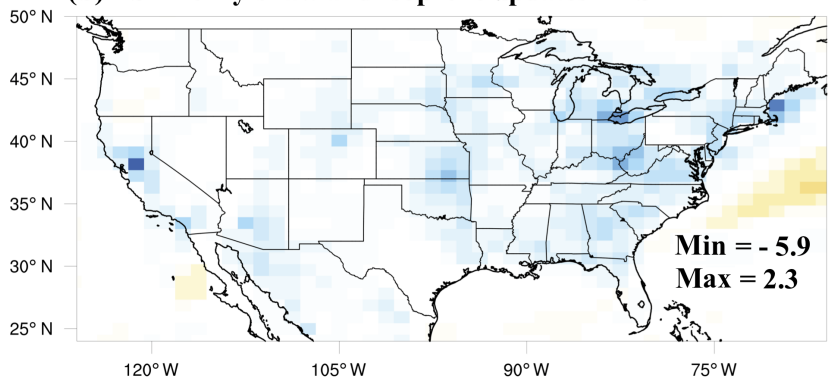

(c) TS2 Henry's law, isoprene, and terpene updates - TS1

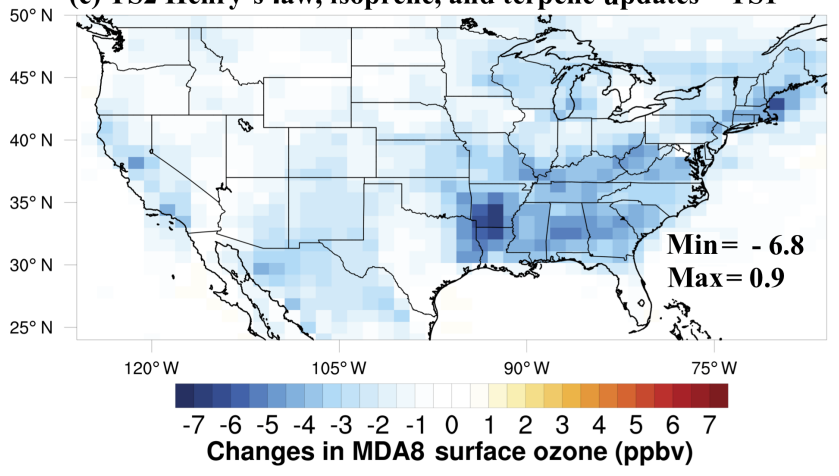

Figure 8. Changes in surface ozone daily max $8 \mathrm{~h}$ average (MDA8) between the TS2 updated case and the TS1 case averaged over August 2013. The minimum and maximum over the domain pictured is displayed on the bottom right for each case.

et al., 2018). Although the emissions factors are likely the same in the two models, the surface temperatures are different and CESM/CAM-chem uses LAI and plant functional types from the Community Land Model. Future work will evaluate whether using a finer horizontal resolution $(14 \mathrm{~km})$ removes these biases in biogenic VOCs in CAM-chem. If isoprene and monoterpenes are still underpredicted, increasing these biogenic emissions will enhance the overall bias in ozone.

TS2 updated with isoprene chemistry generally improves the description of isoprene first- and later-generation oxidation products (Fig. 9). Because isoprene is underpredicted in CESM/CAM-chem, as expected the isoprene firstgeneration products are also underpredicted. The high bias in isoprene hydroxy hydroperoxide (ISOPOOH), which forms under low-NO conditions, is corrected in TS2 relative to TS1. HPALD, which includes all four isomers of isoprene hydroperoxy aldehydes as well as the isoprene carbonyl hydroxy epoxide, is closer to the observations in TS2 than TS1 but still underpredicted. HPALD yields and photolysis/oxidation are rather uncertain. Additionally, HPALD formation, which occurs under very-low-NO levels from peroxy radical $\mathrm{H}$ shifts (Fig. 1), may be quite sensitive to horizontal resolution. For example, large grid boxes with averaged medium levels of $\mathrm{NO}_{x}$ will produce different HPALD production rates than smaller grid boxes with separated high and low levels of $\mathrm{NO}_{x}$. HPALD formation will be further evaluated in future work at a finer horizontal resolution. In TS2, the formation and loss processes of isoprene hydroxy nitrates (ISOPN) are both increased resulting in very little overall difference in ISOPN concentration even though there are clear differences in the chemistry. TS1 groups all later-generation organic nitrates as propanone nitrate (NOA). The addition of more tracers in TS2 improves the description of these latergeneration organic nitrates (NOA, MACRN + MVKN, and $\mathrm{NO}_{3} \mathrm{CH}_{2} \mathrm{CHO}$ ) when compared to observations. Grouping all later-generation isoprene organic nitrates as NOA produces too many later-generation organic nitrates, as the fate of NOA is different from the fate of the newly added tracers (MACRN + MVKN, and $\mathrm{NO}_{3} \mathrm{CH}_{2} \mathrm{CHO}$ ). More measurements of terpene oxidation products in future field campaigns would be useful for a similar evaluation of reduced terpene mechanisms.

Total organic nitrates are underpredicted in all simulations compared to observations, while total PANs are slightly overpredicted. If the ultimate fate of these missing organic nitrates is to remove $\mathrm{NO}_{x}$, this could explain part of the remaining ozone bias. The low model bias of total organic nitrates is concerning, as this implies that the $\mathrm{NO}_{x}$ budget is not completely understood. Part of this bias is caused by not including organic nitrates from small-chain $\left(\mathrm{C}_{3}\right.$ and under) alkanes and alkenes as demonstrated by Fisher et al. (2016). Although the organic-nitrate yields are lower for smallerchain alkanes and alkenes (Arey et al., 2001; Butkovskaya et al., 2010, 2012; Teng et al., 2015), these alkyl nitrates are still important in the atmosphere (Teng et al., 2015). Alkane and alkene nitrates and resulting chemistry will be added to the model in the future, but they will only explain a small part of this model bias (Fisher et al., 2016). The overall low model bias for total organic nitrates is consistent with past work using other models (Fisher et al., 2016; Li et al., 2018). CESM/CAM-chem with the TS2 scheme produces less of a bias for total organic nitrates than GEOS-Chem (Fisher et al., 2016) likely due to the improved terpene chemistry as further explained in Sect. 5.1.

\section{Discussion}

The differences in simulated ozone between TS1 and TS2 mechanisms are largely caused by differences in the formation and fate of organic nitrates, which is explained in 

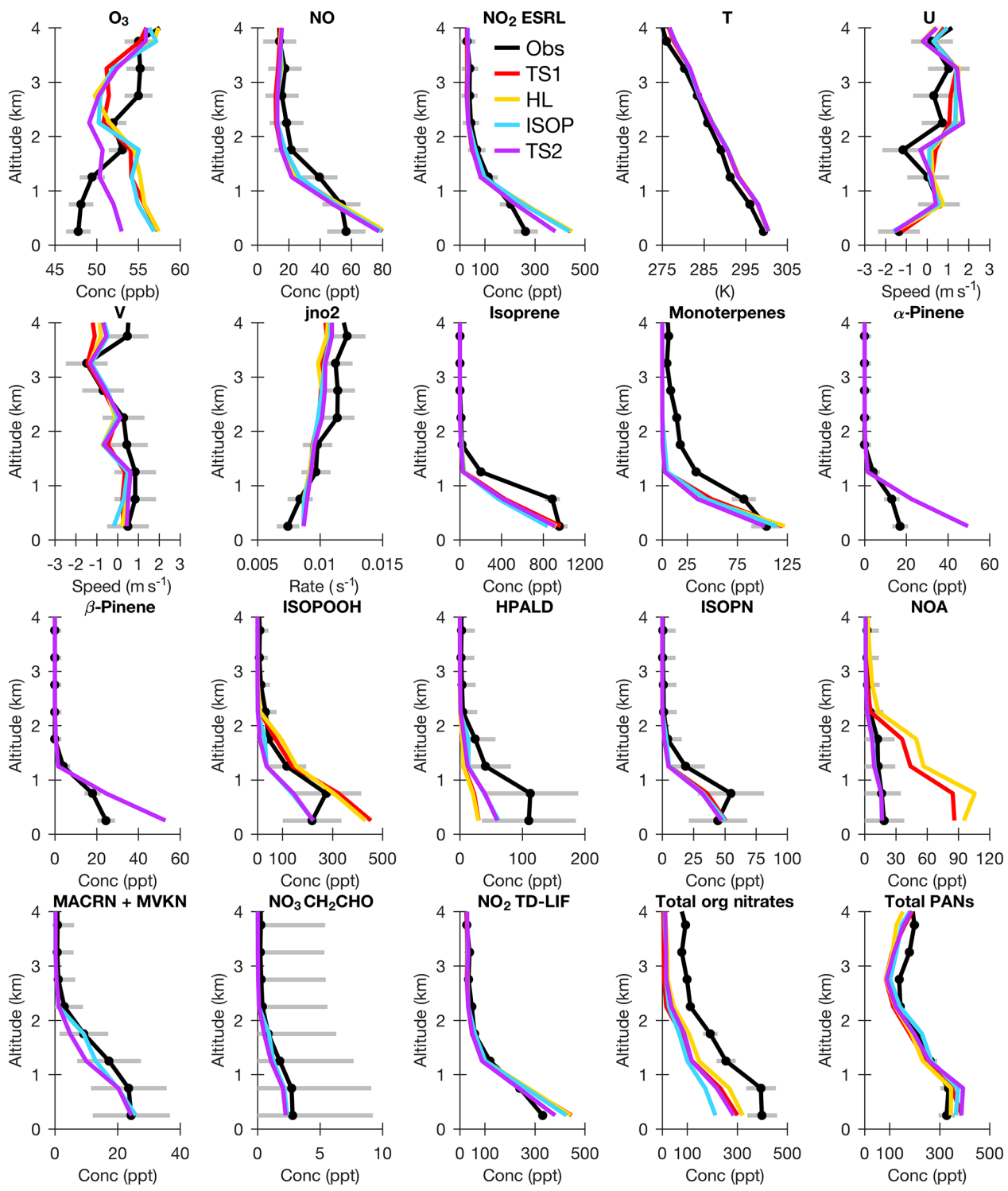

Figure 9. Median vertical profile plots over the SEAC ${ }^{4} \mathrm{RS}$ flight tracks for observations (Obs - black), TS1 (red), TS2 with only Henry's law updates (HL - gold), TS2 with Henry's law and isoprene updates (ISOP - blue), and TS2 with Henry's law, isoprene and terpene updates (TS2 - purple). Acronyms are defined in Fig. 3. Data are grouped into $0.5 \mathrm{~km}$ bins and exclude urban plumes $\left(\mathrm{NO}_{2}>4 \mathrm{ppb}\right)$, fire plumes (acetonitrile $>0.2 \mathrm{ppb}$ ), and stratospheric air $\left(\mathrm{O}_{3} / \mathrm{CO}>1.25\right)$ as done in previous work (Travis et al., 2016). Domain includes the southeastern US $\left(29.5-40^{\circ} \mathrm{N}, 75-94.5^{\circ} \mathrm{W}\right)$, and local sun time 09:00 to 17:00. Observational uncertainty is shown in gray bars.

Sect. 5.1. Although much is known about isoprene and terpene chemistry, lingering uncertainties remain. These uncertainties are evaluated in Sect. 5.2 demonstrating that further studies on terpene oxidation and isoprene- and terpenederived organic-nitrate loss processes, in particular aerosol uptake, are needed in order to reduce uncertainties in simulated surface ozone.

\subsection{Organic-nitrate formation and fate}

Because the total organic nitrates for all simulations are underpredicted compared to the $\mathrm{SEAC}^{4} \mathrm{RS}$ observations
(Fig. 9), the speciation of organic nitrates in TS1 versus TS2 over the SEAC ${ }^{4} \mathrm{RS}$ flight tracks are compared, demonstrating that large differences in isoprene- and terpene-derived organic nitrates exist between the two mechanisms (Fig. 10). For isoprene-derived organic nitrates, TS2 clearly has more $\beta$ - than $\delta$-isoprene hydroxy nitrates, consistent with recent experimental and theoretical studies (Teng et al., 2017; Peeters et al., 2014) (Fig. 10a and b). The total isoprenederived organic nitrates are lower in TS2 than TS1 largely due to the more explicit treatment of later-generation organic nitrates in TS2. In TS1, all later-generation organic 

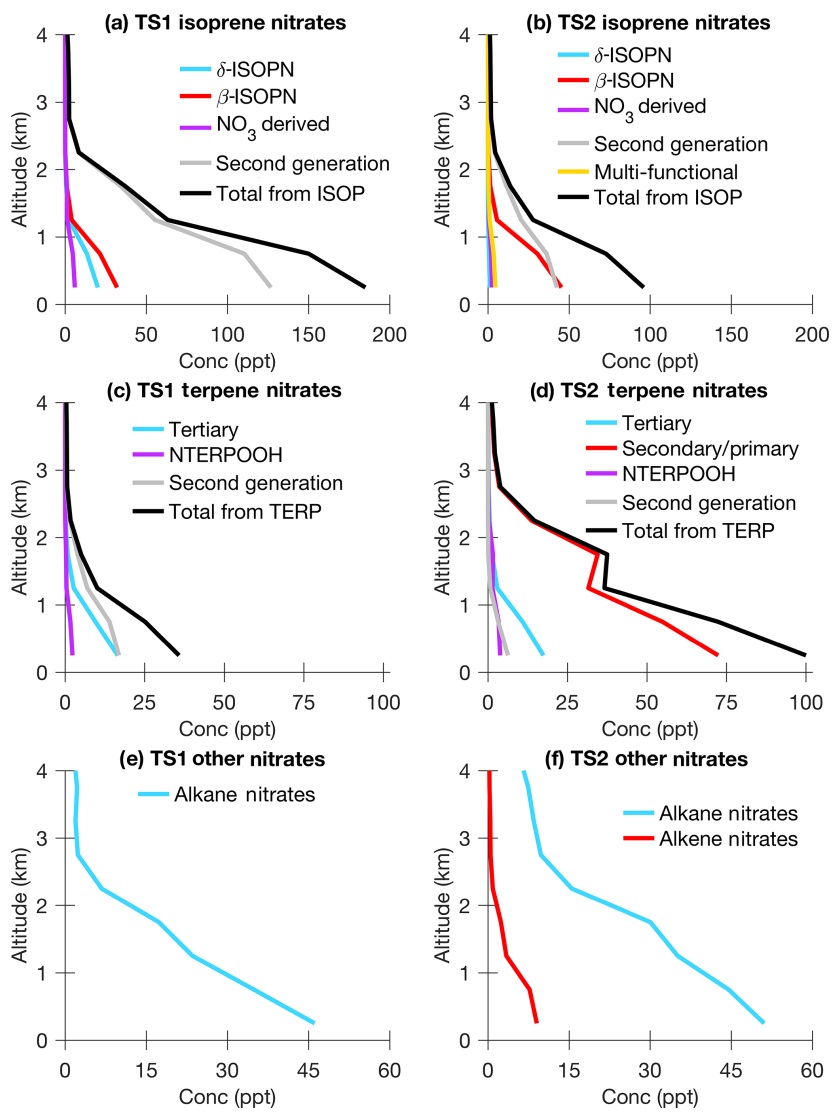

Figure 10. Median vertical profile plots over the SEAC ${ }^{4} \mathrm{RS}$ flight tracks for all isoprene, terpene, and other nitrates formed in the TS1 and TS2 mechanisms binned as specified in Fig. 9. For isoprene, ISOPN includes all isoprene hydroxy nitrates; $\mathrm{NO}_{3}$ derived includes all nitrates derived only from $\mathrm{NO}_{3}$-initiated oxidation (i.e., ISOPNOOH, INHE, and NC4CHO; Fig. S1); second generation includes all second-generation nitrates; and multi-functional includes all multi-functional later-generation nitrates. For terpenes, tertiary includes all tertiary hydroxy nitrates; secondary/primary includes all secondary/primary hydroxy nitrates; NTERPOOH includes all tertiary hydroperoxy nitrates; and second generation includes all second-generation nitrates, which for TS2 includes only the multifunctional low-volatility organic nitrates (Sect. 4.2). All dinitrates are doubled.

nitrates are grouped as NOA. Additional surrogate compounds are added in TS2, including MACRN, MVKN, and $\mathrm{NO}_{3} \mathrm{CH}_{2} \mathrm{CHO}$, which have higher photolysis rates than NOA. The faster loss processes lead to a lower total organicnitrate level from isoprene and faster $\mathrm{NO}_{x}$ recycling in TS2 versus TS1. The model comparisons against SEAC ${ }^{4} \mathrm{RS}$ observations (Fig. 9) confirm that the representation of latergeneration isoprene organic nitrates in TS2 is more accurate than TS1.

In contrast, terpene-derived organic nitrates are higher in TS2 than TS1 (Fig. 10c and d), which is largely due to the separation of tertiary and primary/secondary organic nitrates in TS2. Tertiary organic nitrates will undergo aerosol uptake and rapid hydrolysis to nitric acid, while primary/secondary organic nitrates will not (Jacobs et al., 2014; Hu et al., 2011; Darer et al., 2011). In TS1, terpene-derived hydroxy nitrates undergo aerosol uptake slower than TS2, but all hydroxy nitrates undergo aerosol uptake (Sect. 2.4). In comparison, TS2 has a higher uptake rate, but only tertiary hydroxy nitrates undergo aerosol uptake. Thus, in TS2, primary/secondary organic nitrates remain in the gas phase to be lost by other processes such as reaction with $\mathrm{OH}$ and photolysis. Consistent with other recent studies (Müller et al., 2019; Bates and Jacob, 2019; Zare et al., 2018), separating terpene tertiary organic nitrates from primary/secondary organic nitrates is clearly important for accurately representing organic-nitrate concentrations and fate in the atmosphere (Fig. 10).

Most of the organic nitrates in TS2 are from isoprene and terpene chemistry. The other organic nitrates (Fig. 10e and f) are derived from alkanes and alkenes. Some isoprene-derived nitrates are grouped with alkene nitrates in TS1. By adding in additional tracers into TS2 (MACRN and MVKN), the alkene nitrates are largely separated in TS2 and so can be evaluated independently. Even though isoprene and terpene emissions dominate, alkane and alkene nitrates are fairly important over the southeastern US in their contribution to the total organic nitrates (Fig. 10) likely due to their relatively long atmospheric lifetime.

In order to accurately simulate ozone for the right reasons in any model, the fate of the organic nitrates must be accurately described. As $\mathrm{NO}_{x}$ levels decrease, mixed regimes are becoming more prevalent. For example, during the Southern Oxidant and Aerosol Study (SOAS), isoprene dihydroxy hydroperoxide nitrates were measured, which are likely derived from first-generation isoprene hydroxy nitrates reacting with $\mathrm{OH}$ to form a peroxy radical that reacts with $\mathrm{HO}_{2}$ (Lee et al., 2016; Xiong et al., 2015). TS1 fails to capture this mixed regime chemistry because when first-generation unsaturated organic nitrates react with $\mathrm{OH}$, the resulting peroxy radical is assumed to immediately react with NO to form stable products. In contrast, TS2 assumes first-generation unsaturated isoprene and terpene organic nitrates react with $\mathrm{OH}$ to form peroxy radicals that then react with $\mathrm{NO}$ or $\mathrm{HO}_{2}$ or in the case of isoprene to isomerize. As an example in Fig. 11, the dominant fate of the peroxy radicals $\left(\mathrm{ISOPNO}_{2}\right)$ formed from isoprene hydroxy nitrates reaction with $\mathrm{OH}$ in TS2 is to isomerize. For peroxy radicals $\left(\mathrm{TERPNO}_{2}\right)$ formed from terpene unsaturated hydroxy nitrates $+\mathrm{OH}$, the dominant fate is reaction with $\mathrm{NO}$, but $\mathrm{HO}_{2}$ is still relevant across the US. Not constraining the fate of the peroxy radicals to the firstgeneration fate as in TS2 will be increasingly important as $\mathrm{NO}_{x}$ levels decrease in the future.

The possible fates for organic nitrates in the atmosphere include reactions with $\mathrm{OH}$ or $\mathrm{O}_{3}$, photolysis, wet/dry deposition, or aerosol uptake. Typically photolysis and reactions with $\mathrm{OH}$ or $\mathrm{O}_{3}$ release $\mathrm{NO}_{2}$ back into the atmosphere, while wet/dry deposition and aerosol uptake permanently remove $\mathrm{NO}_{x}$ from the atmosphere. In TS2 aerosol uptake is the dom- 

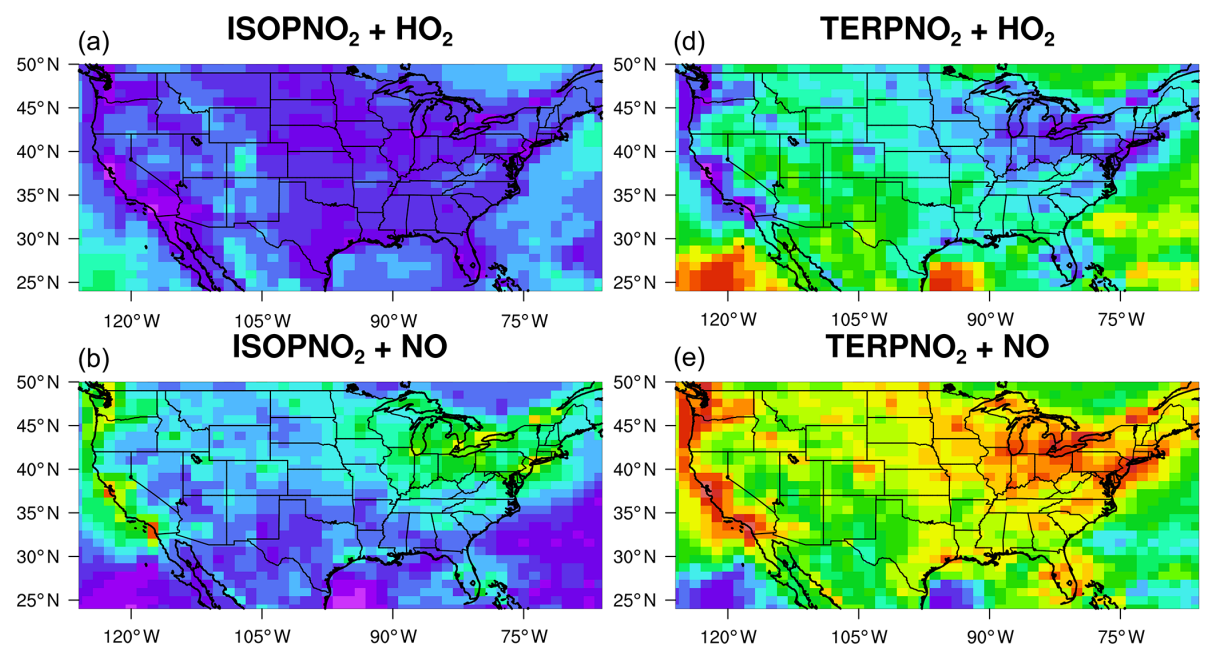

(e)
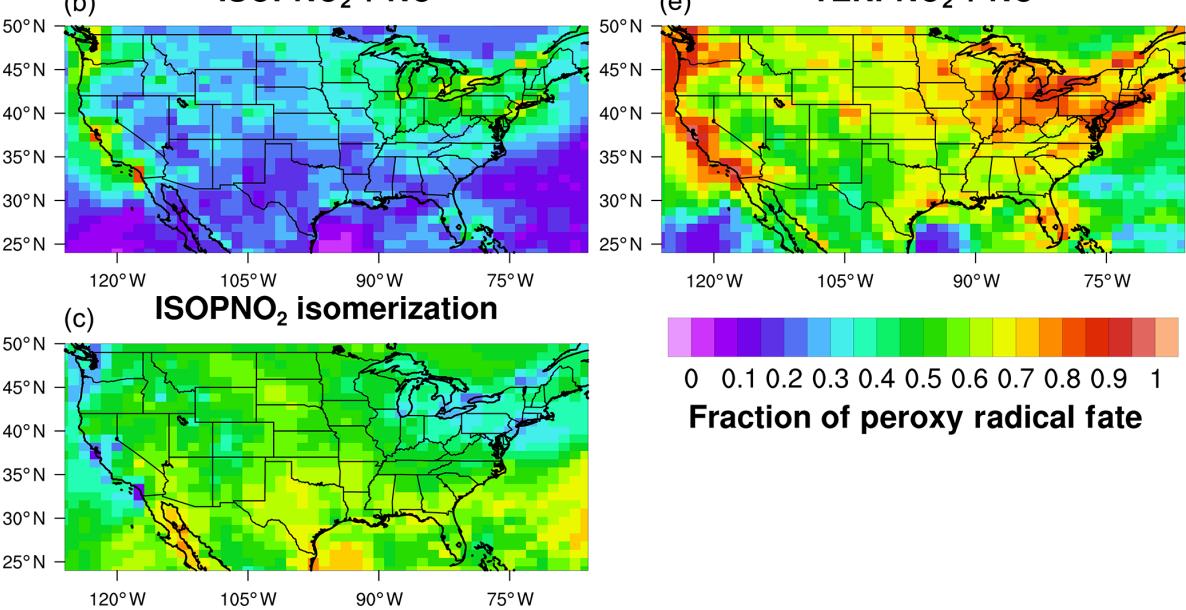

0.10 .20 .30 .40 .50 .60 .70 .80 .9

Fraction of peroxy radical fate

Figure 11. August 2013 average peroxy radical fate (fraction) below $2 \mathrm{~km}$ using TS2 for the isoprene dihydroxy nitrate peroxy radical $\left(\mathrm{ISOPNO}_{2}\right)$ formed from isoprene first-generation hydroxy nitrate $+\mathrm{OH}(\mathbf{a}-\mathbf{c})$ and terpene dihydroxy nitrate peroxy radical $\left(\mathrm{TERPNO}_{2}\right)$ produced from terpene unsaturated hydroxy nitrate $+\mathrm{OH}(\mathbf{d}, \mathbf{e})$.

inant fate of the organic nitrates, consistent with previous studies (Fisher et al., 2016; Romer et al., 2016; Wolfe et al., 2015; Müller et al., 2019; Bates and Jacob, 2019) (Fig. 12). Overall, TS2 has a greater proportion of organic nitrates undergoing aerosol uptake than TS1, which is largely driven by an increase in aerosol uptake of isoprene-derived organic nitrates (Figs. 12 and S8). There are also differences in the fraction of organic nitrates depositing. TS2 has more terpenederived organic nitrates depositing and less isoprene-derived organic nitrates depositing than TS1 (Figs. 12 and S8).

\subsection{Chemical mechanism uncertainties impact on surface ozone}

Although our understanding of isoprene and terpene chemistry has substantially improved over the last decade, many uncertainties remain generally from disagreement between measurements for first-generation chemistry and a lack of experimental data for later-generation chemistry. A number of sensitivity tests were performed in order to evaluate how these uncertainties impact simulated surface ozone. Each sensitivity test is briefly described in Table 1 and more completely described in Table S8. We note that the uncertainties evaluated here are only the known uncertainties, and we prioritize sensitivity tests related to organic-nitrate formation and fate. The bias in simulated surface ozone is still large in CESM/CAM-chem (Fig. 7), so contributions from unknown chemistry are also possible. For example, our understanding of reaction rates and products from the isomerization of peroxy radicals that leads to auto-oxidation is rudimentary and underconstrained (Wennberg et al., 2018). Because much is unknown about peroxy radical isomerization reactions, there is not a clear understanding of how important these reactions are in the ambient atmosphere.

\subsubsection{Uncertainties in the formation of organic nitrates}

The measured first-generation isoprene nitrate yield has been converging in recent experimental studies (Jenkin et al., 2015), but a moderately sized uncertainty still remains $(0.09$ 0.13) (Xiong et al., 2015; Teng et al., 2017). This study uses $\sim 0.13$, consistent with Teng et al. (2017). The chemical ionization mass spectrometer (CIMS) instrument in Teng et al. (2017) is potentially more reliable for measuring isoprene hydroxy nitrates than that used by Xiong et al. (2015) because the CIMS in Teng et al. (2017) has nearly equal sensitivities for all isoprene hydroxy nitrate isomers, while the CIMS in Xiong et al. (2015) varies in sensitivity depending on the isomer. As shown in Fig. 13a, this uncertainty is still important. Using the 0.09 yield from Xiong et al. (2015) increases the MDA8 surface ozone up to $2.6 \mathrm{ppb}$. Consistent with other systems, the first-generation isoprene chemistry is significantly better resolved than the second generation. In TS2 the later-generation organic-nitrate yields are largely 

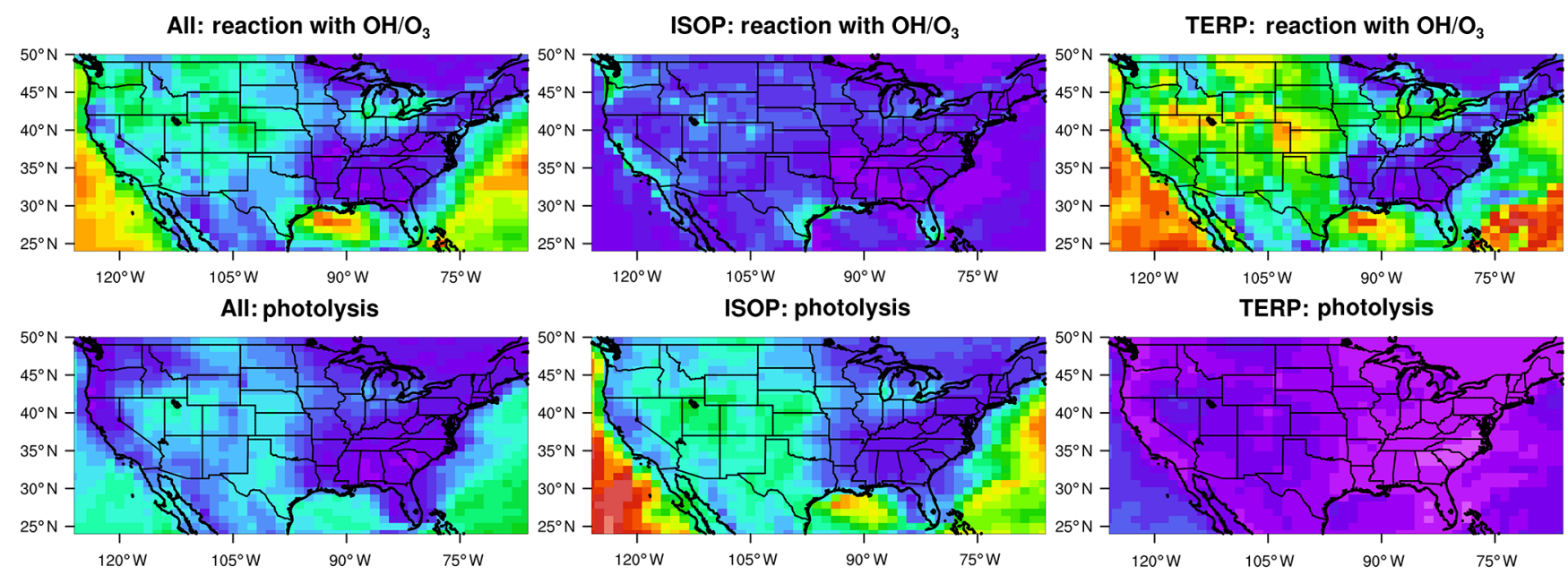

All: wet/dry deposition

ISOP: wet/dry deposition
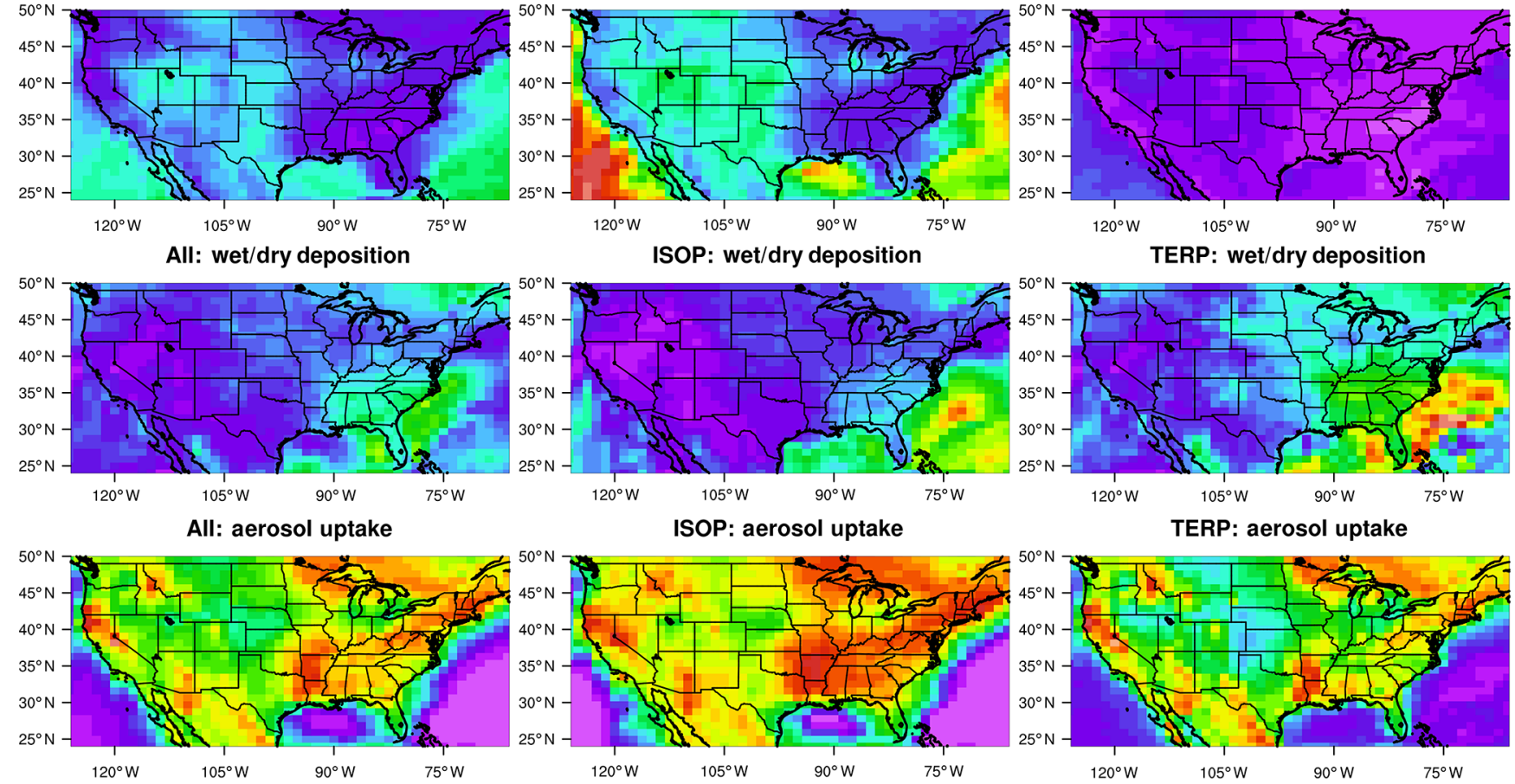

TERP: wet/dry deposition

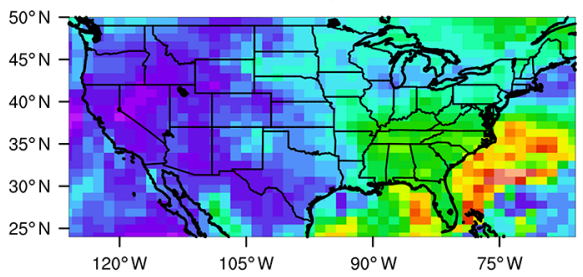

ISOP: aerosol uptake
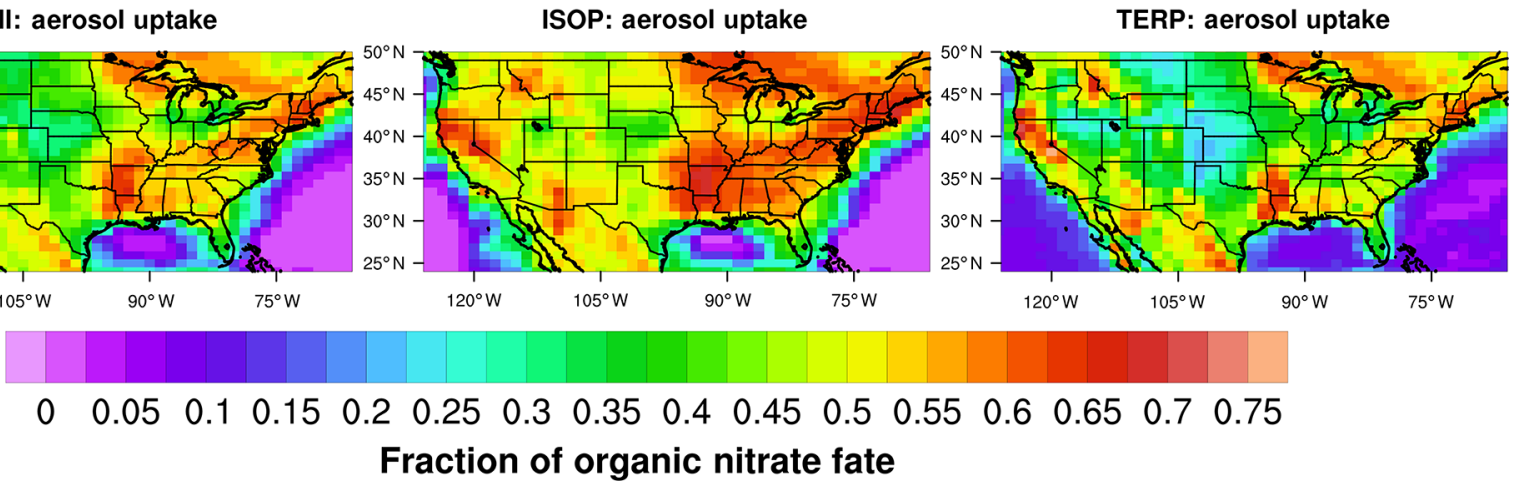

Figure 12. August 2013 average organic-nitrate fate below $2 \mathrm{~km}$ using TS2 for all organic nitrates (left), isoprene organic nitrates (middle), and terpene organic nitrates (right). To avoid double counting, only the final fate is included, so the reaction with $\mathrm{OH} / \mathrm{O}_{3}$ to form another organic nitrate is omitted from this calculation.

based on a parameterization developed by Wennberg et al. (2018). If the second-generation nitrate yield is increased to an upper level limit of 0.3 , modest changes in the MDA8 surface ozone occur with a decrease of up to 2.3 ppb (Fig. 13b). When isoprene first-generation hydroxy nitrates react with $\mathrm{OH}$, the peroxy radicals that form possibly undergo isomerization reactions (Wennberg et al., 2018), but this pathway is quite uncertain and not well studied. Removing this isomerization pathway also has modest impacts on MDA8 ozone (Fig. 13c).

For terpenes, even the first-generation nitrate yields are not well constrained (Sect. 2.3.1). For $\alpha$-pinene, $\beta$-pinene, and limonene generally past experimental studies found that the organic-nitrate yields varied from 0.15 to 0.26 (Noziere et al., 1999; Ruppert et al., 1999; Capouet et al., 2004; Rindelaub et al., 2015; Ruppert et al., 1999) with one study measuring a very low organic-nitrate yield (0.01) from $\alpha$-pinene (Aschmann et al., 2002b). A more recent study (Xu et al., 2019) measured substantially lower hydroxy nitrate yields from $\alpha$ pinene (0.033) and $\beta$-pinene (0.064) with slightly higher total organic-nitrate yields for $\alpha$-pinene (0.09) and $\beta$-pinene (0.11). As Xu et al. (2019) acknowledge, their instrument is not sensitive to organic nitrates from the $\mathrm{H}$-abstraction pathway, bringing their totals close but not quite to the lower end of the previous studies. Understanding why low organicnitrate yields from $\alpha$-and $\beta$-pinene have been measured in some cases is quite important. Additionally, a greater understanding of how structure impacts the organic-nitrate yield is especially valuable for terpenes given their large variety of chemical structures and reactivities (Guenther et al., 2012). 
(a) I_TEST1 (first-generation nitrate yield decrease) - TS2

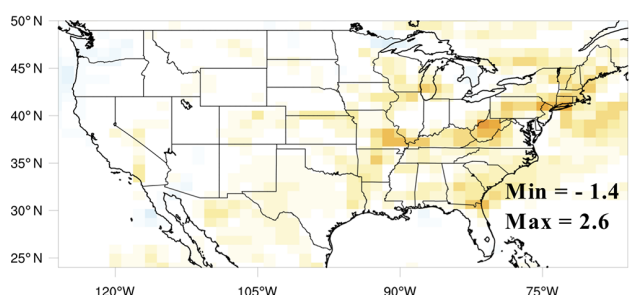

(c) I_TEST3 (second-generation no isomerization) - TS2

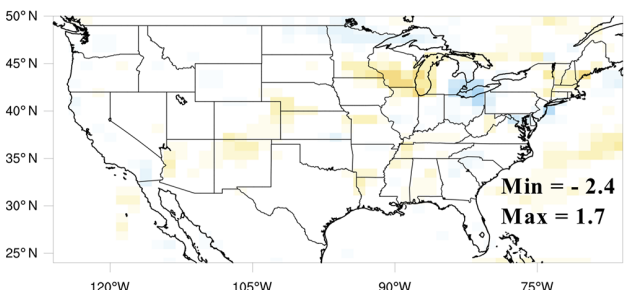

(e) T_TEST2 (first-generation nitrate yield decrease) - TS2

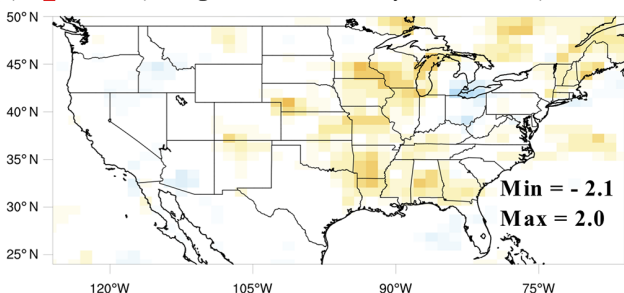

(g) T_TEST4 (MCM second-generation nitrate yield) - TS2

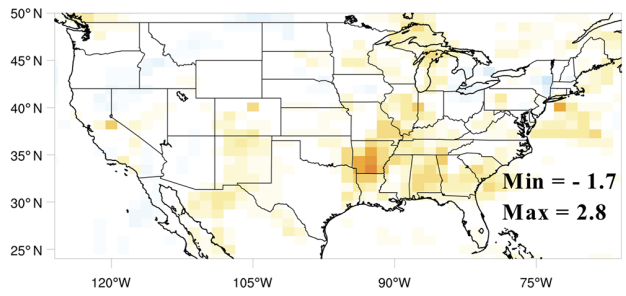

(i) A_TEST2 (Fisher et al. 2016 aerosol uptake) - TS2

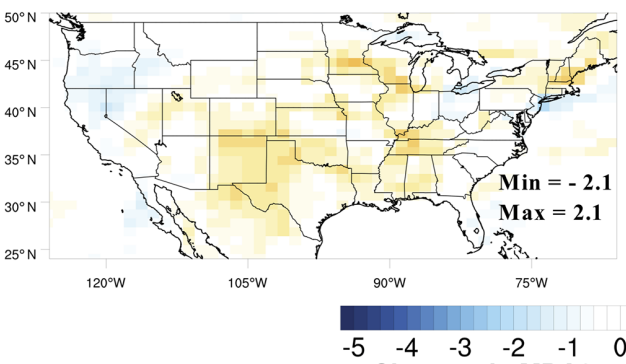

(b) I_TEST2 (second-generation nitrate yield increase) - TS2

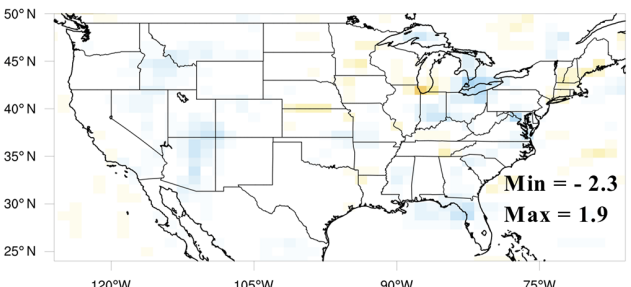

(d) T_TEST1 (first-generation nitrate yield increase) - TS2

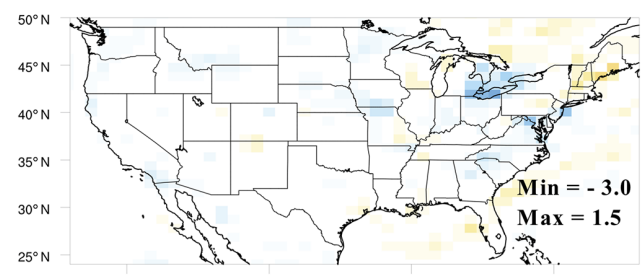

$120^{\circ} \mathrm{W} \quad 105^{\circ} \mathrm{W} \quad 90^{\circ} \mathrm{W} \quad 75^{\circ} \mathrm{W}$

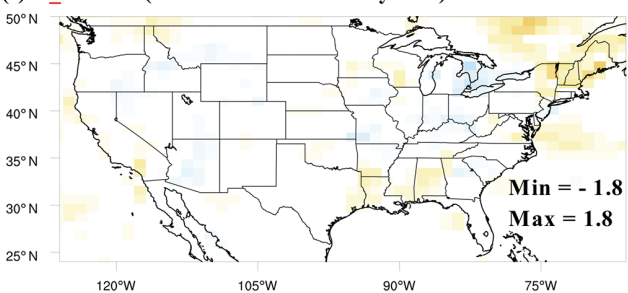

(h) A_TEST1 (no aerosol uptake) - TS2

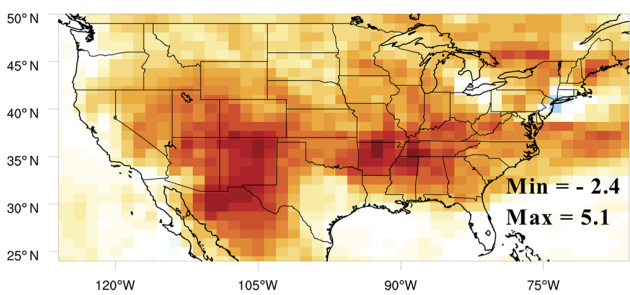

(j) A TEST3 (Wolfe et al. 2015 aerosol uptake) - TS2

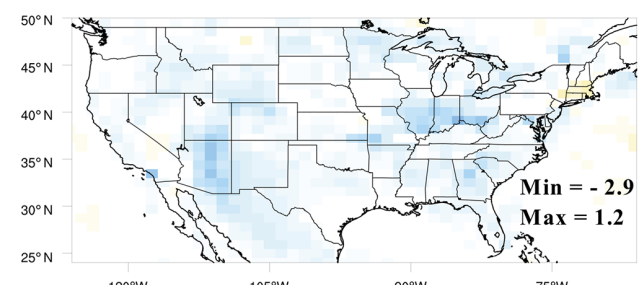

$90^{\circ} \mathrm{W}$

$75^{\circ} \mathrm{W}$

Changes in MDA8 surface ozone (ppbv)

Figure 13. Difference in surface ozone daily max $8 \mathrm{~h}$ average (MDA8) averaged over August 2013 between each sensitivity test described in Table 1 and the TS2 case. For each case, the minimum and maximum over the domain pictured is displayed on the bottom right.

As shown in Fig. 13d and e, increasing the first-generation organic-nitrate yield to 0.3 or decreasing the organic-nitrate yield to 0.15 for all terpenes impacts simulated MDA8 surface ozone by up to a couple parts per billion in either direction. Decreasing the first-generation organic-nitrate yield from terpenes to 0.15 has a similar impact on simulated surface ozone as decreasing the isoprene first-generation organic nitrate to 0.09. Using the assumptions from Xu et al. (2019)
(Fig. 13f) also has modest impacts on simulated surface ozone increasing the MDA8 by up to $1.8 \mathrm{ppb}$. The changes from Xu et al. (2019) are likely moderate because only $\alpha$-and $\beta$-pinene oxidation was updated, and although the organicnitrate yield is lower, the chemistry is quite similar to the theoretical studies that were used to develop TS2 (Vereecken et al., 2007; Vereecken and Peeters, 2012). Uncertainties in the later-generation organic-nitrate yields have a large im- 
Table 1. Sensitivity tests to determine the impact of uncertainties in TS2 on simulated surface ozone.

\begin{tabular}{|c|c|}
\hline Name & Description \\
\hline \multicolumn{2}{|c|}{ Uncertainties in isoprene chemistry } \\
\hline I_TEST1 & $\begin{array}{l}\text { Isoprene first-generation organic-nitrate yield up- } \\
\text { dated to } 0.09 \text { from } \sim 0.13\end{array}$ \\
\hline I_TEST2 & $\begin{array}{l}\text { Isoprene second-generation organic-nitrate yield } \\
\text { updated to } 0.3 \text { from } 0.02 \text { to } 0.2\end{array}$ \\
\hline I_TEST3 & Isoprene second-generation no isomerization \\
\hline \multicolumn{2}{|c|}{ Uncertainties in terpene chemistry } \\
\hline T_TEST1 & $\begin{array}{l}\text { Terpene first-generation organic-nitrate yield up- } \\
\text { dated to } 0.3\end{array}$ \\
\hline T_TEST2 & $\begin{array}{l}\text { Terpene first-generation organic-nitrate yield up- } \\
\text { dated to } 0.15\end{array}$ \\
\hline T_TEST3 & $\begin{array}{l}\text { APIN and BPIN first-generation chemistry based } \\
\text { on Xu et al. (2019) }\end{array}$ \\
\hline T_TEST4 & $\begin{array}{l}\text { Terpene second-generation MCM v3.3.1 organic- } \\
\text { nitrate yields for pinonaldehyde and limonalde- } \\
\text { hyde/limaketone oxidation }\end{array}$ \\
\hline \multicolumn{2}{|c|}{ Uncertainties in aerosol uptake of organic nitrates } \\
\hline A_TEST1 & Aerosol uptake of all organic nitrates turned off \\
\hline A_TEST2 & $\begin{array}{l}\gamma \text { values similar to GEOS-Chem (Fisher et al., } \\
2016 \text { ) }\end{array}$ \\
\hline A_TEST3 & $\gamma$ values similar to Wolfe et al. (2015) \\
\hline
\end{tabular}

pact on ozone. When nitrate yields from MCM were used for pinonaldehyde and limonaldehyde oxidation rather than the parameterization in Wennberg et al. (2018) used throughout TS2, MDA8 ozone increased by up to $2.8 \mathrm{ppb}$ (Fig. 13g).

In general, the uncertainties in isoprene and terpene oxidation evaluated here lead to similar impacts on simulated surface ozone even though terpene emissions are lower than isoprene in the southeastern US. Consistent with past work (Mao et al., 2018), uncertainties in isoprene chemistry have been significantly reduced over the last decade (Wennberg et al., 2018) such that uncertainties in terpene chemistry contribute equally to uncertainties in ozone. These results suggest more experimental constraints on terpene chemistry would be beneficial to further reduce biases in simulated surface ozone. Based on the results from these terpene sensitivity tests, there is a clear need for more organic-nitrate yield measurements from a variety of terpenes and terpene oxidation products with different chemical structures.

\subsubsection{Uncertainties in the loss of organic nitrates}

The uncertainties in aerosol uptake of organic nitrates causes the largest impact on simulated MDA8 (Fig. 13h-j). Aerosol uptake was only recently identified as an important loss process for organic nitrates (Fisher et al., 2016; Romer et al., 2016; Li et al., 2018; Müller et al., 2019; Bates and Jacob, 2019). If no aerosol uptake is included in TS2, this increases the MDA8 ozone by up to $5.1 \mathrm{ppb}$ (Fig. 13h). Interestingly, in contrast, Li et al. (2018) concluded aerosol uptake had little impact on simulated ozone using GFDL AM3, which is likely caused by differences in the representation of the organic-nitrate fate. For example, in Li et al. (2018) when aerosol uptake is removed, the $\beta$-isoprene hydroxy nitrate surrogate will react with $\mathrm{OH}$ to dominantly form other organic nitrates, so there is little expected impact on ozone. Conversely, in TS2 when aerosol uptake is removed, ISOPN2B (the $\beta$-isoprene hydroxy nitrate isomer that undergoes aerosol uptake; Fig. 1) will instead react with $\mathrm{OH}$ to predominantly release $\mathrm{NO}_{2}$ (Wennberg et al., 2018) and ozone will increase.

Most models like CESM/CAM-chem represent aerosol uptake of organic nitrates fairly simply (Sect. 2.4). Past studies indicate that aerosol uptake of organic nitrates is highly uncertain and underconstrained, leading to quite a few different model implementations. For example, Fisher et al. (2016) determined bulk aerosol uptake coefficients for all isoprene $(\gamma=0.005)$ and terpene $(\gamma=0.01)$ hydroxy nitrates were needed when comparing GEOS-Chem model results with SEAC ${ }^{4}$ RS observations. Wolfe et al. (2015) used SEAC ${ }^{4} R S$ observations over the Ozark Mountains to estimate an aerosol uptake coefficient for isoprene hydroxy nitrates $(\gamma=0.02)$. More recently, Bates and Jacob (2019) increased the tertiary organic-nitrate aerosol uptake rate in GEOS-Chem by a factor of 10 compared to previous versions, and Müller et al. (2019) used an aerosol uptake coefficient of 0.1 for all isoprene tertiary organic nitrates and 0.01 for all terpene organic nitrates.

From numerous laboratory studies (Jacobs et al., 2014; Hu et al., 2011; Darer et al., 2011), it is now clear that tertiary organic nitrates will undergo aerosol uptake and rapid hydrolysis, while primary and secondary organic nitrates generally will not. Thus, in TS2 all tertiary organic nitrates undergo aerosol uptake with the aerosol uptake coefficient measured by Wolfe et al. (2015), and primary and secondary organic nitrates are largely lost by other processes such as oxidation, photolysis, or deposition. To evaluate the range of possibilities, when all isoprene- and terpene-derived organic nitrates (tertiary, primary, and secondary) underwent aerosol uptake, but with the lower aerosol uptake used by Fisher et al. (2016), the MDA8 ozone increased by up to $2.1 \mathrm{ppb}$ (Fig. 13i). On the other hand, when aerosol uptake of all isoprene- and terpene-derived organic nitrates occurred with the higher aerosol uptake from Wolfe et al. (2015), the MDA8 ozone decreased by up to 3 ppb (Fig. 13j).

Considering the large impact aerosol uptake of organic nitrates has on simulated surface ozone (Fig. 13) and the varied interpretations of past model studies explained above, more constraints are clearly needed. There have been noticeably more studies evaluating the formation of organic nitrates than their losses, but uncertainties in loss processes like aerosol uptake have substantial impacts on simulated ozone (Fig. 13) and thus deserve equal attention. 


\section{Conclusions}

The overall objective of this study is to add more observationally based constraints to models (e.g., results from laboratory kinetic and product studies), in order to more realistically describe the chemistry and reduce uncertainty introduced by lumped species. To do this, more complex and updated isoprene and terpene chemistry was added into the default MOZART-TS1 mechanism in CESM2/CAM-chem, creating a new mechanism called MOZART-TS2. TS2 has isoprene chemistry with similar complexity as other recent work (Bates and Jacob, 2019; Müller et al., 2019) and terpene chemistry significantly more complex than past work (Browne et al., 2014; Fisher et al., 2016). The TS2 scheme could be easily adapted for use by other models. Although the focus of this work was to evaluate the impact of biogenic VOCs on simulated ozone, the TS2 mechanism will also be useful for other emission sources. For example, the use of volatile chemical products (McDonald et al., 2018a) and also biomass burning (Koss et al., 2018) lead to the emission of a variety of terpenes into the atmosphere. TS2 with more speciated terpenes and more complex chemistry will be useful for accurately simulating ozone from these systems as well.

The box-modeling results (Sect. 4.1 and 4.2) demonstrate that TS2 simulates first- and later-generation isoprene and terpene oxidation products better than TS1 in comparison to more explicit schemes like the Caltech mechanism and MCM. Verification that the isoprene and terpene oxidation chemistry is correctly represented in TS2 enhances confidence that ozone is accurately simulated for the right reasons. The box-modeling results also uncovered a simplification in MCM where terpene unsaturated hydroxy nitrate oxidation is not accurately represented, leading to large impacts on $\mathrm{NO}_{x}$ recycling and ozone formation (Sect. 4.2). Future studies using MCM v3.3.1 to simulate the oxidation of terpenes, especially those that contain more than one double bond, should update this simplification.

Global model simulations using CESM/CAM-chem demonstrate enhanced capability of TS2 versus TS1 in simulating MDA8 surface ozone compared to CASTNET monitoring data, with a reduction of biases up to $7 \mathrm{ppb}$ in the eastern US (Sect. 4.3). TS2 more accurately represents ozone, ozone precursors, and $\mathrm{NO}_{x}$ reservoir species than TS1, when compared to the SEAC ${ }^{4} \mathrm{RS}$ field campaign data (Sect. 4.4). Considering TS2 greatly increases the accuracy of isoprene and terpene chemistry, the $\sim 50 \%$ increase in computational cost caused by adding 86 new species is reasonable. In particular, results from this study demonstrate the importance of terpene chemistry, which has been heavily reduced or ignored in models in the past. Future work is needed to improve terpene schemes used in other models, to measure more terpene oxidation products in the field, and to conduct more laboratory studies to better understand terpene oxidation.

Comparisons of TS2 with the SEAC ${ }^{4} \mathrm{RS}$ field campaign data also demonstrate remaining biases. Although substan- tial changes were made to organic-nitrate formation and fate in TS2 compared to TS1 (Sect. 5.1), there remain large biases in modeled and observed total organic nitrates, which are not unique to CESM/CAM-chem (e.g., Fisher et al., 2016). If these missing organic nitrates have large losses, they could help to explain the remaining bias in simulated surface ozone.

Although our understanding of isoprene and terpene chemistry has increased significantly over the last several decades, many lingering uncertainties in the chemistry remain. A number of sensitivity tests were performed in order to evaluate how uncertainties in isoprene and terpene chemistry, with a focus on organic-nitrate formation and fate, translate to uncertainties in simulated MDA8 surface ozone (Sect. 5.2). Even though isoprene emissions are much larger than terpene emissions because isoprene chemistry is better understood, uncertainties in isoprene and terpene chemistry have similarly modest impacts on MDA8 surface ozone. An increased understanding of terpene oxidation including later-generation chemistry will provide important further constraints to CESM/CAM-chem. Considering the diversity of terpenes and their oxidation products, measurements of organic-nitrate yields from all compounds is not practical. Perhaps, measurements from a small subset of terpene and terpene oxidation products with wide structural differences may be particularly useful for identifying patterns and creating parameterizations that will reasonably extrapolate to the rest.

Past work has largely focused on formation processes of organic nitrates, but the sensitivity tests performed here (Sect. 5.2) suggest loss processes are equally important and quite underconstrained. In particular, future work to better understand aerosol uptake of organic nitrates and to incorporate more complex parameterizations in models is needed. In the future organic-nitrate aerosol uptake will be updated to a more complex scheme in CESM/CAM-chem. Organic nitrates will undergo aerosol uptake based on their volatility like the volatility basis set scheme for SOA formation, and hydrolysis reactions will be added to the mechanism to convert the particulate organic nitrate to nitric acid. Hydrolysis rates of many organic nitrates have already been measured in the laboratory (e.g., Liu et al., 2012; Jacobs et al., 2014; Rindelaub et al., 2015) or inferred from field campaign observations (Lee et al., 2016; Romer et al., 2016). Additional processes to represent the aqueous-phase chemistry of organic-nitrate loss in clouds through a similar process as that which occurs on aerosols should also be considered and included. Currently in CAM-chem, organic nitrates are lost to clouds via wet deposition but do not undergo hydrolysis in the cloud to form $\mathrm{HNO}_{3}$. Additionally, accounting for the potential for organic-nitrate monomers to oligomerize in the particle phase to form dimers, which are lower in volatility than their monomer counterparts, is likely also important for terpenes (e.g., Claflin and Ziemann, 2018, for $\beta$-pinene $\mathrm{NO}_{3}$ oxidation) and deserves further study and implementa- 
tion into models. Because tertiary nitrates have very different loss processes than secondary/primary nitrates, a greater understanding of the isomer distribution is also needed. Recent studies investigating the isomer distribution of various compounds have been conducted using both experimental (Teng et al., 2017; Boyd et al., 2015; Xu et al., 2019) and theoretical (Vereecken et al., 2007; Vereecken and Peeters, 2012) approaches, but more future studies are needed to ensure the fate of organic nitrates is accurately represented in models.

Additionally, TS2 has been designed to include surrogates for isoprene and terpene SOA precursors, which is the beginning framework for coupling SOA formation directly to gas-phase chemistry in CESM/CAM-chem, as recent studies have done with other models (Marais et al., 2016; Bates and Jacob, 2019; Stadtler et al., 2018; Zare et al., 2019). Considering the sensitivity of simulated ozone on aerosol uptake of organic nitrates (Fig. 13), accurately representing SOA and ozone seems to be a more connected problem than previously recognized. Better coupling SOA formation to gasphase chemistry in models is likely important for accurately simulating both ozone and SOA.

As shown in Fig. 7, TS2 greatly reduces the surface ozone bias in CESM/CAM-chem, but a relatively large bias remains. This bias could be caused by remaining uncertainties in the chemistry (Sect. 5.2) or by processes other than chemistry, which will be evaluated in future work. Considering the analysis against the SEAC ${ }^{4} \mathrm{RS}$ field campaign results, the first step toward reducing the remaining ozone bias will be to evaluate how a finer horizontal resolution $(14 \mathrm{~km})$ impacts the results. Because biogenic and anthropogenic emissions in the southeastern US are spatially segregated, improvements in simulated ozone and biogenic VOCs are expected with finer horizontal resolutions. Future work will also include evaluating different anthropogenic emission inventories, and a more thorough investigation into whether biogenic emissions are accurately represented by MEGAN in CAM-chem. Additionally, cloud biases in CAM-chem will be investigated more in the future given their likelihood for improving the vertical profile shape of ozone, ozone precursors, and $j_{\mathrm{NO}_{2}}$. Considering that biases in the ozone profile shape are enhanced with stronger nudging to meteorological data (Fig. S6), a more thorough analysis on the impact of nudging on CAM-chem dynamics and cloud parameterizations should be conducted. Future work will also evaluate whether enhanced vertical resolution is needed to improve PBL height and mixing schemes. Further evaluation of different chemical solvers (Sun et al., 2017) is also needed. Additionally, ozone dry deposition has a large impact on simulated surface ozone (Val Martin et al., 2014; Clifton et al., 2019), and a thorough evaluation and update to the ozone dry deposition scheme used in CAM-chem should be performed. Ozone is a complicated pollutant to accurately simulate in models. This work demonstrates that updating isoprene and terpene gas-phase chemistry clearly improves simulated surface ozone in CAM-chem and that additional studies evaluat- ing and updating other processes are needed to further reduce the ozone bias.

Code and data availability. CESM2.1.0 is a publicly released version of the Community Earth System Model available from http: //www.cesm.ucar.edu/ (last access: 1 April 2019; NCAR, 2018). The code updates described in this work will be made available as a new component set (i.e., standard configuration of the model) in a future release of CESM, likely CESM2.2. Chemical mechanisms used in CAM-chem are listed on the CAM-chem wiki page at https://wiki.ucar.edu/display/camchem/Gas-Phase+ Chemistry (Schwantes, 2020), which includes a brief description, a citation reference, and information on their current status. Please contact Rebecca H. Schwantes (rschwant@ucar.edu) if you would like the TS2 updates prior to their future release in CESM. CESM/CAM-chem output for August 2013 hourly ozone, August 2013 monthly average default output, and SEAC ${ }^{4}$ RS flight tracks used in this work are provided on National Center for Atmospheric Research's (NCAR) Digital Asset Services Hub (DASH) at https://dashrepo.ucar.edu/dataset/68_rschwant.html (Schwantes and Emmons, 2020). BOXMOX is also publicly available (https: //boxmodeling.meteo.physik.uni-muenchen.de/, Knote and Barre, 2017). The MCM v3.3.1 mechanism, which was added into BOXMOX for this work, will be added to a future release of BOXMOX. Please contact Rebecca H. Schwantes (rschwant@ucar.edu) if you would like the BOXMOX mechanisms, initialization files, or output used in this work.

Supplement. The supplement related to this article is available online at: https://doi.org/10.5194/acp-20-3739-2020-supplement.

Author contributions. RHS designed the study. RHS updated the isoprene and terpene chemistry with assistance from JJO, GST, and LKE. MCB determined all updates to Henry's law constants for the MOZART-TS1 mechanism. RHS expanded this for the MOZARTTS2 mechanism and incorporated all values into CESM/CAMchem. RHS performed all model simulations with help from LKE. $\mathrm{SRH}$ and KU collected actinic-flux spectroradiometer measurements and calculated photolysis rate constants during the SEAC ${ }^{4} \mathrm{RS}$ field campaign. JMSC measured isoprene oxidation products with the Caltech $\mathrm{CF}_{3} \mathrm{O}^{-}$CIMS. DRB measured carbon monoxide, isoprene, and $\alpha$ - and $\beta$-pinene using the whole-air sampler during SEAC ${ }^{4} \mathrm{RS}$. AW measured acetonitrile and monoterpenes using proton transfer reaction mass spectrometry (PTR-MS) during SEAC ${ }^{4}$ RS. TPVB measured wind and temperature during $\mathrm{SEAC}^{4} \mathrm{RS}$.

Competing interests. The authors declare that they have no conflict of interest.

Acknowledgements. We thank Simone Tilmes for assistance with CESM simulations. We thank the following for collecting SEAC ${ }^{4} \mathrm{RS}$ field campaign data: Paul O. Wennberg and 
John D. Crounse for measuring isoprene oxidation products with the Caltech $\mathrm{CF}_{3} \mathrm{O}^{-}$CIMS; Ronald $\mathrm{C}$. Cohen for measuring $\mathrm{NO}_{2}$, organic nitrates, and total peroxy acyl nitrates with the thermal dissociation laser-induced fluorescence (TD-LIF) instrument; and Thomas B. Ryerson and the NOAA NOyO3 team for measuring $\mathrm{NO}, \mathrm{NO}_{2}$, and $\mathrm{O}_{3}$. PTR-MS VOC measurements aboard the NASA DC-8 during SEAC ${ }^{4}$ RS were supported by the Austrian Federal Ministry for Transport, Innovation and Technology (bmvit) through the Austrian Space Applications Programme (ASAP) of the Austrian Research Promotion Agency (FFG). Tomas Mikoviny is acknowledged for his support during SEAC ${ }^{4} \mathrm{RS}$ with the PTR-MS. We thank Alma Hodzic and Siyuan Wang for helpful discussions.

Financial support. This material is based upon work supported by the National Center for Atmospheric Research, which is a major facility sponsored by the National Science Foundation (NSF) under Cooperative Agreement No. 1852977. Rebecca H. Schwantes acknowledges the NCAR Advanced Study Program postdoctoral fellowship for support of this work. The CESM project is supported primarily by the NSF. Computing and data storage resources, including the Cheyenne supercomputer (https://doi.org/10.5065/D6RX99HX), were provided by the Computational and Information Systems Laboratory (CISL) at NCAR (CISL, 2017).

Review statement. This paper was edited by Nga Lee Ng and reviewed by three anonymous referees.

\section{References}

Allen, H. M., Crounse, J. D., Bates, K. H., Teng, A. P., KrawiecThayer, M. P., Rivera-Rios, J. C., Keutsch, F. N., St. Clair, J. M., Hanisco, T. F., Moller, K. H., Kjaergaard, H. G., and Wennberg, P. O.: Kinetics and product yields of the $\mathrm{OH}$ initiated oxidation of hydroxymethyl hydroperoxide, J. Phys. Chem. A, 122, 62926302, https://doi.org/10.1021/acs.jpca.8b04577, 2018.

Allou, L., Maimouni, L. E., and Le Calve, S.: Henry's law constant measurements for formaldehyde and benzaldehyde as a function of temperature and water composition, Atmos. Environ., 45, 2991-2998, https://doi.org/10.1016/j.atmosenv.2010.05.044, 2011.

Arey, J., Atkinson, R., and Aschmann, S. M.: Product study of the gas-phase reactions of monoterpenes with the $\mathrm{OH}$ radical in the presence of $\mathrm{NO}_{x}$, J. Geophys. Res.-Atmos., 95, 18539-18546, https://doi.org/10.1029/JD095iD11p18539, 1990.

Arey, J., Aschmann, S. M., Kwok, E. S. C., and Atkinson, R.: Alkyl nitrate, hydroxyalkyl nitrate, and hydroxycarbonyl formation from the $\mathrm{NO}_{x}$-air photooxidations of $\mathrm{C}_{5}-\mathrm{C}_{8} \mathrm{n}$-alkanes, J. Phys. Chem. A, 105, 1020-1027, https://doi.org/10.1021/jp003292z, 2001.

Aschmann, S. M. and Atkinson, R.: Formation yields of methyl vinyl ketone and methacrolein from the gas-phase reaction of $\mathrm{O}_{3}$ with isoprene, Environ. Sci. Technol., 28, 1539-1542, https://doi.org/10.1021/es00057a025, 1994.

Aschmann, S. M., Reisseil, A., Atkinson, R., and Arey, J.: Products of the gas phase reactions of the $\mathrm{OH}$ radical with $\alpha$ - and $\beta$-pinene in the presence of NO, J. Geophys. Res.-Atmos., 103, 25553 25561, https://doi.org/10.1029/98JD01676, 1998.

Aschmann, S. M., Arey, J., and Atkinson, R.: OH radical formation from the gas-phase reactions of $\mathrm{O}_{3}$ with a series of terpenes, Atmos. Environ., 36, 4347-4355, https://doi.org/10.1016/S13522310(02)00355-2, 2002a.

Aschmann, S. M., Atkinson, R., and Arey, J.: Products of reaction of $\mathrm{OH}$ radicals with $\alpha$-pinene, J. Geophys. Res.-Atmos., 107, ACH 6-1-ACH 6-7, https://doi.org/10.1029/2001JD001098, $2002 \mathrm{~b}$.

Atkinson, R. and Arey, J.: Gas-phase tropospheric chemistry of biogenic volatile organic compounds: a review, Atmos. Environ., 37, S197-S219, https://doi.org/10.1016/S1352-2310(03)00391$1,2003$.

Atkinson, R., Aschmann, S. M., Arey, J., and Shores, B.: Formation of $\mathrm{OH}$ radicals in the gas phase reactions of $\mathrm{O}_{3}$ with a series of terpenes, J. Geophys. Res.-Atmos., 97, 6065-6073, https://doi.org/10.1029/92JD00062, 1992.

Atkinson, R., Baulch, D. L., Cox, R. A., Crowley, J. N., Hampson, R. F., Hynes, R. G., Jenkin, M. E., Rossi, M. J., and Troe, J.: Evaluated kinetic and photochemical data for atmospheric chemistry: Volume $\mathrm{I}-$ gas phase reactions of $\mathrm{O}_{x}, \mathrm{HO}_{x}$, $\mathrm{NO}_{x}$ and $\mathrm{SO}_{x}$ species, Atmos. Chem. Phys., 4, 1461-1738, https://doi.org/10.5194/acp-4-1461-2004, 2004.

Atkinson, R., Baulch, D. L., Cox, R. A., Crowley, J. N., Hampson, R. F., Hynes, R. G., Jenkin, M. E., Rossi, M. J., Troe, J., and IUPAC Subcommittee: Evaluated kinetic and photochemical data for atmospheric chemistry: Volume II - gas phase reactions of organic species, Atmos. Chem. Phys., 6, 3625-4055, https://doi.org/10.5194/acp-6-3625-2006, 2006.

Aumont, B., Szopa, S., and Madronich, S.: Modelling the evolution of organic carbon during its gas-phase tropospheric oxidation: development of an explicit model based on a self generating approach, Atmos. Chem. Phys., 5, 2497-2517, https://doi.org/10.5194/acp-5-2497-2005, 2005.

Bates, K. and Wennberg, P.: Isoprene Oxidation Model, https://doi.org/10.22002/d1.247, version 4.1, 2017.

Bates, K. H. and Jacob, D. J.: A new model mechanism for atmospheric oxidation of isoprene: global effects on oxidants, nitrogen oxides, organic products, and secondary organic aerosol, Atmos. Chem. Phys., 19, 9613-9640, https://doi.org/10.5194/acp19-9613-2019, 2019.

Bates, K. H., Crounse, J. D., St. Clair, J. M., Bennett, N. B., Nguyen, T. B., Seinfeld, J. H., Stoltz, B. M., and Wennberg, P. O.: Gas phase production and loss of isoprene epoxydiols, J. Phys. Chem. A, 118, 1237-1246, https://doi.org/10.1021/jp4107958, 2014.

Bates, K. H., Nguyen, T. B., Teng, A. P., Crounse, J. D., Kjaergaard, H. G., Stoltz, B. M. Seinfeld, J. H., and Wennberg, P. O.: Production and fate of $\mathrm{C}_{4}$ dihydroxycarbonyl compounds from isoprene oxidation, J. Phys. Chem. A, 120, 106-117, https://doi.org/10.1021/acs.jpca.5b10335, 2016.

Berndt, T. and Boge, O.: Products and mechanism of the gas-phase reaction of $\mathrm{NO}_{3}$ radicals with $\alpha$-pinene, J. Chem. Soc. Faraday T., 93, 3021-3027, https://doi.org/10.1039/A702364B, 1997.

Berndt, T., Boge, O., and Stratmann, F.: Gas-phase ozonolysis of $\alpha$-pinene:gaseous products and particle formation, Atmos. Environ., 37, 3933-3945, https://doi.org/10.1016/S13522310(03)00501-6, 2003.

Berndt, T., Richters, S., Jokinen, T., Hyttinen, N., Kurten, T., Otkjaer, R. V., Kjaergaard, H. G., Stratmann, F., Herrmann, H., Sip- 
ila, M., Kulmala, M., and Ehn, M.: Hydroxyl radical-induced formation of highly oxidized organic compounds, Nat. Commun., 7, 13677, https://doi.org/10.1038/ncomms13677, 2016.

Boge, O., Mutzel, A., Iinuma, Y., Yli-Pirila, P., Kahnt, A., Joutsensaari, J., and Herrmann, H.: Gas-phase products and secondary organic aerosol formation from the ozonolysis and photooxidation of myrcene, Atmos. Environ., 79, 553-560, https://doi.org/10.1016/j.atmosenv.2013.07.034, 2013.

Boyd, C. M., Sanchez, J., Xu, L., Eugene, A. J., Nah, T., Tuet, W. Y., Guzman, M. I., and Ng, N. L.: Secondary organic aerosol formation from the $\beta$-pinene $+\mathrm{NO}_{3}$ system: effect of humidity and peroxy radical fate, Atmos. Chem. Phys., 15, 7497-7522, https://doi.org/10.5194/acp-15-7497-2015, 2015.

Brown-Steiner, B., Hess, P. G., and Lin, M. Y.: On the capabilities and limitations of GCCM simulations of summertime regional air quality: A diagnostic analysis of ozone and temperature simulations in the US using CESM CAM-Chem, Atmos. Environ., 101, 134-148, https://doi.org/10.1016/j.atmosenv.2014.11.001, 2015.

Browne, E. C., Wooldridge, P. J., Min, K.-E., and Cohen, R. C.: On the role of monoterpene chemistry in the remote continental boundary layer, Atmos. Chem. Phys., 14, 1225-1238, https://doi.org/10.5194/acp-14-1225-2014, 2014.

Burkholder, J. B., Sander, S. P., Abbatt, J., Barker, J. R., Huie, R. E., Kolb, C. E., Kurylo, M. J., Orkin, V. L., Wilmouth, D. M., and Wine, P. H.: Chemical Kinetics and Photochemical Data for Use in Atmospheric Studies, Evaluation No. 18, Tech. Rep. JPL Publication 15-10, Jet Propulsion Laboratory, Pasadena, CA, available at: http://jpldataeval.jpl.nasa.gov (last access: 24 March 2017), 2015.

Butkovskaya, N., Kukui, A., and Le Bras, G.: Pressure and temperature dependence of ethyl nitrate formation in the $\mathrm{C}_{2} \mathrm{H}_{5} \mathrm{O}_{2}+\mathrm{NO}$ reaction, J. Phys. Chem. A, 114, 956-964, https://doi.org/10.1021/jp910003a, 2010.

Butkovskaya, N., Kukui, A., and Le Bras, G.: Pressure and temperature dependence of methyl nitrate formation in the $\mathrm{CH}_{3} \mathrm{O}_{2}+\mathrm{NO}$ reaction, J. Phys. Chem. A, 116, 5972-5980, https://doi.org/10.1021/jp210710d, 2012.

Calogirou, A., Jensen, N. R., Nielsen, C. J., Kotzias, D., and Hjorth, J.: Gas-phase reactions of nopinone, 3-isopropenyl6-oxo-heptanal, and 5-methyl-5-vinyltetrahydrofuran-2-ol with $\mathrm{OH}, \mathrm{NO}_{3}$, and ozone, Environ. Sci. Technol., 33, 453-460, https://doi.org/10.1021/es980530j, 1999.

Canty, T. P., Hembeck, L., Vinciguerra, T. P., Anderson, D. C., Goldberg, D. L., Carpenter, S. F., Allen, D. J., Loughner, C. P., Salawitch, R. J., and Dickerson, R. R.: Ozone and $\mathrm{NO}_{x}$ chemistry in the eastern US: evaluation of CMAQ/CB05 with satellite (OMI) data, Atmos. Chem. Phys., 15, 10965-10982, https://doi.org/10.5194/acp-15-10965-2015, 2015.

Capouet, M., Peeters, J., Nozière, B., and Müller, J.-F.: Alphapinene oxidation by $\mathrm{OH}$ : simulations of laboratory experiments, Atmos. Chem. Phys., 4, 2285-2311, https://doi.org/10.5194/acp4-2285-2004, 2004.

Chameides, W. L.: The Photochemistry of a Remote Marine Stratiform Cloud, J. Geophys. Res.-Atmos., 89, 4739-4755, https://doi.org/10.1029/JD089iD03p04739, 1984.

Chan, M. N., Surratt, J. D., Claeys, M., Edgerton, E. S., Tanner, R. L., Shaw, S. L., Zheng, M., Knipping, E. M., Eddingsaas, N. C., Wennberg, P. O., and Seinfeld, J. H.: Characterization and quantification of isoprene-derived epoxydiols in ambient aerosol in the Southeastern United States, Environ. Sci. Technol., 44, 4590-4596, https://doi.org/10.1021/es100596b, 2010.

Chew, A. A. and Atkinson, R.: $\mathrm{OH}$ radical formation yields from the gas-phase reactions of $\mathrm{O}_{3}$ with alkenes and monoterpenes, J. Geophys. Res., 101, 28649-28653, https://doi.org/10.1029/96JD02722, 1996.

CISL: Cheyenne: HPE/SGI ICE XA System (NCAR Community Computing), Computational and Information Systems Laboratory, National Center for Atmospheric Research, Boulder, CO, https://doi.org/10.5065/D6RX99HX, 2017.

Claflin, M. S. and Ziemann, P. J.: Identification and quantitation of aerosol products of the reaction of $\beta$-pinene with $\mathrm{NO}_{3}$ radicals and implications for gas- and particle phase reaction mechanisms, J. Phys. Chem. A, 122, 3640-3652, https://doi.org/10.1021/acs.jpca.8b00692, 2018.

Clifton, O. E., Fiore, A. M., Munger, J. W., and Wehr, R.: Spatiotemporal Controls on Observed Daytime Ozone Deposition Velocity Over Northeastern U.S. Forests During Summer, J. Geophys. Res.-Atmos., 124, 5612-5628, https://doi.org/10.1029/2018JD029073, 2019.

Cooper, O. R., Langford, A. O., Parrish, D. D., and Fahey, D. W.: Challenges of a lowered U.S. ozone standard: Source attribution science can help areas of the U.S. west, Science, 348, 10961097, https://doi.org/10.1126/science.aaa5748, 2015.

Copolovici, L. O. and Niinemets, U.: Temperature dependencies of Henry's law constants and octanol/water partition coefficients for key plant volatile monoterpenoids, Chemosphere, 61, 1390 1400, https://doi.org/10.1016/j.chemosphere.2005.05.003, 2005.

Crounse, J. D., Knap, H. C., Ornso, K. B., Jorgensen, S., Paulot, F., Kjaergaard, H. G., and Wennberg, P. O.: Atmospheric fate of methacrolein. 1. peroxy radical isomerization following addition of $\mathrm{OH}$ and $\mathrm{O}_{2}$, J. Phys. Chem. A, 116, 5756-5762, https://doi.org/10.1021/jp211560u, 2012.

Darer, A. I., Cole-Filipiak, N., O'Connor, A. E., and Elrod, M. J.: Formation and stability of atmospherically relevant isoprenederived organosulfates and organonitrates, Environ. Sci. Technol., 45, 1895-1902, https://doi.org/10.1021/es103797z, 2011.

Dillon, T. J. and Crowley, J. N.: Direct detection of OH formation in the reactions of $\mathrm{HO}_{2}$ with $\mathrm{CH}_{3} \mathrm{C}(\mathrm{O}) \mathrm{O}_{2}$ and other substituted peroxy radicals, Atmos. Chem. Phys., 8, 4877-4889, https://doi.org/10.5194/acp-8-4877-2008, 2008.

Dohnal, V. and Fenclova, D.: Air-water partitioning and aqueous solubility of phenols, J. Chem. Eng. Data, 40, 478-483, https://doi.org/10.1021/je00018a027, 1995.

Eddingsaas, N. C., Loza, C. L., Yee, L. D., Seinfeld, J. H., and Wennberg, P. O.: $\alpha$-pinene photooxidation under controlled chemical conditions - Part 1: Gas-phase composition in low- and high-NO ${ }_{x}$ environments, Atmos. Chem. Phys., 12, 6489-6504, https://doi.org/10.5194/acp-12-6489-2012, 2012.

Emmons, L. K., Schwantes, R. H., Orlando, J. J., Tyndall, G., Kinnison, D., Lamarque, J.-F., Marsh, D., Mills, M. J., Tilmes, S., Bardeen, C., Buchholz, R. R., Conley, A., Gettelman, A., Garcia, R., Simpson, I., Blake, D. R., Meinardi, S., and Petron, G.: The chemistry mechanism in the Community Earth System Model version 2 (CESM2), J. Adv. Model. Earth Sy., https://doi.org/10.1029/2019MS001882, online first, 2020.

Fiore, A. M., Dentener, F. J., Wild, O., Cuvelier, C., Schultz, M. G., Hess, P., Textor, C., Schulz, M., Doherty, R. M., Horowitz, L. W., 
MacKenzie, I. A., Sanderson, M. G., Shindell, D. T., Stevenson, D. S., Szopa, S., Van Dingenen, R., Zeng, G., Atherton, C., Bergmann, D., Bey, I., Carmichael, G., Collins, W. J., Duncan, B. N., Faluvegi, G., Folberth, G., Gauss, M., Gong, S., Hauglustaine, D., Holloway, T., Isaksen, I. S. A., Jacob, D. J., Jonson, J. E., Kaminski, J. W., Keating, T. J., Lupu, A., Marmer, E., Montanaro, V., Park, R. J., Pitari, G., Pringle, K. J., Pyle, J. A., Schroeder, S., Vivanco, M. G., Wind, P., Wojcik, G., Wu, S., and Zuber, A.: Multimodel estimates of intercontinental sourcereceptor relationships for ozone pollution, J. Geophys. Res.Atmos., 114, D04301, https://doi.org/10.1029/2008JD010816, 2009.

Fisher, J. A., Jacob, D. J., Travis, K. R., Kim, P. S., Marais, E. A., Chan Miller, C., Yu, K., Zhu, L., Yantosca, R. M., Sulprizio, M. P., Mao, J., Wennberg, P. O., Crounse, J. D., Teng, A. P., Nguyen, T. B., St. Clair, J. M., Cohen, R. C., Romer, P., Nault, B. A., Wooldridge, P. J., Jimenez, J. L., CampuzanoJost, P., Day, D. A., Hu, W., Shepson, P. B., Xiong, F., Blake, D. R., Goldstein, A. H., Misztal, P. K., Hanisco, T. F., Wolfe, G. M., Ryerson, T. B., Wisthaler, A., and Mikoviny, T.: Organic nitrate chemistry and its implications for nitrogen budgets in an isoprene- and monoterpene-rich atmosphere: constraints from aircraft $\left(\mathrm{SEAC}^{4} \mathrm{RS}\right)$ and ground-based (SOAS) observations in the Southeast US, Atmos. Chem. Phys., 16, 5969-5991, https://doi.org/10.5194/acp-16-5969-2016, 2016.

Forester, C. D. and Wells, J. R.: Hydroxyl radical yields from reactions of terpene mixtures with ozone, Indoor Air, 21, 400-409, https://doi.org/10.1111/j.1600-0668.2011.00718.x, 2011.

Fried, A., Henry, B. E., Calvert, J. G., and Mozurkewich, M.: The reaction probability of $\mathrm{N}_{2} \mathrm{O}_{5}$ with sulfuric acid aerosols at stratospheric temperatures and compositions, J. Geophys. Res.Atmos., 99, 3517-3532, https://doi.org/10.1029/93JD01907, 1994.

Fry, J. L., Kiendler-Scharr, A., Rollins, A. W., Wooldridge, P. J., Brown, S. S., Fuchs, H., Dubé, W., Mensah, A., dal Maso, M., Tillmann, R., Dorn, H.-P., Brauers, T., and Cohen, R. C.: Organic nitrate and secondary organic aerosol yield from $\mathrm{NO}_{3}$ oxidation of $\beta$-pinene evaluated using a gas-phase kinetics/aerosol partitioning model, Atmos. Chem. Phys., 9, 14311449, https://doi.org/10.5194/acp-9-1431-2009, 2009.

Fry, J. L., Draper, D. C., Barsanti, K. C., Smith, J. N., Ortega, J., Winkler, P. M., Lawler, M. J., Brown, S. S., Edwards, P. M., Cohen, R. C., and Lee, L.: Secondary organic aerosol formation and organic nitrate yield from $\mathrm{NO}_{3}$ oxidation of biogenic hydrocarbons, Environ. Sci. Technol., 48, 11944-11953, https://doi.org/10.1021/es502204x, 2014.

Gelaro, R., McCarty, W., Suarez, M. J., Todling, R., Molod, A., Takacs, L., Randles, C. A., Darmenov, A., Bosilovich, M. G., Reichle, R., Wargan, K., Coy, L., Cullather, R., Draper, C., Akella, S., Buchard, V., Conaty, A., da Silva, A. M., Gu, W., Kim, G. K., Koster, R., Lucchesi, R., Merkova, D., Nielsen, J. E., Partyka, G., Pawson, S., Putman, W., Rienecker, M., Schubert, S. D., Sienkiewicz, M., and Zhao, B.: The Modern-Era Retrospective Analysis for Research and Applications, Version 2 (MERRA-2), J. Climate, 30, 5419-5454, https://doi.org/10.1175/JCLI-D-160758.1, 2017.

Goldstein, S. and Czapski, G.: Reactivity of peroxynitric acid $\left(\mathrm{O}_{2} \mathrm{NOOH}\right)$ : A pulse radiolysis study, Inorg. Chem., 36, 41564162, https://doi.org/10.1021/ic961186z, 1997.
Grob, C. B. M., Dillon, T. J., Schuster, G., Lelieveld, J., and Crowley, J. N.: Direct kinetic study of $\mathrm{OH}$ and $\mathrm{O}_{3}$ formation in the reaction of $\mathrm{CH}_{3} \mathrm{C}(\mathrm{O}) \mathrm{O}_{2}$ with $\mathrm{HO}_{2}$, J. Phys. Chem. A, 118, 974 985, https://doi.org/10.1021/jp412380z, 2014.

Grosjean, D., Williams, E. L., and Grosjean, E.: Atmospheric chemistry of isoprene and of its carbonyl products, Environ. Sci. Technol., 27, 830-840, https://doi.org/10.1021/es00042a004, 1993a.

Grosjean, D., Williams, E. L., Grosjean, E., Andino, J. M., and Seinfeld, J. H.: Atmospheric oxidation of biogenic hydrocarbons: reaction of ozone with $\beta$-pinene, $D$-limonene and trans-caryophyllene, Environ. Sci. Technol., 27, 2754-5758, https://doi.org/10.1021/es00049a014, 1993b.

Guenther, A. B., Jiang, X., Heald, C. L., Sakulyanontvittaya, T., Duhl, T., Emmons, L. K., and Wang, X.: The Model of Emissions of Gases and Aerosols from Nature version 2.1 (MEGAN2.1): an extended and updated framework for modeling biogenic emissions, Geosci. Model Dev., 5, 1471-1492, https://doi.org/10.5194/gmd-5-1471-2012, 2012.

Guo, X. X. and Brimblecombe, P.: Henry's law constants of phenol and mononitrophenols in water and aqueous sulfuric acid, Chemosphere, 68, 436-444, https://doi.org/10.1016/j.chemosphere.2007.01.011, 2007.

Hakola, H., Arey, J., Ashmann, S. M., and Atkinson, R.: Product formation from the gas-phase reactions of $\mathrm{OH}$ radicals and $\mathrm{O}_{3}$ with a series of monoterpenes, J. Atmos. Chem., 18, 75-102, https://doi.org/10.1007/BF00694375, 1994.

Hall, S. R., Ullmann, K., Prather, M. J., Flynn, C. M., Murray, L. T., Fiore, A. M., Correa, G., Strode, S. A., Steenrod, S. D., Lamarque, J.-F., Guth, J., Josse, B., Flemming, J., Huijnen, V., Abraham, N. L., and Archibald, A. T.: Cloud impacts on photochemistry: building a climatology of photolysis rates from the Atmospheric Tomography mission, Atmos. Chem. Phys., 18, 1680916828, https://doi.org/10.5194/acp-18-16809-2018, 2018.

Hallquist, M., Wangberg, I., Ljungstrom, E., Barnes, I., and Becker, K.-H.: Aerosol and product yields from $\mathrm{NO}_{3}$ radical-initiated oxidation of selected monoterpenes, Environ. Sci. Technol., 33, 553-559, https://doi.org/10.1021/es980292s, 1999.

Hasson, A. S., Ho, A. W., Kuwata, K. T., and Paulson, S. E.: Production of stabilized Criegee intermediates and peroxides in the gas phase ozonolysis of alkenes 2. Asymmetric and biogenic alkenes, J. Geophys. Res.-Atmos., 106, 34143-34153, https://doi.org/10.1029/2001JD000598, 2001.

Hasson, A. S., Tyndall, G. S., and Orlando, J. J.: A product yield study of the reaction of $\mathrm{HO}_{2}$ radicals with ethyl peroxy $\left(\mathrm{C}_{2} \mathrm{H}_{5} \mathrm{O}_{2}\right)$, acetyl peroxy $\left(\mathrm{CH}_{3} \mathrm{C}(\mathrm{O}) \mathrm{O}_{2}\right)$, and acetonyl peroxy $\left(\mathrm{CH}_{3} \mathrm{C}(\mathrm{O}) \mathrm{CH}_{2} \mathrm{O}_{2}\right)$ radicals, J. Phys. Chem. A, 108, 5979-5989, https://doi.org/10.1021/jp048873t, 2004.

Hatakeyama, S., Izumi, K., Fukuyama, T., Akimoto, H., and Washida, N.: Reactions of $\mathrm{OH}$ with $\alpha$-pinene and $\beta$-pinene in air: Estimate of global $\mathrm{CO}$ production from the atmospheric oxidation of teprenes, J. Geophys. Res.-Atmos., 96, 947-958, https://doi.org/10.1029/90JD02341, 1991.

Herrmann, F., Winterhalter, R., Moortgat, G. K., and Williams, J.: Hydroxyl radical $(\mathrm{OH})$ yields from the ozonolysis of both double bonds for five monoterpenes, Atmos. Envrion., 44, 3458-3464, https://doi.org/10.1016/j.atmosenv.2010.05.011, 2010.

Hiatt, M. H.: Determination of Henry's law constants using internal standards with benchmark values, J. Chem. Eng. Data, 58, 902 908, https://doi.org/10.1021/je3010535, 2013. 
Hodzic, A., Aumont, B., Knote, C., Lee-Taylor, J., Madronich, S., and Tyndall, G.: Volatility dependence of Henry's law constants of condensable organics: Application to estimate depositional loss of secondary organic aerosols, Geophys. Res. Lett., 41, 4795-4804, https://doi.org/10.1002/2014GL060649, 2014.

Hodzic, A., Kasibhatla, P. S., Jo, D. S., Cappa, C. D., Jimenez, J. L., Madronich, S., and Park, R. J.: Rethinking the global secondary organic aerosol (SOA) budget: stronger production, faster removal, shorter lifetime, Atmos. Chem. Phys., 16, 7917-7941, https://doi.org/10.5194/acp-16-7917-2016, 2016.

Hoesly, R. M., Smith, S. J., Feng, L., Klimont, Z., JanssensMaenhout, G., Pitkanen, T., Seibert, J. J., Vu, L., Andres, R. J., Bolt, R. M., Bond, T. C., Dawidowski, L., Kholod, N., Kurokawa, J.-I., Li, M., Liu, L., Lu, Z., Moura, M. C. P., O'Rourke, P. R., and Zhang, Q.: Historical (1750-2014) anthropogenic emissions of reactive gases and aerosols from the Community Emissions Data System (CEDS), Geosci. Model Dev., 11, 369-408, https://doi.org/10.5194/gmd-11-369-2018, 2018.

Horie, O. and Moortgat, G. K.: Reactions of $\mathrm{CH}_{3} \mathrm{C}(\mathrm{O}) \mathrm{O}_{2}$ radicals with $\mathrm{CH}_{3} \mathrm{O}_{2}$ and $\mathrm{HO}_{2}$ between 263 and $333 \mathrm{~K}$. A product study, J. Chem. Soc. Faraday T., 88, 3305-3312, https://doi.org/10.1039/FT9928803305, 1992.

Hu, K. S., Darer, A. I., and Elrod, M. J.: Thermodynamics and kinetics of the hydrolysis of atmospherically relevant organonitrates and organosulfates, Atmos. Chem. Phys., 11, 8307-8320, https://doi.org/10.5194/acp-11-8307-2011, 2011.

Im, U., Bianconi, R., Solazzo, E., Kioutsioukis, I., Badia, A., Balzarini, A., Baro, R., Bellasio, R., Brunner, D., Chemel, C., Curci, G., Flemming, J., Forkel, R., Giordano, L., JimenezGuerrero, P., Hirtl, M., Hodzic, A., Honzak, L., Jorba, O., Knote, C., Kuenen, J. J. P., Makar, P. A., Manders-Groot, A., Neal, L., Perez, J. L., Pirovano, G., Pouliot, G., San Jose, R., Savage, N., Tuccella, P., Werhahn, J., Wolke, R., Yahya, K., Zabkar, R., Zhang, Y., Zhang, J., Hogrefe, C., and Galmarini, S.: Evaluation of operational on-line-coupled regional air quality models over Europe and North America in the context of AQMEII phase 2. Part I: Ozone, Atmos. Environ., 115, 404-420, https://doi.org/10.1016/j.atmosenv.2014.09.042, 2015.

IPCC: Climate Change 2013: The Physical Science Basis. Contribution of Working Group I to the Fifth Assessment Report of the Intergovernmental Panel on Climate Change, edited by: Stocker, T. F., Qin, D., Plattner, G.-K., Tignor, M., Allen, S. K., Boschung, J., Nauels, A., Xia, Y., Bex, V., and Midgley, P. M., Cambridge University Press, Cambridge, UK and New York, NY, USA, 2013.

Iraci, L. T., Baker, B. M., Tyndall, G. S., and Orlando, J. J.: Measurements of the Henry's law coefficients of 2-methyl-3-buten-2ol, methacrolein, and methylvinyl ketone, J. Atmos. Chem., 33, 321-330, https://doi.org/10.1023/A:1006169029230, 1999.

Jacobs, M. I., Darer, A. I., and Elrod, M. J.: Rate constants and products of the $\mathrm{OH}$ reaction with isoprenederived epoxides, Environ. Sci. Technol., 47, 12868-12876, https://doi.org/10.1021/es403340g, 2013.

Jacobs, M. I., Burke, W. J., and Elrod, M. J.: Kinetics of the reactions of isoprene-derived hydroxynitrates: gas phase epoxide formation and solution phase hydrolysis, Atmos. Chem. Phys., 14, 8933-8946, https://doi.org/10.5194/acp-14-8933-2014, 2014.

Jaoui, M. and Kamens, R. M.: Mass balance of gaseous and particulate products from $\beta$-pinene $/ \mathrm{O}_{3} /$ air in the absence of light and $\beta$-pinene/ $\mathrm{NO}_{x} /$ air in the presence of natural sunlight, J. Atmos. Chem., 45, 101-141, https://doi.org/10.1023/A:1024093710794, 2003.

Jaoui, M., Leungsakul, S., and Kamens, R. M.: Gas and particle products distribution from the reaction of $\beta$ caryophyllene with ozone, J. Atmos. Chem., 45, 261-287, https://doi.org/10.1023/A:1024263430285, 2003.

Jenkin, M. E., Saunders, S. M., and Pilling, M. J.: The tropospheric degradation of volatile organic compounds: A protocol for mechanism development, Atmos. Environ., 31, 81-104, https://doi.org/10.1016/S1352-2310(96)00105-7, 1997.

Jenkin, M. E., Hurley, M. D., and Wallington, T. J.: Investigation of the radical product channel of the $\mathrm{CH}_{3} \mathrm{C}(\mathrm{O}) \mathrm{O}_{2}+\mathrm{HO}_{2}$ reaction in the gas phase, Phys. Chem. Chem. Phys., 9, 3149-3162, https://doi.org/10.1039/B702757E, 2007.

Jenkin, M. E., Wyche, K. P., Evans, C. J., Carr, T., Monks, P. S., Alfarra, M. R., Barley, M. H., McFiggans, G. B., Young, J. C., and Rickard, A. R.: Development and chamber evaluation of the MCM v3.2 degradation scheme for $\beta$-caryophyllene, Atmos. Chem. Phys., 12, 5275-5308, https://doi.org/10.5194/acp12-5275-2012, 2012.

Jenkin, M. E., Young, J. C., and Rickard, A. R.: The MCM v3.3.1 degradation scheme for isoprene, Atmos. Chem. Phys., 15, 11433-11459, https://doi.org/10.5194/acp-15-11433-2015, 2015.

Jiang, Z., McDonald, B. C., Worden, H., Worden, J. R., Miyazaki, K., Qu, Z., Henze, D. K., Jones, D. B. A., Arellano, A. F., Fischer, E. V., Zhu, L., and Boersma, K. F.: Unexpected slowdown of US pollutant emission reduction in the past decade, P. Natl. Acad. Sci. USA, 115, 5099-5104, https://doi.org/10.1073/pnas.1801191115, 2018.

Johnson, D. and Marston, G.: The gas-phase ozonolysis of unsaturated volatile organic compounds in the troposphere, Chem. Soc. Rev., 37, 699-716, https://doi.org/10.1039/B704260B, 2008.

Kaiser, J., Jacob, D. J., Zhu, L., Travis, K. R., Fisher, J. A., González Abad, G., Zhang, L., Zhang, X., Fried, A., Crounse, J. D., St. Clair, J. M., and Wisthaler, A.: High-resolution inversion of OMI formaldehyde columns to quantify isoprene emission on ecosystem-relevant scales: application to the southeast US, Atmos. Chem. Phys., 18, 5483-5497, https://doi.org/10.5194/acp18-5483-2018, 2018.

Kames, J. and Schurath, U.: Henry's law and hydrolysis-rate constants for peroxyacyl nitrates (PANs) using a homogeneous gas-phase source, J. Atmos. Chem., 21, 151-164, https://doi.org/10.1007/BF00696578, 1995.

Karl, T., Harley, P., Emmons, L., Thornton, B., Guenther, A., Basu, C., Turnipseed, A., and Jardine, K.: Efficient atmospheric cleansing of oxidized organic trace gases by vegetation, Science, 330, 816-819, https://doi.org/10.1126/science.1192534, 2010.

Kharol, S. K., Martin, R. V., Philip, S., Boys, B., Lamsal, L. N., Jerrett, M., Brauer, M., Crouse, D. L., McLinden, C., and Burnett, R. T.: Assessment of the magnitude and recent trends in satellite-derived ground-level nitrogen dioxide over North America, Atmos. Environ., 118, 236-245, https://doi.org/10.1016/j.atmosenv.2015.08.011, 2015.

Kim, S.-W., Barth, M. C., and Trainer, M.: Impact of turbulent mixing on isoprene chemistry, Geophys. Res. Lett., 43, 7701-7708, https://doi.org/10.1002/2016GL069752, 2016. 
Knote, C. and Barre, J.: Getting BOXMOX, Box Modeling, available at: https://boxmodeling.meteo.physik.uni-muenchen. de/downloads/boxmox.html (last access: 1 August 2018), 2017.

Knote, C., Hodzic, A., Jimenez, J. L., Volkamer, R., Orlando, J. J., Baidar, S., Brioude, J., Fast, J., Gentner, D. R., Goldstein, A. H., Hayes, P. L., Knighton, W. B., Oetjen, H., Setyan, A., Stark, H., Thalman, R., Tyndall, G., Washenfelder, R., Waxman, E., and Zhang, Q.: Simulation of semi-explicit mechanisms of SOA formation from glyoxal in aerosol in a 3-D model, Atmos. Chem. Phys., 14, 6213-6239, https://doi.org/10.5194/acp14-6213-2014, 2014.

Knote, C., Hodzic, A., and Jimenez, J. L.: The effect of dry and wet deposition of condensable vapors on secondary organic aerosols concentrations over the continental US, Atmos. Chem. Phys., 15, 1-18, https://doi.org/10.5194/acp-15-1-2015, 2015a.

Knote, C., Tuccella, P., Curci, G., Emmons, L., Orlando, J. J., Madronich, S., Baro, R., Jimenez-Guerrero, P., Luecken, D., Hogrefe, C., Forkel, R., Werhahn, J., Hirtl, M., Perez, J. L., San Jose, R., Giordano, L., Brunner, D., Yahya, K., and Zhang, Y.: Influence of the choice of gas-phase mechanism on predictions of key gaseous pollutants during the AQMEII phase-2 intercomparison, Atmos. Environ., 115, 553568, https://doi.org/10.1016/j.atmosenv.2014.11.066, 2015 b.

Koss, A. R., Sekimoto, K., Gilman, J. B., Selimovic, V., Coggon, M. M., Zarzana, K. J., Yuan, B., Lerner, B. M., Brown, S. S., Jimenez, J. L., Krechmer, J., Roberts, J. M., Warneke, C., Yokelson, R. J., and de Gouw, J.: Non-methane organic gas emissions from biomass burning: identification, quantification, and emission factors from PTR-ToF during the FIREX 2016 laboratory experiment, Atmos. Chem. Phys., 18, 3299-3319, https://doi.org/10.5194/acp-18-3299-2018, 2018.

Krechmer, J. E., Coggon, M. M., Massoli, P., Nguyen, T. B., Crounse, J. D., Hu, W., Day, D. A., Tyndall, G. S., Henze, D. K., Rivera-Rios, J. C., Nowak, J. B., Kimmel, J. R., Mauldin, R. L., Stark, H., Jayne, J. T., Sipila, M., Junninen, H., St. Clair, J. M., Zhang, X., Feiner, P. A., Zhang, L., Miller, D. O., Brune, W. H., Keutsch, F. N., Wennberg, P. O., Seinfeld, J. H., Worsnop, D. R., Jimenez, J. L., and Canagaratna, M. R.: Formation of low volatility organic compounds and secondary organic aerosol from isoprene hydroxyhydroperoxide low-NO oxidation, Environ. Sci. Technol., 49, 10330-10339, https://doi.org/10.1021/acs.est.5b02031, 2015.

Kurten, T., Rissanen, M. P., Mackeprang, K., Thronton, J. A., Hyttinen, N., Jorgensen, S., Ehn, M., and Kjaergaard, H. G.: Computational study of hydrogen shifts and ring-opening mechanisms in $\alpha$-pinene ozonolysis products, J. Phys. Chem. A, 119, 1136611375, https://doi.org/10.1021/acs.jpca.5b08948, 2015.

Kurten, T., Moller, K. H., Nguyen, T. B., Schwantes, R. H., Misztal, P. K., Su, L., Wennberg, P. O., Fry, J. L., and Kjaergaard, H. G.: Alkoxy radical bond scissions explain the anomalously low secondary organic aerosol and organonitrate yields from $\alpha$-pinene $+\mathrm{NO}_{3}$, J. Phys. Chem. Lett., 8, 2826-2834, https://doi.org/10.1021/acs.jpclett.7b01038, 2017.

Kwan, A. J., Chan, A. W. H., Ng, N. L., Kjaergaard, H. G., Seinfeld, J. H., and Wennberg, P. O.: Peroxy radical chemistry and $\mathrm{OH}$ radical production during the $\mathrm{NO}_{3}$-initiated oxidation of isoprene, Atmos. Chem. Phys., 12, 7499-7515, https://doi.org/10.5194/acp-12-7499-2012, 2012.
Lamarque, J.-F., Emmons, L. K., Hess, P. G., Kinnison, D. E., Tilmes, S., Vitt, F., Heald, C. L., Holland, E. A., Lauritzen, P. H., Neu, J., Orlando, J. J., Rasch, P. J., and Tyndall, G. K.: CAM-chem: description and evaluation of interactive atmospheric chemistry in the Community Earth System Model, Geosci. Model Dev., 5, 369-411, https://doi.org/10.5194/gmd-5369-2012, 2012.

Lawrence, P. J. and Chase, T. N.: Representing a new MODIS consistent land surface in the CommunityLand Model (CLM 3.0), J. Geophys. Res.-Biogeo., 112, G01023, https://doi.org/10.1029/2006JG000168, 2007.

Lee, A., Goldstein, A. H., Keywood, M. D., Gao, S., Varutbangkul, V., Bahreini, R., Ng, N. L., Flagan, R. C., and Seinfeld, J. H.: Gas-phase products and secondary aerosol yields from the ozonolysis of ten different terpenes, J. Geophys. Res.-Atmos. 111, D07302, https://doi.org/10.1029/2005JD006437, 2006a.

Lee, A., Goldstein, A. H., Kroll, J. H., Ng, N. L., Varutbangkul, V., Flagan, R. C., and Seinfeld, J. H.: Gas-phase products and secondary aerosol yields from the photooxidation of 16 different terpenes, J. Geophys. Res.-Atmos., 111, D17305, https://doi.org/10.1029/2006JD007050, 2006b.

Lee, B. H., Mohr, C., Lopez-Hilfiker, F. D., Lutz, A., Hallquist, M., Lee, L., Romer, P., Cohen, R. C., Iyer, S., Kurten, T., Hu, W., Day, D. A., Campuzano-Jost, P., Jimenez, J. L., Xu, L., Ng, N. L., Guo, H., Weber, R. J., Wild, R. J., Brown, S. S., Koss, A., de Gouw, J., Olson, K., Goldstein, A. H., Seco, R., Kim, S., McAvey, K., Shepson, P. B., Starn, T., Baumann, K., Edgerton, E. S., Liu, J., Shilling, J. E., Miller, D. O., Brune, W., Schobesberger, S., D'Ambro, E. L., and Thornton, J. A.: Highly functionalized organic nitrates in the southeast United States: Contribution to secondary organic aerosol and reactive nitrogen budgets, P. Natl. Acad. Sci. USA, 113, 1516-1521, https://doi.org/10.1073/pnas.1508108113, 2016.

Lee, L., Teng, A. P., Wennberg, P. O., Crounse, J. D., and Cohen, R. C.: On rates and mechanisms of $\mathrm{OH}$ and $\mathrm{O}_{3}$ reactions with isoprene-derived hydroxy nitrates, J. Phys. Chem. A, 118, 16221637, https://doi.org/10.1021/jp4107603, 2014.

Leng, C., Kish, J. D., Kelley, J., Mach, M., Hiltner, J., Zhang, Y., and Liu, Y.: Temperature-dependent henry's law constants of atmospheric organics of biogenic origin, J. Phys. Chem. A, 117, 10359-10367, https://doi.org/10.1021/jp403603z, 2013.

Leu, M.-T. and Zhang, R.: Solubilities of $\mathrm{CH}_{3} \mathrm{C}(\mathrm{O}) \mathrm{O}_{2} \mathrm{NO}_{2}$ and $\mathrm{HO}_{2} \mathrm{NO}_{2}$ in water and liquid $\mathrm{H}_{2} \mathrm{SO}_{4}$, Geophys. Res. Lett., 26, 1129-1132, https://doi.org/10.1029/1999GL900158, 1999.

Li, J., Mao, J., Fiore, A. M., Cohen, R. C., Crounse, J. D., Teng, A. P., Wennberg, P. O., Lee, B. H., Lopez-Hilfiker, F. D., Thornton, J. A., Peischl, J., Pollack, I. B., Ryerson, T. B., Veres, P., Roberts, J. M., Neuman, J. A., Nowak, J. B., Wolfe, G. M., Hanisco, T. F., Fried, A., Singh, H. B., Dibb, J., Paulot, F., and Horowitz, L. W.: Decadal changes in summertime reactive oxidized nitrogen and surface ozone over the Southeast United States, Atmos. Chem. Phys., 18, 2341-2361, https://doi.org/10.5194/acp18-2341-2018, 2018.

Li, Y., Barth, M. C., Patton, E. G., and Steiner, A. L.: Impact of In-Cloud Aqueous Processes on the Chemistry and Transport of Biogenic Volatile Organic Compounds, J. Geophys. Res.-Atmos., 122, 11131-11153, https://doi.org/10.1002/2017JD026688, 2017. 
Liu, J., D’Ambro, E. L., Lee, B. H., Lopez-Hilfiker, F. D., Zaveri, R. A., Rivera-Rios, J. C., Keutsch, F. N., Iyer, S., Kurten, T., Zhang, Z., Gold, A., Surratt, J. D., Shilling, J. E., and Thornton, J. A.: Efficient isoprene secondary organic aerosol formation from a non-IEPOX pathway, Environ. Sci. Technol., 50, 98729880, https://doi.org/10.1021/acs.est.6b01872, 2016.

Liu, S., Shilling, J. E., Song, C., Hiranuma, N., Zaveri, R. A., and Russell, L. M.: Hydrolysis of organonitrate functional groups in aerosol particles, Aerosol Sci. Tech., 462, 1359-1369, https://doi.org/10.1080/02786826.2012.716175, 2012.

Liu, Y. J., Herdlinger-Blatt, I., McKinney, K. A., and Martin, S. T.: Production of methyl vinyl ketone and methacrolein via the hydroperoxyl pathway of isoprene oxidation, Atmos. Chem. Phys., 13, 5715-5730, https://doi.org/10.5194/acp-135715-2013, 2013.

Liu, Z., Nguyen, V. S., Harvey, J., Muller, J. F., and Peeters, J.: Theoretically derived mechanisms of HPALD photolysis in isoprene oxidation, Phys. Chem. Chem. Phys., 19, 9096-9106, https://doi.org/10.1039/c7cp00288b, 2017.

Ma, Y. and Marston, G.: Multifunctional acid formation from the gas-phase ozonolysis of $\beta$-pinene, Phys. Chem. Chem. Phys., 10, 6115-6126, https://doi.org/10.1039/b807863g, 2008.

Ma, Y., Russell, A. T., and Marston, G.: Mechanisms for the formation of secondary organic aerosol components from the gasphase ozonolysis of $\alpha$-pinene, Phys. Chem. Chem. Phys., 10, 4294-4312, https://doi.org/10.1039/B803283A, 2008.

Mao, J., Carlton, A., Cohen, R. C., Brune, W. H., Brown, S. S., Wolfe, G. M., Jimenez, J. L., Pye, H. O. T., Lee Ng, N., Xu, L., McNeill, V. F., Tsigaridis, K., McDonald, B. C., Warneke, C., Guenther, A., Alvarado, M. J., de Gouw, J., Mickley, L. J., Leibensperger, E. M., Mathur, R., Nolte, C. G., Portmann, R. W., Unger, N., Tosca, M., and Horowitz, L. W.: Southeast Atmosphere Studies: learning from model-observation syntheses, Atmos. Chem. Phys., 18, 2615-2651, https://doi.org/10.5194/acp18-2615-2018, 2018.

Marais, E. A., Jacob, D. J., Jimenez, J. L., Campuzano-Jost, P., Day, D. A., Hu, W., Krechmer, J., Zhu, L., Kim, P. S., Miller, C. C., Fisher, J. A., Travis, K., Yu, K., Hanisco, T. F., Wolfe, G. M., Arkinson, H. L., Pye, H. O. T., Froyd, K. D., Liao, J., and McNeill, V. F.: Aqueous-phase mechanism for secondary organic aerosol formation from isoprene: application to the southeast United States and co-benefit of $\mathrm{SO}_{2}$ emission controls, Atmos. Chem. Phys., 16, 1603-1618, https://doi.org/10.5194/acp16-1603-2016, 2016.

McDonald, B. C., de Gouw, J. A., Gilman, J. B., Jathar, S. H., Akherati, A., Cappa, C. D., Jimenez, J. L., Lee-Taylor, J., Hayes, P. L., McKeen, S. A., Cui, Y. Y., Kim, S.-W., Gentner, D. R., Isaacman-VanWertz, G., Goldstein, A. H., Harley, R. A., Frost, G. J., Roberts, J. M., Ryerson, T. B., and Trainer, M.: Volatile chemical products emerging as largest petrochemical source of urban organic emissions, Science, 359, 760-764, https://doi.org/10.1126/science.aaq0524, 2018a.

McDonald, B. C., McKeen, S. A., Cui, Y. Y., Ahmadov, R., Kim, S.-W., Frost, G. J., Pollack, I. B., Peischl, J., Ryerson, T. B., Holloway, J. S., Graus, M., Warneke, C., Gilman, J. B., de Gouw, J. A., Kaiser, J., Keutsch, F. N., Hanisco, T. F., Wolfe, G. M., and Trainer, M.: Modeling ozone in the Eastern U.S. using a fuelbased mobile source emissions inventory, Environ. Sci. Technol., 52, 7360-7370, https://doi.org/10.1021/acs.est.8b00778, 2018b.
McNeill, V. F., Woo, J. L., Kim, D. D., Schwier, A. N., Wannell, N. J., Sumner, A. J., and Barakat, J. M.: Aqueous-phase secondary organic aerosol and organosulfate formation in atmospheric aerosols: A modeling study, Environ. Sci. Technol., 46, 8075-8081, https://doi.org/10.1021/es3002986, 2012.

Monks, P. S., Archibald, A. T., Colette, A., Cooper, O., Coyle, M., Derwent, R., Fowler, D., Granier, C., Law, K. S., Mills, G. E., Stevenson, D. S., Tarasova, O., Thouret, V., von Schneidemesser, E., Sommariva, R., Wild, O., and Williams, M. L.: Tropospheric ozone and its precursors from the urban to the global scale from air quality to short-lived climate forcer, Atmos. Chem. Phys., 15, 8889-8973, https://doi.org/10.5194/acp-15-8889-2015, 2015.

Müller, J.-F., Peeters, J., and Stavrakou, T.: Fast photolysis of carbonyl nitrates from isoprene, Atmos. Chem. Phys., 14, 24972508, https://doi.org/10.5194/acp-14-2497-2014, 2014.

Müller, J.-F., Stavrakou, T., and Peeters, J.: Chemistry and deposition in the Model of Atmospheric composition at Global and Regional scales using Inversion Techniques for Trace gas Emissions (MAGRITTE v1.1) - Part 1: Chemical mechanism, Geosci. Model Dev., 12, 2307-2356, https://doi.org/10.5194/gmd-122307-2019, 2019.

NCAR: Downloading CESM2, available at: https://escomp.github. io/CESM/release-cesm2/downloading_cesm.html (last access: 4 January 2019), 2018.

Ng, N. L., Brown, S. S., Archibald, A. T., Atlas, E., Cohen, R. C., Crowley, J. N., Day, D. A., Donahue, N. M., Fry, J. L., Fuchs, H., Griffin, R. J., Guzman, M. I., Herrmann, H., Hodzic, A., Iinuma, Y., Jimenez, J. L., Kiendler-Scharr, A., Lee, B. H., Luecken, D. J., Mao, J., McLaren, R., Mutzel, A., Osthoff, H. D., Ouyang, B., Picquet-Varrault, B., Platt, U., Pye, H. O. T., Rudich, Y., Schwantes, R. H., Shiraiwa, M., Stutz, J., Thornton, J. A., Tilgner, A., Williams, B. J., and Zaveri, R. A.: Nitrate radicals and biogenic volatile organic compounds: oxidation, mechanisms, and organic aerosol, Atmos. Chem. Phys., 17, 2103-2162, https://doi.org/10.5194/acp-17-2103-2017, 2017.

Nguyen, T. B., Crounse, J. D., Teng, A. P., St. Clair, J. M., Paulot, F., Wolfe, G. M., and Wennberg, P. O.: Rapid deposition of oxidized biogenic compounds to a temperate forest, P. Natl. Acad. Sci. USA, 112, E392-E401, https://doi.org/10.1073/pnas.1418702112, 2015.

Nguyen, T. B., Tyndall, G. S., Crounse, J. D., Teng, A. P., Bates, K. H., Schwantes, R. H., Coggon, M. M., Zhang, L., Feiner, P., Milller, D. O., Skog, K. M., Rivera-Rios, J. C., Dorris, M., Olson, K. F., Koss, A., Wild, R. J., Brown, S. S., Goldstein, A. H., de Gouw, J. A., Brune, W. H., Keutsch, F. N., Seinfeld, J. H., and Wennberg, P. O.: Atmospheric fates of Criegee intermediates in the ozonolysis of isoprene, Phys. Chem. Chem. Phys., 18, 10241-10254, https://doi.org/10.1039/C6CP00053C, 2016.

Nguyen, T. L., Winterhalter, R., Moortgat, G., Kanawati, B., Peeters, J., and Vereecken, L.: The gas-phase ozonolysis of $\beta$-caryophyllene $\left(\mathrm{C}_{15} \mathrm{H}_{24}\right)$. Part II: A theoretical study, Phys. Chem. Chem. Phys., 11, 4173-4183, https://doi.org/10.1039/B817913A, 2009.

Niki, H., Maker, P. D., Savage, C. M., and Breitenbach, L. P.: FTIR study of the kinetics and mechanism for chlorine-atominitiated reactions of acetaldehyde, J. Phys. Chem., 89, 588-591, https://doi.org/10.1021/j100250a008, 1985.

Noziere, B., Barnes, I., and Becker, K. H.: Product study and mechanisms of the reactions of $\alpha$-pinene and of pinonaldehyde 
with OH radicals, J. Geophys. Res.-Atmos., 104, 23645-23656, https://doi.org/10.1029/1999JD900778, 1999.

Orlando, J. J. and Tyndall, G. S.: Laboratory studies of organic peroxy radical chemistry: an overview with emphasis on recent issues of atmospheric significance, Chem. Soc. Rev., 41, 62946317, https://doi.org/10.1039/C2CS35166H, 2012.

Orlando, J. J., Noziere, B., Tyndall, G. S., Orzechowska, G. E., Paulson, S. E., and Rudich, Y.: Product studies of the $\mathrm{OH}-$ and ozone-initiated oxidation of some monoterpenes, J. Geophys. Res.-Atmos., 105, 11561-11572, https://doi.org/10.1029/2000JD900005, 2000.

Paulson, S. E., Chung, M., Sen, A. D., and Orzechowska, G.: Measurement of $\mathrm{OH}$ radical formation from the reaction of ozone with several biogenic alkenes, J. Geophys. Res.-Atmos., 103, 25533-25539, https://doi.org/10.1029/98JD01951, 1998.

Peeters, J., Boullart, W., Pultau, V., Vandenberk, S., and Vereecken, L.: Structure-activity relationship for the addition of $\mathrm{OH}$ to (poly)alkenes: Site-specific and total rate constants, J. Phys. Chem. A, 111, 1618-1631, https://doi.org/10.1021/jp066973o, 2007

Peeters, J., Muller, J.-F., Stavrakou, T., and Nguyen, V.: Hydroxyl radical recycling in isoprene oxidation driven by hydrogen bonding and hydrogen tunneling: The upgraded LIM1 mechanism, J. Phys. Chem. A, 118, 8625-8643, https://doi.org/10.1021/jp5033146, 2014.

Pfrang, C., King, M. D., Canosa-Mas, C. E., and Wayne, R. P.: Structure-activity relations (SARs) for gas-phase reactions of $\mathrm{NO}_{3}, \mathrm{OH}$ and $\mathrm{O}_{3}$ with alkenes: An update, Atmos. Environ., 40, 1180-1186, https://doi.org/10.1016/j.atmosenv.2005.09.080, 2006.

Piletic, I. R., Howell, R., Bartolotti, L. J., Kleindienst, T. E., Kaushik, S. M., and Edney, E. O.: Multigenerational theoretical study of isoprene peroxy radical 1-5-hydrogen shift reactions that regenerate $\mathrm{HO}_{\mathrm{x}}$ radicals and produce highly oxidized molecules, J. Phys. Chem. A, 123, 906-919, https://doi.org/10.1021/acs.jpca.8b09738, 2019.

Praske, E., Crounse, J. D., Bates, K. H., Kurten, T., Kjaergard, H. G., and Wennberg, P. O.: Atmospheric fate of methyl vinyl ketone: Peroxy radical reactions with $\mathrm{NO}$ and $\mathrm{HO}_{2}$, J. Phys. Chem. A, 119, 4562-4572, https://doi.org/10.1021/jp5107058, 2015.

Pye, H. O. T., Pinder, R. W., Piletic, I. R., Xie, Y., Capps, S. L., Lin, Y.-H., Surratt, J. D., Zhang, Z., Gold, A., Leucken, D. J., Hutzell, W. T., Jaoui, M., Offenberg, J. H., Kleindienst, T. E., Lewandowski, M., and Edney, E. O.: Epoxide pathways improve model predictions of isoprene markers and reveal key role of acidity in aerosol formation, Environ. Sci. Technol., 47, 1105611064, https://doi.org/10.1021/es402106h, 2013.

Raventos-Duran, T., Camredon, M., Valorso, R., Mouchel-Vallon, C., and Aumont, B.: Structure-activity relationships to estimate the effective Henry's law constants of organics of atmospheric interest, Atmos. Chem. Phys., 10, 7643-7654, https://doi.org/10.5194/acp-10-7643-2010, 2010.

Reichl, A.: Messung und Korrelierung von Gaslöslichkeiten halogenierter Kohlenwasserstoffe, $\mathrm{PhD}$ thesis, Technische Universitat Berlin, Germany, 1995.

Reidmiller, D. R., Fiore, A. M., Jaffe, D. A., Bergmann, D., Cuvelier, C., Dentener, F. J., Duncan, B. N., Folberth, G., Gauss, M., Gong, S., Hess, P., Jonson, J. E., Keating, T., Lupu, A., Marmer, E., Park, R., Schultz, M. G., Shindell, D. T., Szopa, S., Vivanco,
M. G., Wild, O., and Zuber, A.: The influence of foreign vs. North American emissions on surface ozone in the US, Atmos. Chem. Phys., 9, 5027-5042, https://doi.org/10.5194/acp-9-50272009, 2009.

Reissell, A., Harry, C., Aschmann, S., Atkinson, R., and Arey, J.: Formation of acetone from the $\mathrm{OH}$ radical- and $\mathrm{O}_{3}$-initiated reactions of a series of monoterpenes, J. Geophys. Res.-Atmos., 104, 13869-13879, https://doi.org/10.1029/1999JD900198, 1999.

Rickard, A. R., Johnson, D., McGill, C. D., and Marston, G.: OH yields in the gas-phase reactions of ozone with alkenes, J. Phys. Chem. A, 103, 7656-7664, https://doi.org/10.1021/jp9916992, 1999.

Rindelaub, J. D., McAvey, K. M., and Shepson, P. B.: The photochemical production of organic nitrates from $\alpha$-pinene and loss via acid-dependent particle phase hydrolysis, Atmos. Environ., 100, 193-201, https://doi.org/10.1016/j.atmosenv.2014.11.010, 2015.

Riva, M., Budisulistiorini, S. H., Chen, Y., Zhang, Z., D’Ambro, E. L., Zhang, X., Gold, A., Turpin, B. J., Thornton, J. A., Canagaratna, M. R., and Surratt, J. D.: Chemical characterization of secondary organic aerosol from oxidation of isoprene hydroxyhydroperoxides, Environ. Sci. Technol., 50, 9889-9899, https://doi.org/10.1021/acs.est.6b02511, 2016.

Roehl, C. M., Marka, Z., Fry, J. L., and Wennberg, P. O.: Near-UV photolysis cross sections of $\mathrm{CH}_{3} \mathrm{OOH}$ and $\mathrm{HOCH}_{2} \mathrm{OOH}$ determined via action spectroscopy, Atmos. Chem. Phys., 7, 713-720, https://doi.org/10.5194/acp-7-713-2007, 2007.

Rollins, A. W., Kiendler-Scharr, A., Fry, J. L., Brauers, T., Brown, S. S., Dorn, H.-P., Dubé, W. P., Fuchs, H., Mensah, A., Mentel, T. F., Rohrer, F., Tillmann, R., Wegener, R., Wooldridge, P. J., and Cohen, R. C.: Isoprene oxidation by nitrate radical: alkyl nitrate and secondary organic aerosol yields, Atmos. Chem. Phys., 9, 6685-6703, https://doi.org/10.5194/acp-9-6685-2009, 2009.

Romer, P. S., Duffey, K. C., Wooldridge, P. J., Allen, H. M., Ayres, B. R., Brown, S. S., Brune, W. H., Crounse, J. D., de Gouw, J., Draper, D. C., Feiner, P. A., Fry, J. L., Goldstein, A. H., Koss, A., Misztal, P. K., Nguyen, T. B., Olson, K., Teng, A. P., Wennberg, P. O., Wild, R. J., Zhang, L., and Cohen, R. C.: The lifetime of nitrogen oxides in an isoprene-dominated forest, Atmos. Chem. Phys., 16, 7623-7637, https://doi.org/10.5194/acp16-7623-2016, 2016.

Ruppert, L., Becker, K. H., Noziere, B., and Spittler, M.: Development of monoterpene oxidation mechanisms: Results from laboratory and smog chamber studies, WIT Trans. Ecol. Envir., 28, 63-68, 1999.

Ryu, Y.-H., Hodzic, A., Barre, J., Descombes, G., and Minnis, P.: Quantifying errors in surface ozone predictions associated with clouds over the CONUS: a WRF-Chem modeling study using satellite cloud retrievals, Atmos. Chem. Phys., 18, 7509-7525, https://doi.org/10.5194/acp-18-7509-2018, 2018.

Sander, R.: Compilation of Henry's law constants (version 4.0) for water as solvent, Atmos. Chem. Phys., 15, 4399-4981, https://doi.org/10.5194/acp-15-4399-2015, 2015.

Sandu, A. and Sander, R.: Technical note: Simulating chemical systems in Fortran90 and Matlab with the Kinetic PreProcessor KPP-2.1, Atmos. Chem. Phys., 6, 187-195, https://doi.org/10.5194/acp-6-187-2006, 2006.

Saunders, S. M., Jenkin, M. E., Derwent, R. G., and Pilling, M. J.: Protocol for the development of the Master Chemical Mech- 
anism, MCM v3 (Part A): tropospheric degradation of nonaromatic volatile organic compounds, Atmos. Chem. Phys., 3, 161-180, https://doi.org/10.5194/acp-3-161-2003, 2003.

Schwantes, R. H.: Gas-phase Chemistry, CAM-chem Wiki, available at: https://wiki.ucar.edu/display/camchem/Gas-Phase+ Chemistry, last access: 13 January 2020.

Schwantes, R. H. and Emmons, L. K.: CESM/CAM-chem Data for Evaluation of MOZART-TS2., UCAR/NCAR - DASH Repository, https://doi.org/10.5065/70zg-0t17, 2020.

Schwantes, R. H., Teng, A. P., Nguyen, T. B., Coggon, M. M., Crounse, J. D., St. Clair, J. M., Zhang, X., Schilling, K. A., Seinfeld, J. H., and Wennberg, P. O.: Isoprene $\mathrm{NO}_{3}$ oxidation products from the $\mathrm{RO}_{2}+\mathrm{HO}_{2}$ pathway, J. Phys. Chem. A, 119, 10158-10171, https://doi.org/10.1021/acs.jpca.5b06355, 2015.

Schwartz, S. E. and White, W. H.: Solubility equilibria of the nitrogen oxides and oxyacids in dilute aqueous solution, in: Advances in Environmental Science and Engineering, edited by: Pfafflin, J. R. and Ziegler, E. N., Vol. 4, 1-45, Gordon and Breach Science Publisher, NY, 1981.

Shu, Y. and Atkinson, R.: Rate constants for the gas-phase reactions of $\mathrm{O}_{3}$ with a series of terpenes and $\mathrm{OH}$ radical formation from the $\mathrm{O}_{3}$ reactions with sesquiterpenes at $296 \pm 2 \mathrm{~K}$, Int. J. Chem. Kinet., 26, 1193-1205, https://doi.org/10.1002/kin.550261207, 1994.

Sieg, K., Starokozhev, E., Schmidt, M. U., and Puttmann, W.: Inverse temperature dependence of Henry's law coefficients for volatile organic compounds in supercooled water, Chemosphere, 77, 8-14, https://doi.org/10.1016/j.chemosphere.2009.06.028, 2009.

Siese, M., Becker, K. H., Brockmann, K. J., Geiger, H., Hofzumahaus, A., Holland, F., Mihelcic, D., and Wirtz, K.: Direct measurement of $\mathrm{OH}$ radicals from ozonolysis of selected alkenes: A EUPHORE simulation chamber study, Envrion. Sci. Technol., 35, 4660-4667, https://doi.org/10.1021/es010150p, 2001.

Smith, R. M. and Martell, A. E.: Critical stability constants, Vol 4: Inorganic complexes, Plenum Press, New York, 1976.

Spittler, M., Barnes, I., Bejan, I., Brockmann, K. J., Benter, T., and Wirtz, K.: Reactions of $\mathrm{NO}_{3}$ radicals with limonene and $\alpha$ pinene: Product and SOA formation, Atmos. Environ., 40, S116S127, https://doi.org/10.1016/j.atmosenv.2005.09.093, 2006.

Squire, O. J., Archibald, A. T., Griffiths, P. T., Jenkin, M. E., Smith, D., and Pyle, J. A.: Influence of isoprene chemical mechanism on modelled changes in tropospheric ozone due to climate and land use over the 21 st century, Atmos. Chem. Phys., 15, 5123-5143, https://doi.org/10.5194/acp-15-5123-2015, 2015.

Stadtler, S., Kühn, T., Schröder, S., Taraborrelli, D., Schultz, M. G., and Kokkola, H.: Isoprene-derived secondary organic aerosol in the global aerosol-chemistry-climate model ECHAM6.3.0-HAM2.3-MOZ1.0, Geosci. Model Dev., 11, 3235-3260, https://doi.org/10.5194/gmd-11-3235-2018, 2018.

Staudinger, J. and Roberts, P. V.: A critical compilation of Henry's law constant temperature dependence relations for organic compounds in dilute aqueous solutions, Chemosphere, 44, 561-576, https://doi.org/10.1016/S0045-6535(00)00505-1, 2001.

St. Clair, J. M., Rivera, J. C., Crounse, J. D., Knap, H. C., Bates, K. H., Teng, A. P., Jorgensen, S., Kjaergaard, H. G., Keutsch, F. N., and Wennberg, P. O.: Kinetics and products of the reaction of the first-generation isoprene hydroxy hydroperoxide
(ISOPOOH) with OH, J. Phys. Chem. A, 120, 1441-1451, https://doi.org/10.1021/acs.jpca.5b06532, 2016.

Sun, J., Fu, J. S., Drake, J., Lamarque, J.-F., Tilmes, S., and Vitt, F.: Improvement of the prediction of surface ozone concentration over conterminous U.S. by a computationally efficient secondorder Rosenbrock solver in CAM4-Chem, J. Adv. Model. Earth Syst., 9, 482-500, https://doi.org/10.1002/2016MS000863, 2017.

Takeuchi, M. and Ng, N. L.: Chemical composition and hydrolysis of organic nitrate aerosol formed from hydroxyl and nitrate radical oxidation of $\alpha$-pinene and $\beta$-pinene, Atmos. Chem. Phys., 19, 12749-12766, https://doi.org/10.5194/acp-19-127492019, 2019.

Teng, A. P., Crounse, J. D., Lee, L., St. Clair, J. M., Cohen, R. C., and Wennberg, P. O.: Hydroxy nitrate production in the $\mathrm{OH}-$ initiated oxidation of alkenes, Atmos. Chem. Phys., 15, 42974316, https://doi.org/10.5194/acp-15-4297-2015, 2015.

Teng, A. P., Crounse, J. D., and Wennberg, P. O.: Isoprene peroxy radical dynamics, J. Am. Chem. Soc., 139, 5367-5377, https://doi.org/10.1021/jacs.6b12838, 2017.

Tilmes, S., Lamarque, J.-F., Emmons, L. K., Kinnison, D. E., Ma, P.-L., Liu, X., Ghan, S., Bardeen, C., Arnold, S., Deeter, M., Vitt, F., Ryerson, T., Elkins, J. W., Moore, F., Spackman, J. R., and Val Martin, M.: Description and evaluation of tropospheric chemistry and aerosols in the Community Earth System Model (CESM1.2), Geosci. Model Dev., 8, 1395-1426, https://doi.org/10.5194/gmd8-1395-2015, 2015.

Tilmes, S., Hodzic, A., Emmons, L. K., Mills, M. J., Gettelman, A., Kinnison, D. E., Park, M., Lamarque, J.-F., Vitt, F., Shrivastava, M., Campuzano-Jost, P., Jimenez, J. L., and Liu, X.: Climate forcing and trends of organic aerosols in the Community Earth System Model (CESM2), J. Adv. Model. Earth Syst., 11, 4323-4351, https://doi.org/10.1029/2019MS001827, 2019.

Toon, O. B., Maring, H., Dibb, J., Ferrare, R., Jacob, D. J., Jensen, E. J., Luo, Z. J., Mace, G. G., Pan, L. L., Pfister, L., Rosenlof, K. H., Redemann, J., Reid, J. S., Singh, H. B., Thompson, A. M., Yokelson, R., Minnis, P., Chen, G., Jucks, K. W., and Pszenny, A.: Planning, implementation, and scientific goals of the Studies of Emissions and Atmospheric Composition, Clouds and Climate Coupling by Regional Surveys (SEAC ${ }^{4} \mathrm{RS}$ ) field mission, J. Geophys. Res.-Atmos., 121, 49675009, https://doi.org/10.1002/2015JD024297, 2016.

Travis, K. R., Jacob, D. J., Fisher, J. A., Kim, P. S., Marais, E. A., Zhu, L., Yu, K., Miller, C. C., Yantosca, R. M., Sulprizio, M. P., Thompson, A. M., Wennberg, P. O., Crounse, J. D., St. Clair, J. M., Cohen, R. C., Laughner, J. L., Dibb, J. E., Hall, S. R., Ullmann, K., Wolfe, G. M., Pollack, I. B., Peischl, J., Neuman, J. A., and Zhou, X.: Why do models overestimate surface ozone in the Southeast United States?, Atmos. Chem. Phys., 16, 1356113577, https://doi.org/10.5194/acp-16-13561-2016, 2016.

Turner, M. C., Jerrett, M., Pope, C. A., Krewski, D., Gapstur, S. M., Diver, W. R., Beckerman, B. S., Marshall, J. D., Su, J., Crouse, D. L., and Burnett, R. T.: Long-term ozone exposure and mortality in a large prospective study, Am. J. Resp. Crit. Care., 193, 1134-1142, https://doi.org/10.1164/rccm.201508-1633OC, 2016.

U.S. EPA: The National Ambient Air Quality Standards: Overview of EPA's updates to the air quality standards for groundlevel ozone, available at: https://www.epa.gov/sites/production/ 
files/2015-10/documents/overview_of_2015_rule.pdf (last access: 4 March 2019), 2015.

U.S. EPA: U.S. Environmental Protection Agency Clean Air Markets Division. Clean Air Status and Trends Network (CASTNET): Ozone 8-Hour Daily Max, available at: https://www.epa. gov/castnet, last access: 6 December 2017.

U.S. EPA: Our Nation's Air: Status and Trends Through 2018, available at: https://gispub.epa.gov/air/trendsreport/2019/\#home (last access: 25 September 2019), 2018.

Val Martin, M., Heald, C. L., and Arnold, S. R.: Coupling dry deposition to vegetation phenology in the Community Earth System Model: Implications for the simulation of surface $\mathrm{O}_{3}$, Geophys. Res. Lett., 41, 2988-2996, https://doi.org/10.1002/2014GL059651, 2014.

Val Martin, M., Heald, C. L., Lamarque, J.-F., Tilmes, S., Emmons, L. K., and Schichtel, B. A.: How emissions, climate, and land use change will impact mid-century air quality over the United States: a focus on effects at national parks, Atmos. Chem. Phys., 15, 2805-2823, https://doi.org/10.5194/acp15-2805-2015, 2015.

van Marle, M. J. E., Kloster, S., Magi, B. I., Marlon, J. R., Daniau, A.-L., Field, R. D., Arneth, A., Forrest, M., Hantson, S., Kehrwald, N. M., Knorr, W., Lasslop, G., Li, F., Mangeon, S., Yue, C., Kaiser, J. W., and van der Werf, G. R.: Historic global biomass burning emissions for CMIP6 (BB4CMIP) based on merging satellite observations with proxies and fire models (1750-2015), Geosci. Model Dev., 10, 3329-3357, https://doi.org/10.5194/gmd-10-3329-2017, 2017.

van Roon, A., Parsons, J. R., Kloeze, A.-M. T., and Govers, H. A. J.: Fate and transport of monoterpenes through soils. Part I. Prediction of temperature dependent soil fate model input-parameters, Chemosphere, 61, 599-609, https://doi.org/10.1016/j.chemosphere.2005.02.081, 2005.

Vereecken, L. and Peeters, J.: A theoretical study of the $\mathrm{OH}-$ initiated gas-phase oxidation mechanism of $\beta$-pinene $\left(\mathrm{C}_{10} \mathrm{H}_{16}\right)$ : first generation products, Phys. Chem. Chem. Phys., 14, 38023815, https://doi.org/10.1039/c2cp23711c, 2012.

Vereecken, L., Muller, J. F., and Peeters, J.: Low-volatility poly-oxygenates in the $\mathrm{OH}$-initiated atmospheric oxidation of $\alpha$-pinene: impact of non-traditional peroxyl radical chemistry, Phys. Chem. Chem. Phys., 9, 5241-5248, https://doi.org/10.1039/b708023a, 2007.

Vilà-Guerau de Arellano, J., Kim, S.-W., Barth, M. C., and Patton, E. G.: Transport and chemical transformations influenced by shallow cumulus over land, Atmos. Chem. Phys., 5, 3219-3231, https://doi.org/10.5194/acp-5-3219-2005, 2005.

Wangberg, I., Barnes, I., and Becker, K. H.: Product and mechanistic study of the reaction of $\mathrm{NO}_{3}$ radicals with $\alpha$-pinene, Environ. Sci. Technol., 31, 2130-2135, https://doi.org/10.1021/es960958n, 1997.

Wennberg, P., Bates, K. H., Crounse, J. D., Dodson, L. G., McVay, R. C., Mertens, L. A., Nguyen, T. B., Praske, E., Schwantes, R. H., Smarte, M. D., St Clair, J. M., Teng, A. P., Zhang, X., and Seinfeld, J. H.: Gas-Phase Reactions of Isoprene and Its Major Oxidation Products, Chem. Rev., 118, 3337-3390, https://doi.org/10.1021/acs.chemrev.7b00439, 2018.

Winterhalter, R., Neeb, P., Grossmann, D., Kolloff, A., Horie, O., and Moortgat, G.: Products and mechanism of the gas phase re- action of ozone with $\beta$-pinene, J. Atmos. Chem., 35, 165-197, https://doi.org/10.1023/A:1006257800929, 2000.

Winterhalter, R., Herrmann, F., Kanawati, B., Nguyen, T. L., Peeters, J., Vereecken, L., and Moortgat, G. K.: The gasphase ozonolysis of $\beta$-caryophyllene $\left(\mathrm{C}_{15} \mathrm{H}_{24}\right)$. Part I: an experimental study, Phys. Chem. Chem. Phys., 11, 4152-4172, https://doi.org/10.1039/b817824k, 2009.

Wisthaler, A., Jensen, N. R., Winterhalter, R., Lindinger, W., and Hjorth, J.: Measurements of acetone and other gas phase product yields from the $\mathrm{OH}$-initiated oxidation of terpenes by protontransfer-reaction mass spectrometry(PTR-MS), Atmos. Environ., 35, 6181-6191, https://doi.org/10.1016/S1352-2310(01)003855,2001 .

Wolfe, G. M., Hanisco, T. F., Arkinson, H. L., Bui, T. P., Crounse, J., Dean-Day, J., Goldstein, A., Guenther, A., Hall, S. R., Huey, G., Jacob, D. J., Karl, T., Kim, P. S., Liu, X., Marvin, M. R., Mikoviny, T., Misztal, P. K., Nguyen, T. B., Peischl, J., Pollack, I., Ryerson, T., St. Clair, J. M., Teng, A., Travis, K. R., Ullmann, K., Wennberg, P. O., and Wisthaler, A.: Quantifying sources and sinks of reactive gases in the lower atmosphere using airborne flux observations, Geophys. Res. Lett., 42, 8231-8240, https://doi.org/10.1002/2015GL065839, 2015.

Xiong, F., McAvey, K. M., Pratt, K. A., Groff, C. J., Hostetler, M. A., Lipton, M. A., Starn, T. K., Seeley, J. V., Bertman, S. B., Teng, A. P., Crounse, J. D., Nguyen, T. B., Wennberg, P. O., Misztal, P. K., Goldstein, A. H., Guenther, A. B., Koss, A. R., Olson, K. F., de Gouw, J. A., Baumann, K., Edgerton, E. S., Feiner, P. A., Zhang, L., Miller, D. O., Brune, W. H., and Shepson, P. B.: Observation of isoprene hydroxynitrates in the southeastern United States and implications for the fate of $\mathrm{NO}_{x}$, Atmos. Chem. Phys., 15, 11257-11272, https://doi.org/10.5194/acp-1511257-2015, 2015.

Xiong, F., Borca, C. H., Slipchenko, L. V., and Shepson, P. B.: Photochemical degradation of isoprene-derived 4,1-nitrooxy enal, Atmos. Chem. Phys., 16, 5595-5610, https://doi.org/10.5194/acp-16-5595-2016, 2016.

Xu, L., Guo, H., Boyd, C. M., Klein, M., Bougiatioti, A., Cerully, K. M., Hite, J. R., Isaacman-VanWertz, G., Kreisberg, N. M., Knote, C., Olson, K., Koss, A., Goldstein, A. H., Hering, S. V., de Gouw, J., Baumann, K., Lee, S.-H., Nenes, A., Weber, R. J., and $\mathrm{Ng}, \mathrm{N}$. L.: Effects of anthropogenic emissions on aerosol formation from isoprene and monoterpenes in the southeastern United States, P. Natl. Acad. Sci. USA, 112, 37-42, https://doi.org/10.1073/pnas.1417609112, 2015.

$\mathrm{Xu}$, L., Moller, K. H., Crounse, J. D., Otkjaer, R. V., Kjaergaard, H. G., and Wennberg, P. O.: Unimolecular reactions of peroxy radicals formed in the oxidation of $\alpha$-pinene and $\beta$ pinene by hydroxyl radicals, J. Phys. Chem. A, 123, 1661-1674, https://doi.org/10.1021/acs.jpca.8b11726, 2019.

Yeh, G. K. and Ziemann, P. J.: Alkyl nitrate formation from the reactions of $\mathrm{C}_{8}-\mathrm{C}_{14}$ n-alkanes with $\mathrm{OH}$ radicals in the presence of $\mathrm{NO}_{x}$ : Measured yields with essential corrections for gas-wall partitioning, J. Phys. Chem. A, 118, 8147-8157, https://doi.org/10.1021/jp500631v, 2014.

Young, P. J., Naik, V., Fiore, A. M., Gaudel, A., Guo, J., Lin, M. Y., Neu, J. L., Parrish, D. D., Rieder, H. E., Schnell, J. L., Tilmes, S., Wild, O., Zhang, L., Ziemke, J. R., Brandt, J., Delcloo, A., Doherty, R. M., Geels, C., Hegglin, M. I., Hu, L., Im, U., Kumar, R., Luhar, A., Murray, L., Plummer, D., Ro- 
driguez, J., Saiz-Lopez, A., Schultz, M. G., Woodhouse, M. T., and Zeng, G.: Tropospheric ozone assessment report: Assessment of global-scale model performance for global and regional ozone distributions, variability, and trends, Elem. Sci. Anth., 6, p. 10, https://doi.org/10.1525/elementa.265, 2018.

Yu, J., Cocker, D. R., Griffin, R. J., Flagan, R. C., and Seinfeld, J. H.: Gas-phase ozone oxidation of monoterpenes: Gaseous and particulate products, J. Atmos. Chem., 34, 207-258, https://doi.org/10.1023/A:1006254930583, 1999.

Zare, A., Romer, P. S., Nguyen, T., Keutsch, F. N., Skog, K., and Cohen, R. C.: A comprehensive organic nitrate chemistry: insights into the lifetime of atmospheric organic nitrates, Atmos. Chem. Phys., 18, 15419-15436, https://doi.org/10.5194/acp-18-154192018, 2018.

Zare, A., Fahey, K. M., Sarwar, G., Cohen, R. C., and Pye, H. O. T.: Vapor-pressure pathways initiate but hydrolysis products dominate the aerosol estimated from organic mitrates, ACS Earth Space Chem., 3, 1426-1437, https://doi.org/10.1021/acsearthspacechem.9b00067, 2019.
Zhang, D. and Zhang, R.: Ozonolysis of $\alpha$-pinene and $\beta$ pinene: Kinetics and mechanism, J. Chem. Phys., 122, 114308, https://doi.org/10.1063/1.1862616, 2005.

Zhang, H., Yee, L. D., Lee, B. H., Curtis, M. P., Worton, D. R., Isaacman-VanWertz, G., Offenberg, J. H., Lewandowski, M., Kleindienst, T. E., Beaver, M. R., Holder, A. L., Lonneman, W. A., Docherty, K. S., Jaoui, M., Pye, H. O. T., Hu, W., Day, D. A., Campuzano-Jost, P., Jimenez, J. L., Guo, H., Weber, R. J., de Gouw, J., Koss, A. R., Edgerton, E. S., Brune, W., Mohr, C., Lopez-Hilfiker, F. D., Lutz, A., Kreisberg, N. M., Spielman, S. R., Hering, S. V., Wilson, K. R., Thornton, J. A., and Goldstein, A. H.: Monoterpenes are the largest source of summertime organic aerosol in the southeastern United States, P. Natl. Acad. Sci. USA, 115, 2038-2043, https://doi.org/10.1073/pnas.1717513115, 2018. 